\title{
Unexpectedly strong chiral amplification of chiral/achiral and chiral/chiral copolymers of biphenylylacetylenes and further enhancement/inversion and memory of the macromolecular helicity
}

\section{Citation for published version (APA):}

Ishidate, R., Markvoort, B., Maeda, K., \& Yashima, E. (2019). Unexpectedly strong chiral amplification of chiral/achiral and chiral/chiral copolymers of biphenylylacetylenes and further enhancement/inversion and memory of the macromolecular helicity. Journal of the American Chemical Society, 141(18), 7605-7614. https://doi.org/10.1021/jacs.9b02904

DOI:

10.1021/jacs.9b02904

Document status and date:

Published: 22/04/2019

\section{Document Version:}

Accepted manuscript including changes made at the peer-review stage

\section{Please check the document version of this publication:}

- A submitted manuscript is the version of the article upon submission and before peer-review. There can be important differences between the submitted version and the official published version of record. People interested in the research are advised to contact the author for the final version of the publication, or visit the $\mathrm{DOI}$ to the publisher's website.

- The final author version and the galley proof are versions of the publication after peer review.

- The final published version features the final layout of the paper including the volume, issue and page numbers.

Link to publication

\footnotetext{
General rights

- You may freely distribute the URL identifying the publication in the public portal. follow below link for the End User Agreement:

www.tue.nl/taverne

\author{
Take down policy \\ If you believe that this document breaches copyright please contact us at: \\ openaccess@tue.nl \\ providing details and we will investigate your claim.
}

Copyright and moral rights for the publications made accessible in the public portal are retained by the authors and/or other copyright owners and it is a condition of accessing publications that users recognise and abide by the legal requirements associated with these rights.

- Users may download and print one copy of any publication from the public portal for the purpose of private study or research.

- You may not further distribute the material or use it for any profit-making activity or commercial gain

If the publication is distributed under the terms of Article $25 \mathrm{fa}$ of the Dutch Copyright Act, indicated by the "Taverne" license above, please 


\title{
Unexpectedly Strong Chiral Amplification of Chiral/Achiral and Chiral/Chiral Copolymers of Biphenylylacetylenes and Further En- hancement/Inversion and Memory of the Macromolecular Helicity
}

\author{
Ryoma Ishidate,$\dagger^{\dagger}$ Albert J. Markvoort,${ }^{\ddagger}$ Katsuhiro Maeda, ${ }^{\S, \|}$ and Eiji Yashima* ${ }^{\dagger}, \perp$ \\ 'Department of Molecular Design and Engineering, Graduate School of Engineering, Nagoya University, Chikusa-ku, Nago- \\ ya 464-8603, Japan \\ Institute for Complex Molecular Systems and Computational Biology Group, Eindhoven University of Technology, P.O. \\ Box 513, 5600 MB Eindhoven, The Netherlands \\ ${ }^{\S}$ Graduate School of Natural Science and Technology and "WPI Nano Life Science Institute (WPI-NanoLSI), Kanazawa \\ University, Kakuma-machi, Kanazawa 920-1192, Japan \\ ${ }^{\perp}$ Department of Molecular and Macromolecular Chemistry, Graduate School of Engineering, Nagoya University, Chikusa-ku, \\ Nagoya 464-8603, Japan
}

\begin{abstract}
We report an unexpectedly strong amplification of the macromolecular helicity in dynamic helical copolymers of chiral/achiral and chiral/chiral $(R / S)$ biphenylylacetylenes in which the chiral residues are remote from the biphenyl pendants and further from the main chains. The copolymers consisting of $20 \mathrm{~mol} \%$ chiral monomers and chiral monomers of $20 \%$ enantiomeric excess (ee) showed a full induced circular dichroism (ICD) as intense as that of the chiral homopolymer. In contrast, an analogous poly(phenylacetylene) bearing the identical chiral residue $(100 \%$ ee) showed no circular dichroism (CD) in the polymer backbone, indicating the critical role of the biphenyl moieties in the observed high chiral amplification. As anticipated, the helix-sense excesses of the copolymer backbones composed of a small amount of chiral units $(<20 \mathrm{~mol} \%)$ and chiral units of a low ee $(<20 \%)$ were reduced. Interestingly, however, the macromolecular helicity of the copolymers was further drastically enhanced as a greater excess of a one-handed helix or inverted upon noncovalently interacting with nonracemic alcohols and subsequently retained (memorized) after complete removal of the chiral alcohol. Even in a polymer consisting of completely racemic repeating units, one-handed rightand left-handed helices could almost be induced and memorized. These unique hierarchical amplifications and memory of the macromolecular helicity in the copolymers by the covalent and further noncovalent chiral interactions are quantitatively explained on the basis of a linear Ising model.
\end{abstract}

\section{Introduction}

The amplification of chirality is a very unique and attractive phenomenon, through which a small chiral bias is significantly amplified, resulting in generation of chiral molecules, ${ }^{1}$ polymers, ${ }^{2}$ and supramolecular assemblies ${ }^{2 \mathrm{~g}, 3}$ with a higher optical activity or enantiomeric excess (ee). ${ }^{4}$ Therefore, chiral amplification is of key importance for understanding the origin of homochirality in biological macromolecules ${ }^{3 \mathrm{a}, 5}$ as represented by the right-handed $\alpha$-helix for proteins ${ }^{6}$ and the right-handed double helix for $\mathrm{DNA}^{7}$ that definitely consist of L-amino acids and D-sugars, respectively, which has intrigued scientists for many decades.

The first amplification of chirality was discovered in polyisocyanates, a class of stiff rodlike polymers, by Green et al. in $1988 .{ }^{8}$ They experimentally and theoretically demonstrated that polyisocyanates are inherently chiral (dynamically racemic) helical polymers consisting of interconvertible right $(P)$ and left-handed $(M)$ helical conformations separated by rarely occurring helical reversals..$^{2 a, b}$ Because of the low number of helix inversions, preferred-handed helical polyisocyanates can be produced by the copolymerization of an achiral isocyanate with a small amount of an optically-active isocyanate ("sergeants and soldiers effect") $)^{9}$ or by the copolymerization of nonracemic isocyanates with a very low ee ("majority rule"), ${ }^{10}$ through which a small chiral bias introduced in the monomer units via covalent bonding is significantly amplified with a high cooperativity, resulting in a high helical sense excess of the overall polymer chains. ${ }^{2,11}$

Besides such a typical approach using covalent bonds, noncovalent bonding interactions have been proved to be versatile to bias a helical sense with chiral amplification in dynamic helical polymers ${ }^{4,12}$ and supramolecular helical systems based on the helical assemblies of small molecules. ${ }^{3,13}$ Of particular importance is the so-called "memory effect"4 first observed in dynamic helical poly((4-carboxyphenyl)acetylene) with no optical activity. ${ }^{14 a . b}$ A preferred-handed helix could be induced in the optically-inactive polyacetylene by noncovalent acidbase interactions with a nonracemic amine. ${ }^{12 \mathrm{f}, \mathrm{g}}$ The induced helix is further retained (memorized) in solution after the amine was replaced by achiral amines. ${ }^{14 a-f}$ However, the use of achiral amines is essential for the helicity memory. Otherwise, 
the chiral memory is instantly lost as observed in other supramolecular systems showing a chiral memory. ${ }^{13 \mathrm{~g}, 15}$

Recently, we developed novel helical polyacetylenes bearing 2.2'-biphenol-derived pendants (poly-1 $\mathbf{a}^{16}$ and poly-1 $\mathbf{b}^{17}$ ) (Figure 1), which showed a very unique reversible switching and memory of both the macromolecular helicity and axial chirality of the biphenyl pendants accompanied by chiral amplification through noncovalent bonding interactions with various optically-active alcohols, amines, and hydrocarbons in the solid state as well as in solution. ${ }^{16-18}$ In sharp contrast to the helicity memory previously observed in functional poly(phenylacetylene)s, ${ }^{4,14 a-f}$ the induced main chain helicity and pendant axial chirality are automatically memorized. Therefore, replacement of the chiral inducers with achiral compounds is no longer required for this switchable dual memory, ${ }^{16-18}$ leading to the development of the first switchable chiral stationary phase (CSP) for separating enantiomers whose enantioselectivity or elution order can be reversibly controlled and switched. ${ }^{16 a}$ The induced axially twisted biphenyl pendants that arrange in a one-handed helical array along the polymer backbone most likely contribute to the helicity memory as supported by the fact that a copolymer of $\mathbf{1 a}$ with a small amount of a phenylacetylene carrying the same long alkoxy substituent showed almost no memory effect. ${ }^{16 a, 18}$

We now report the unexpectedly strong amplification of the macromolecular helicity of dynamic helical copolymers of chiral/achiral (poly- $\left(\mathbf{1} \mathbf{b}_{1-\mathrm{r}}-\mathrm{co}-\mathbf{2} \boldsymbol{R}_{\mathrm{r}}\right)$ ) (the sergeants and soldiers effect) and chiral/chiral $(R / S)$ (poly- $\left.\left(2 \boldsymbol{R}_{\mathrm{r}}-c o-\mathbf{2} \boldsymbol{S}_{1-\mathrm{r}}\right)\right)$ (the majority rule) biphenylylacetylenes despite the covalently-bonded chiral residues being remote from the biphenyl pendants and further from the main chains (Figure 2B). The helical sense excesses of the copolymers composed of a small amount of chiral monomer units $(<20 \mathrm{~mol} \%)$ and chiral monomer units of a low ee $(<20 \%)$ are not perfect, but can be further significantly enhanced to almost the complete one-handed helix or inverted to the opposite helix through noncovalent weak hydrogen-bonding interactions using enantiomeric alcohols $((R)$ or $(S)-4)$, which are retained (memorized) after complete removal of the chiral alcohols. These hierarchical amplifications of the macromolecular helicity in the copolymers by the covalent and further noncovalent chiral interactions are quantitatively interpreted on the basis of a linear Ising model as a function of the thermodynamic stability parameters developed by Lifson, Green, and Teramoto et al. ${ }^{\text {a-c, } 19}$ with modification.
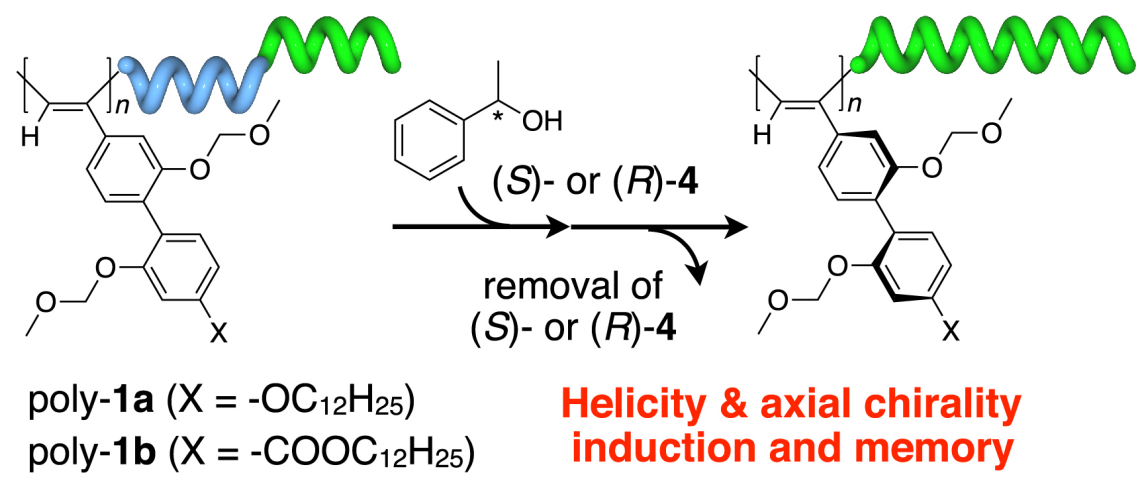

Figure 1. Schematic illustration of a sequential induction of axial chirality at the biphenyl pendants of poly(biphenylylacetylene)s (poly-1a and poly-1b) and their macromolecular helicity accompanied by chiral amplification through noncovalent interactions with a chiral alcohol $((S)$ - or $(R)-4)$ and subsequent memory of the induced axial chirality and helicity of these polymers after complete removal of 4 .

\section{RESULTS AND DISCUSSION}

Synthesis of Chiral/Achiral and Chiral/Chiral $(R / S)$ Copolymers. The homo- and copolymers of the biphenylylacetylene $(\mathbf{1 b}, \mathbf{2 R}$, and $\mathbf{2 S})$ or phenylacetylene $(\mathbf{3 R})$ derivatives were prepared by the homopolymerization of the achiral and chiral monomers $(\mathbf{1 b}, \mathbf{2} \boldsymbol{R}, \mathbf{2} S$, and $\mathbf{3 R})$ and copolymerization of $2 R$ with the achiral monomer $\mathbf{1 b}$ and $\mathbf{2 R}$ with $\mathbf{2 S}$ at different feed ratios using $[\mathrm{Rh}(\mathrm{nbd}) \mathrm{Cl}]_{2}$ (nbd: norbornadiene) as the catalyst in tetrahydrofuran (THF) in the presence of $\mathrm{NEt}_{3} \mathrm{ac}^{-}$ cording to previously reported methods, ${ }^{16-18}$ yielding high molecular weight $\left(M_{\mathrm{n}}=3.6-7.2 \times 10^{5}\right)$ homopolymers (poly-1b, poly-2R, poly-2S, and poly-3R) and copolymers (poly- $\left(\mathbf{1 b}_{1-\mathrm{r}^{-}}\right.$ $\left.c o-2 R_{\mathrm{r}}\right)(\mathrm{r}=0.05,0.1,0.2,0.3,0.5$, and 0.7$)$ and poly- $\left(2 \boldsymbol{R}_{\mathrm{r}}-\mathrm{co}-\right.$ $\left.2 S_{1-\mathrm{r}}\right)(\mathrm{r}=0.05,0.1,0.2,0.3,0.4,0.45,0.475,0.5$, and 0.7$\left.)\right)$ in high yields (91-97\%) (Figure 2, Scheme S2, and Tables S1S3). The cis-transoidal stereoregular structures of these homoand copolymers were confirmed by their typical Raman spectra (Figure S1). ${ }^{20}$

Chiroptical Properties of the Homopolymers and Copolymers and Chiral Amplification (Sergeants and Soldiers and Majority Rule Effects). The chiroptical properties of poly-2 $R$ and poly-3R with different pendant structures (biphenyl versus phenyl groups) were first investigated by measuring their circular dichroism (CD) and absorption spectra in methylcyclohexane $(\mathrm{MCH})$ at $25{ }^{\circ} \mathrm{C}$ (Figures 3A and $\mathrm{S} 16$ ). Poly-2R showed intense Cotton effects induced by the esterlinked chiral pendants in the $\pi$-conjugated polymer backbone regions due to a predominantly one-handed helical conformation. $^{21}$ In contrast, poly-3R carrying the identical chiral pendants exhibited almost no $\mathrm{CD}$ in the same regions in $\mathrm{MCH}$ and other polar and nonpolar solvents (THF, toluene, and chloroform), despite the chiral pendants located close to the main chain. These results clearly indicated the critical role of the axially chiral biphenyl pendants of poly-2R for inducing a preferred-handed helical structure. We speculate that the hierarchical amplification of chirality took place during the onehanded helix formation in poly- $2 \boldsymbol{R}$ through the long-range transfer of chiral information; the axial chirality with an excess twist-sense in the biphenyl pendants is first induced in response to the chiral substituents at the pendants, and subsequently, the induced axially twisted chirality at the biphenyl pendants would be further transferred 
A

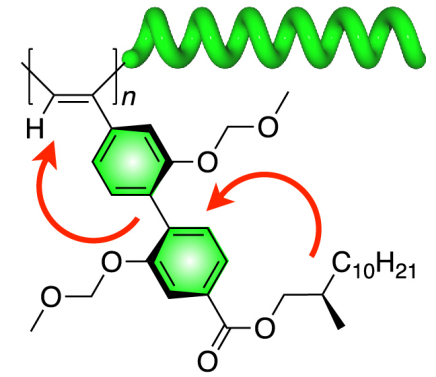

poly-2R

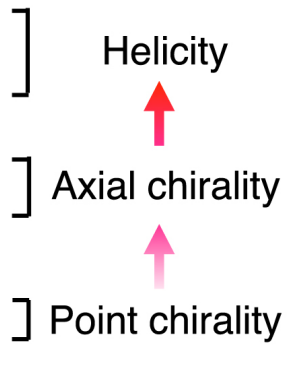

Chirality transfer through dynamic axial pendants

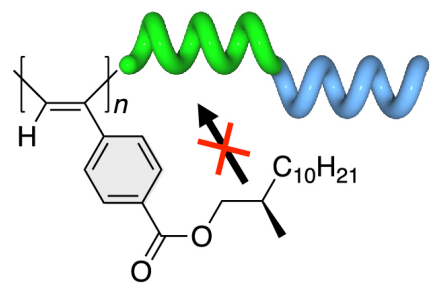

poly-3R<smiles>C#Cc1ccc(-c2ccc(C(=O)OCC)cc2OCOC)c(OCOC)c1</smiles>

1b

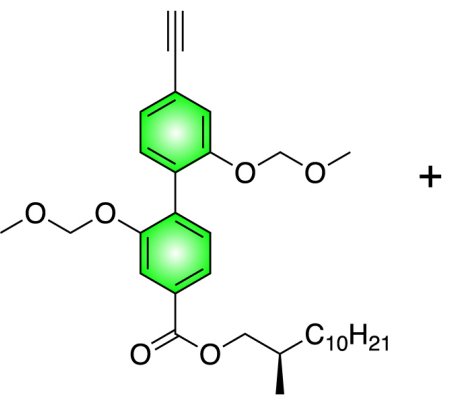

$2 R$<smiles>C#Cc1ccc(-c2ccc(C(=O)OCC(C)CCCCC)cc2OCOC)c(OCOC)c1</smiles>

$2 S$

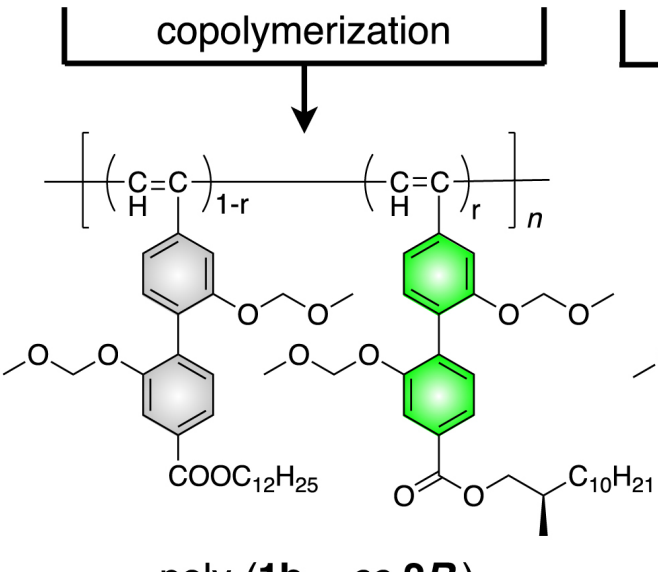

poly-(1 $\left.\mathbf{b}_{1-\mathrm{r}}-\mathrm{CO}-\mathbf{2} \boldsymbol{R}_{\mathrm{r}}\right)$ Sergeants and soldiers effect
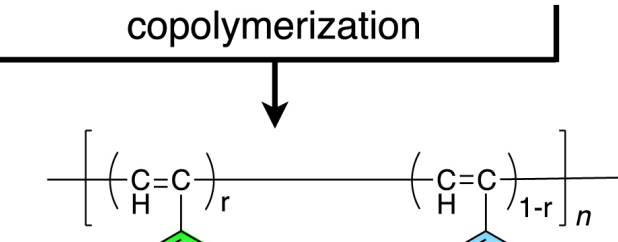

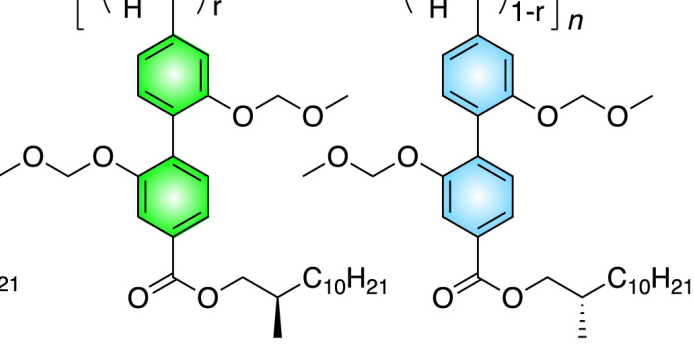

poly- $\left(2 \boldsymbol{R}_{\mathrm{r}}-\mathrm{CO}-2 \boldsymbol{S}_{1-\mathrm{r}}\right)$

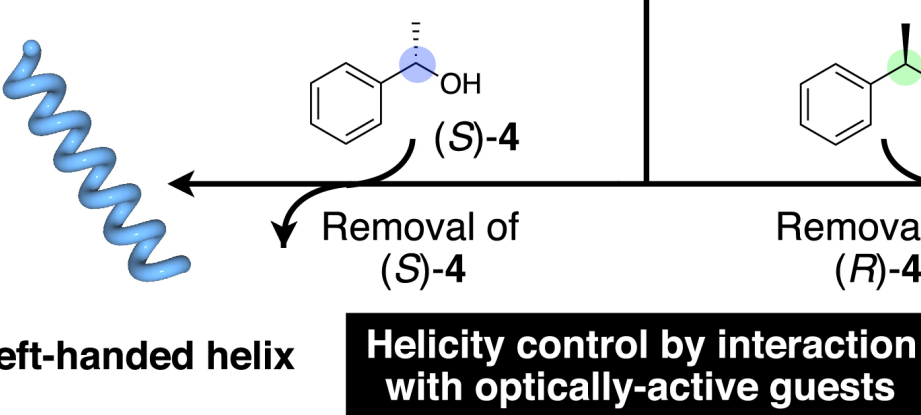

Figure 2. (A) Structures of the poly-2R and poly-3R. (B) Chiral amplification during the copolymerization of $\mathbf{2} \boldsymbol{R}$ with $\mathbf{1 b}$ (poly$\left.\left(\mathbf{1} \mathbf{b}_{1-\mathrm{r}}-\mathrm{co}-\mathbf{2} \boldsymbol{R}_{\mathrm{r}}\right)\right)$ (sergeants and soldiers effect) and with $\mathbf{2} S$ (poly-(2 $\left.\left.\boldsymbol{R}_{\mathrm{r}}-\mathrm{co}-\mathbf{2} S_{1-\mathrm{r}}\right)\right)$ (majority rule). The macromolecular helicities of the copolymers are further enhanced or inverted upon noncovalently interacting with $(R)-\mathbf{4}$ or $(S)-4$, and subsequently memorized after removal of 4 . 

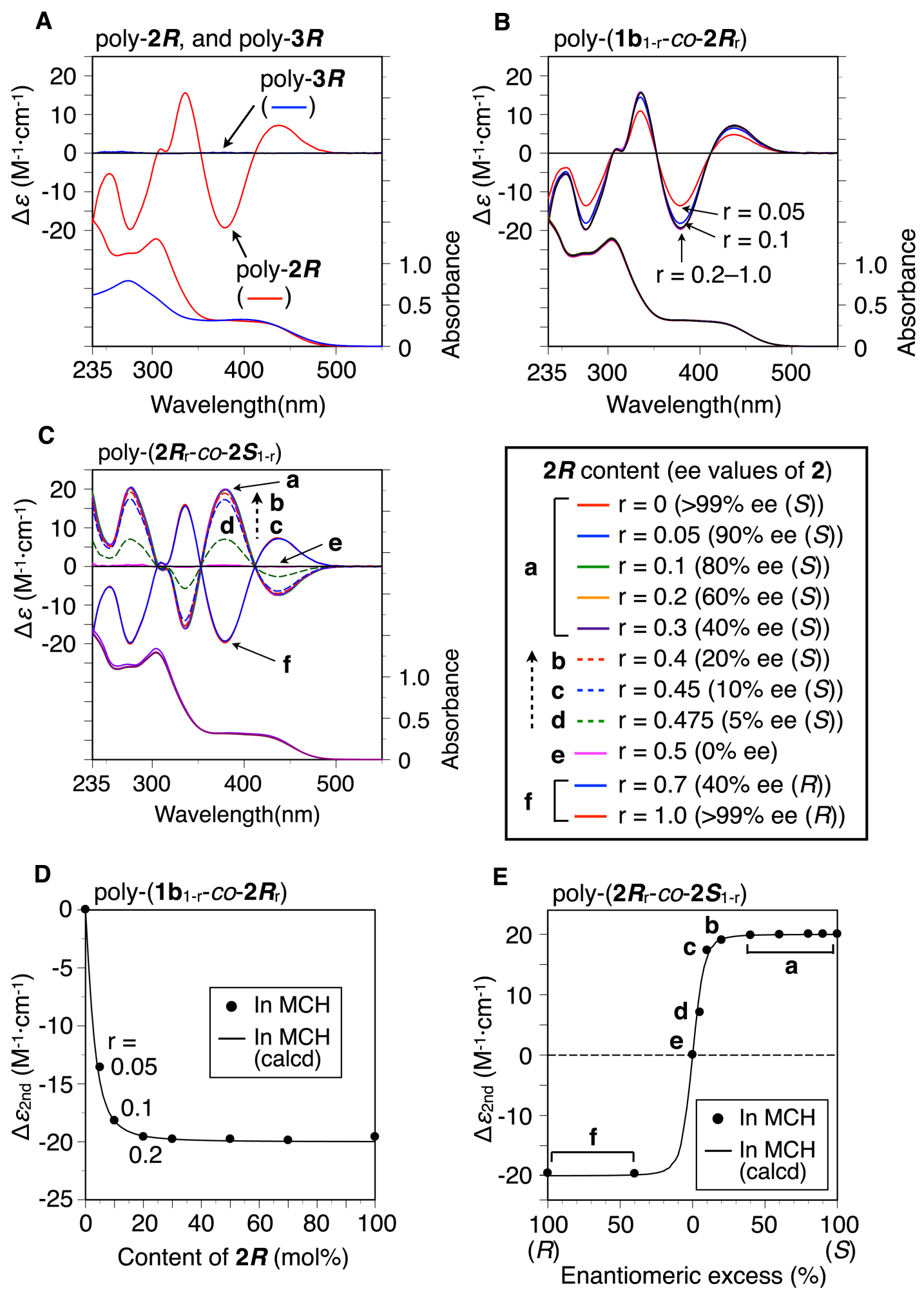

Figure 3. (A-C) CD and absorption spectra of poly-2R and poly-3R (A), poly-(1 $\left.\mathbf{b}_{1-\mathrm{r}}-c o-\mathbf{2} \boldsymbol{R}_{\mathrm{r}}\right)(\mathrm{r}=0.05-1.0)(\mathrm{B})$, and poly- $\left(\mathbf{2} \boldsymbol{R}_{\mathrm{r}}-\mathrm{co}-\right.$ $\left.\mathbf{2 S}_{1-\mathrm{r}}\right)(\mathrm{r}=0-1.0)(\mathrm{C})$ in $\mathrm{MCH}$ at $25^{\circ} \mathrm{C}$. (D and E) Plots of ICD intensity $\left(\Delta \varepsilon_{2 n d}\right.$ at $\left.380 \mathrm{~nm}\right)$ of poly- $\left(\mathbf{1} \mathbf{b}_{1-\mathrm{r}}-\mathrm{Co}-\mathbf{2} \boldsymbol{R}_{\mathrm{r}}\right)$ and poly- $\left(\mathbf{2} \boldsymbol{R}_{\mathrm{r}}-\mathrm{Co}-\right.$ $\mathbf{2} \boldsymbol{S}_{1-\mathrm{r}}$ ) versus the content of $\mathbf{2} \boldsymbol{R}(\mathrm{D})$ and \%ee of $\mathbf{2}(\mathrm{E})$, respectively. [Polymer] $=1.0 \mathrm{mM}$. Solid curves in D and E represent theoretical values calculated by the Ising model theory with a single set of parameters, i.e., mismatch penalty $J=0.29 \mathrm{~kJ} / \mathrm{mol}$ and helix reversal penalty $F=14.6 \mathrm{~kJ} / \mathrm{mol}$. The maximum $\Delta \varepsilon_{2 n d}$ value of the copolymers taking a fully one-handed helix is assumed to be 20 .

to the dynamic helical polymer backbone as an excess helical sense accompanied by the significant amplification of chirality (Figure 2A). The helical sense of poly-2R, showing a negative second Cotton effect at ca. $380 \mathrm{~nm}\left(\Delta \varepsilon_{2 n d}\right)$ can be assigned as a right-handed $(P)$ helix based on the literature. ${ }^{22}$ 
The chiral/achiral copolymers (poly- $\left(\mathbf{1 b}_{1-\mathrm{r}}-\mathrm{co}-\mathbf{2} \boldsymbol{R}_{\mathbf{r}}\right)$ ) showed a remarkable amplification of the helical chirality (the sergeants and soldiers effect), that is, a very strong positive nonlinear effect between the CD intensities $\left(\Delta \varepsilon_{2 \mathrm{nd}}\right)$ induced in the main chains of the copolymers and the molar fraction of the chiral $2 \boldsymbol{R}$ units (Figure 3D); the induced CD (ICD) values increased with the increasing chiral $\mathbf{2} \boldsymbol{R}$ units of the copolymers, and the CD spectra of the copolymers containing more than $20 \mathrm{~mol} \%$ chiral $\mathbf{2} \boldsymbol{R}$ units were identical to that of the homopolymer (poly-2R) (Figure 3B) (for the sergeants and soldiers effect in THF, see Figure S27). The chiral/chiral $(R / S)$ copolymers (poly- $\left(\mathbf{2} \boldsymbol{R}_{\mathrm{r}}-\mathrm{co}-\mathbf{2} \boldsymbol{S}_{1-\mathrm{r}}\right)$ ) also showed a significant amplification of the helicity (the majority rule effect) (Figure $3 \mathrm{C}$ and $\mathrm{E}$ ); even a $20 \%$ ee of the monomer units was sufficient to produce a one-handed helix, thus showing the full ICD as intense as that of poly-2R. Although a number of helical poly(phenylacetylene)s showing amplification of the helicity (sergeants and soldiers and majority rule effects) using covalent bonds have been reported, ${ }^{4,23}$ the present biphenylylacetylene-based copolymers display a superior chiral amplification compared to the previously reported helical
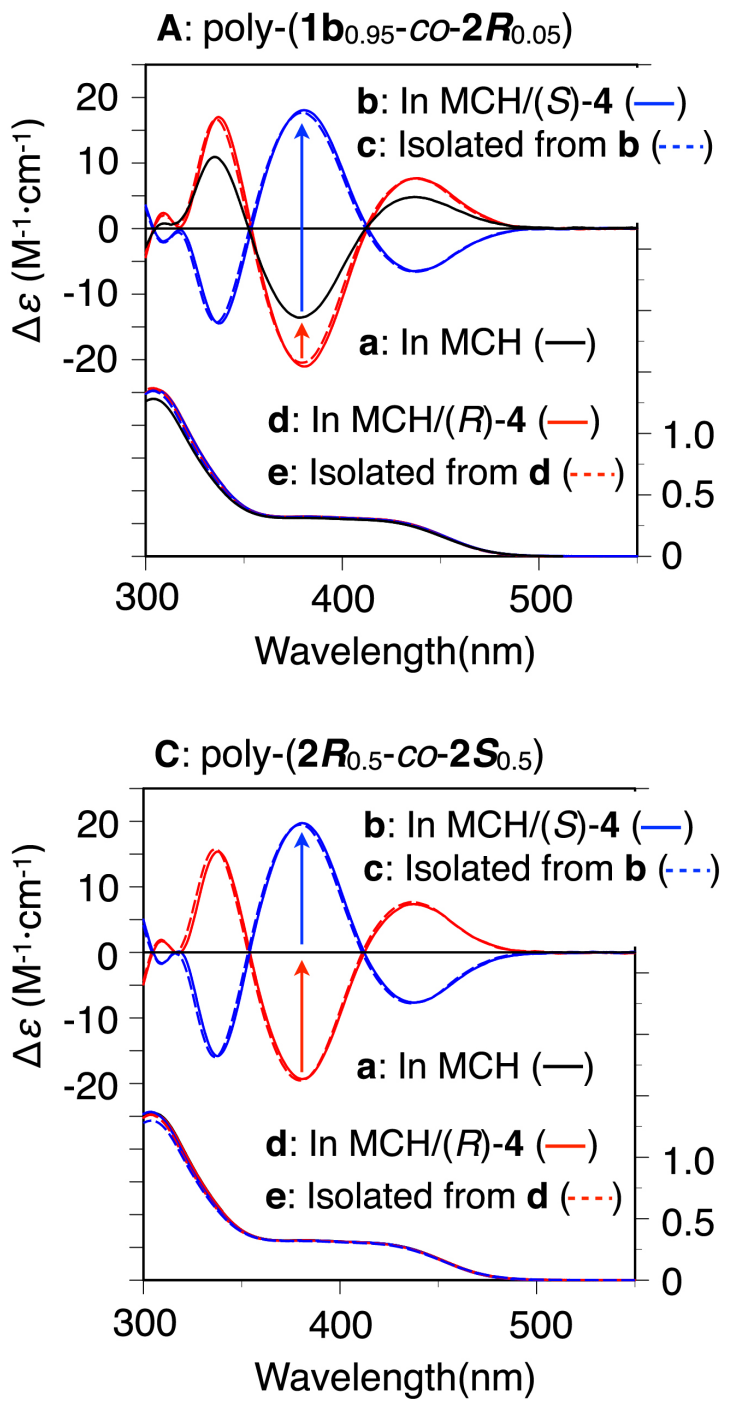

poly(phenylacetylene)s except for those induced by chiral noncovalent bonding systems. ${ }^{12 i, j}$ The cooperative interactions between the neighboring axially chiral biphenyl pendants with the methoxymethoxy (MOM) groups of the copolymers of the biphenylylacetylenes appear to play an important role in the observed unprecedented high chiral amplifications. ${ }^{16-18}$

As previously reported, an almost one-handed helix can be induced in the optically-inactive homopolymers (poly-1a and poly-1b) in the presence of $(R)$ - or $(S)-\mathbf{4}$, and their induced helicities are automatically memorized after complete removal of the optically-active 4. ${ }^{16,17}$ This versatile noncovalent helicity induction and memory strategy was then applied to the covalent helical copolymers composed of chiral/achiral (poly$\left.\left(\mathbf{1} \mathbf{b}_{1-\mathrm{r}}-\mathrm{co}-\mathbf{2} \boldsymbol{R}_{\mathrm{r}}\right)\right)$ and chiral/chiral $(R / S)$ units (poly- $\left(\mathbf{2} \boldsymbol{R}_{\mathrm{r}}-\mathrm{co}-\mathbf{2} \boldsymbol{S}_{1-}\right.$ r)) showing the strong sergeants and soldiers and majority rule effects, respectively. We anticipated that further amplification of the helicity would be possible through noncovalent interactions using chiral alcohols $((R)$ - and $(S)-4)$ for the copolymers whose helical sense excesses are not perfect, leading to a greater enhancement or even inversion of the helicity followed by its memory (Figure 2B).
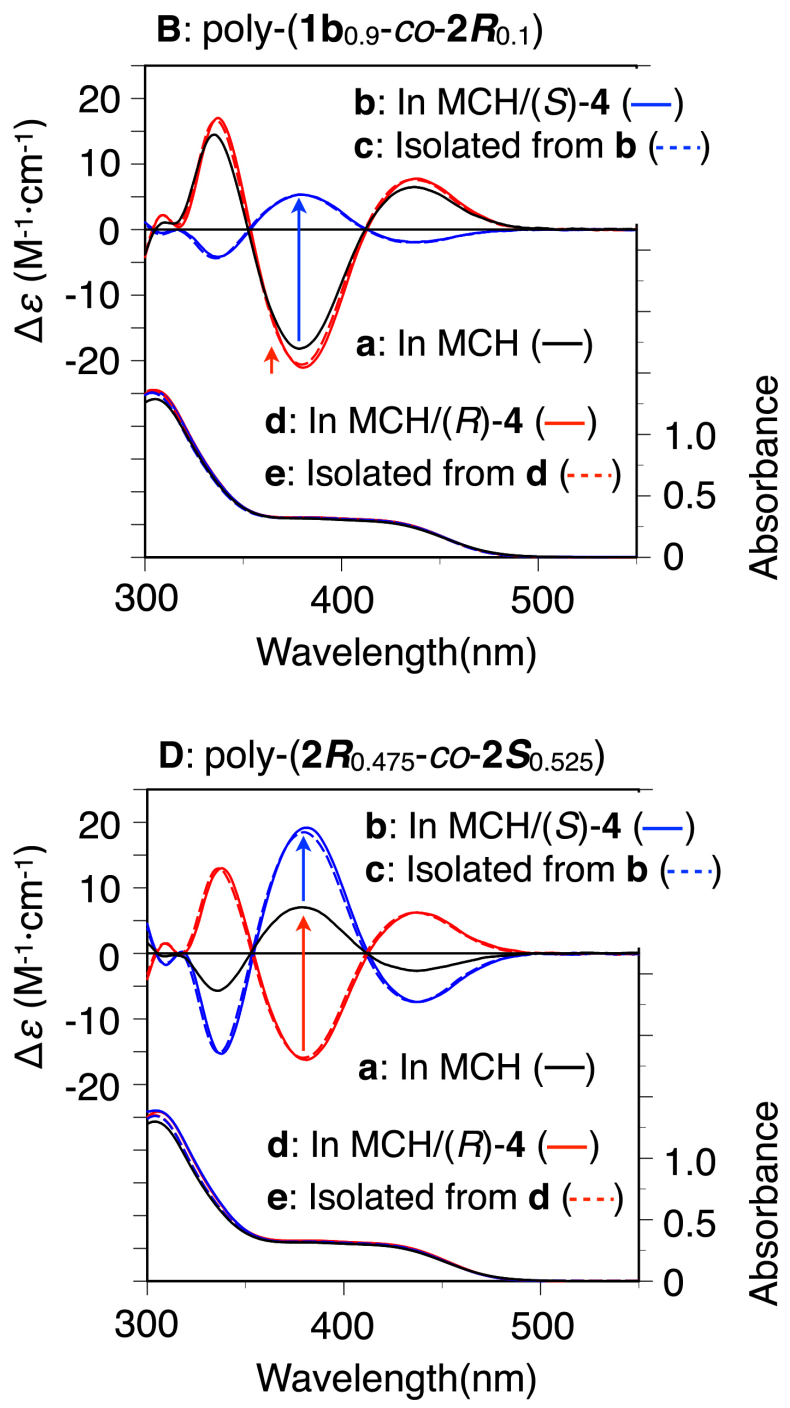

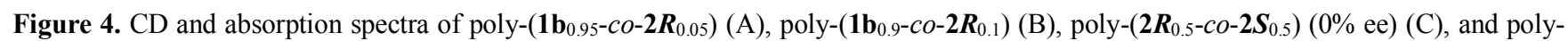
$\left(2 \boldsymbol{R}_{0.475}-\mathrm{co}-\mathbf{2} \boldsymbol{S}_{0.525}\right)(5 \%$ ee, $S$ rich) (D) in the absence (a) and presence of $(S)$ - (b) and $(R)-\mathbf{4}(\mathrm{d})$ in $\mathrm{MCH}(\mathrm{MCH} / \mathbf{4}=80 / 20, \mathrm{v} / \mathrm{v}) \mathrm{measured}$ at $-10{ }^{\circ} \mathrm{C}$ after standing at $25^{\circ} \mathrm{C}$ for 5 days, and those of the isolated polymers in $\mathrm{MCH}$ at $-10{ }^{\circ} \mathrm{C}$ recovered from $\mathrm{b}(\mathrm{c})$ and d (e). [Polymer] $=$ $1.0 \mathrm{mM} ;[4]=1.65 \mathrm{M}$. 
To this end, we followed the changes in the CD spectra of the copolymers (poly- $\left(\mathbf{1} \mathbf{b}_{1-\mathrm{r}}-\mathrm{co}-\mathbf{2} \boldsymbol{R}_{\mathrm{r}}\right)$ and poly- $\left(\mathbf{2} \boldsymbol{R}_{\mathrm{r}}-\mathrm{co}-\mathbf{2} \boldsymbol{S}_{1-\mathrm{r}}\right)(S$ rich)) in $\mathrm{MCH}$ in the presence of $(R)-$ or $(S)-\mathbf{4}(\mathrm{MCH} / \mathbf{4}=$ $80 / 20, \mathrm{v} / \mathrm{v}$ ) at $25^{\circ} \mathrm{C}$ (Figures 4 and 5 and see also Figures S18 and $\mathrm{S} 22)$. Interestingly, the $\mathrm{CD}$ intensities of poly-( $\mathbf{1 b}_{1-\mathrm{r}}-\mathrm{Co}-$ $\left.\mathbf{2 R}_{\mathrm{r}}\right)(\mathrm{r}<0.2$ including $\mathrm{r}=0)$ gradually increased with time by noncovalent interactions with $(R)-4$ accompanied by negligible changes in the absorption spectra and reached the full ICDs as intense as that of the homopolymer (poly-2R) after standing at $25{ }^{\circ} \mathrm{C}$ within ca. 1 day (d in Figure 4A, B and Figures 5B and S20). These results clearly demonstrated the fascinating role of the noncovalent chiral interactions that indeed work for further amplification/enhancement of the macromolecular helicity from an imperfect helicity to the almost completely one-handed helix. In other words, combining the chiral amplification through the covalent bonds in dynamic helical polymers with the noncovalent helicity induction provides a versatile method to produce either a $P$ - or $M$ - macromolecular helicity with an excess one-handedness.

On the other hand, the CD intensities of poly- $\left(\mathbf{1 b}_{1-\mathrm{r}}-\mathrm{Co}-\mathbf{2} \boldsymbol{R}_{\mathrm{r}}\right)$ $(\mathrm{r}<0.2)$ drastically changed in the presence of $(S)-4$ with time (Figure S20). The Cotton effect signs of the copolymers were inverted to give an almost mirror image, although their helical sense excesses were not complete judging from the ICD intensities (b in Figure 4A, B and Figures 5B and S18B, C). This is most likely due to the helical sense preferences of the copolymers (poly- $\left.\left(\mathbf{1} \mathbf{b}_{1-\mathrm{r}}-\mathrm{Co}-\mathbf{2} \boldsymbol{R}_{\mathrm{r}}\right)(\mathrm{r}<0.2)\right)$ that are in competition between the chirality of the covalently-bonded pendant substituents of $\mathbf{2} \boldsymbol{R}$ and that of the alcohol $((R)-$ or $(S)-\mathbf{4})$. For the copolymers (poly- $\left.\left(\mathbf{1} \mathbf{b}_{1-\mathrm{r}}-\mathrm{co}-\mathbf{2} \boldsymbol{R}_{\mathrm{r}}\right)(\mathrm{r}>0.2)\right)$ containing more than $20 \mathrm{~mol} \%$ of the chiral $\mathbf{2} \boldsymbol{R}$ units, the CD intensities hardly changed with $(S)$ - and $(R)-4$ (Figures 5B and S18D-H), indicating that the helical senses of poly- $\left(\mathbf{1 b}_{1-\mathrm{r}}-\mathrm{co}-\mathbf{2} \boldsymbol{R}_{\mathrm{r}}\right)(\mathrm{r}>0.20)$ were mostly governed by the pendant chirality of $\mathbf{2} \boldsymbol{R}$.

Similar noncovalent helix-sense excess enhancements and inversions of the helicity were also observed for the $(R / S)$ copolymers, poly- $\left(2 \boldsymbol{R}_{\mathrm{r}}-\mathrm{co}-\mathbf{2} S_{1-\mathrm{r}}\right)(\mathrm{r}=0.475(5 \%$ ee, $S$-rich $))$ in the presence of $(S)$ - and $(R)-4$ in $\mathrm{MCH}(\mathrm{MCH} / 4=80 / 20, \mathrm{v} / \mathrm{v})$, respectively (Figures $4 \mathrm{D}, 5 \mathrm{C}$, and $\mathrm{S} 23$ ), while the $\mathrm{CD}$ spectra of poly- $\left(2 \boldsymbol{R}_{\mathrm{r}}-\mathrm{co}-\mathbf{2} \boldsymbol{S}_{1-\mathrm{r}}\right)(\mathrm{r} \leq 0.4(\geq 20 \%$ ee, $S$-rich $))$ remained unchanged with $(S)$ - and $(R)-\mathbf{4}$ (Figures 5C and S22D-J). It is noteworthy that both the almost one-handed $P$ - and $M$ - helices of the mirror images of each other can be induced in poly$\left(2 \boldsymbol{R}_{0.5}-\mathrm{co}-\mathbf{2} \boldsymbol{S}_{0.5}\right)$ composed of the totally racemic $\mathbf{2}(0 \%$ ee) by noncovalent interactions with $(R)$ - and $(S)-4$, respectively (Figures $4 \mathrm{C}$ and $5 \mathrm{C}$ ). More importantly, both the induced $P$ and $M$-helices of poly- $\left(2 \boldsymbol{R}_{0.5}-\mathrm{co}-\mathbf{2} \boldsymbol{S}_{0.5}\right)$ can be further automatically memorized (see below), as previously demonstrated for poly-1a and poly-1b. ${ }^{16,17}$ We are not aware of any precedent in polymeric and supramolecular helical systems for such an intriguing chiral amplification phenomenon of a racemic helical polymer consisting of totally racemic repeating units toward almost completely one-handed helical polymers. ${ }^{4 c}$

\section{A Enhancement and inversion of the macromolecular helicity}
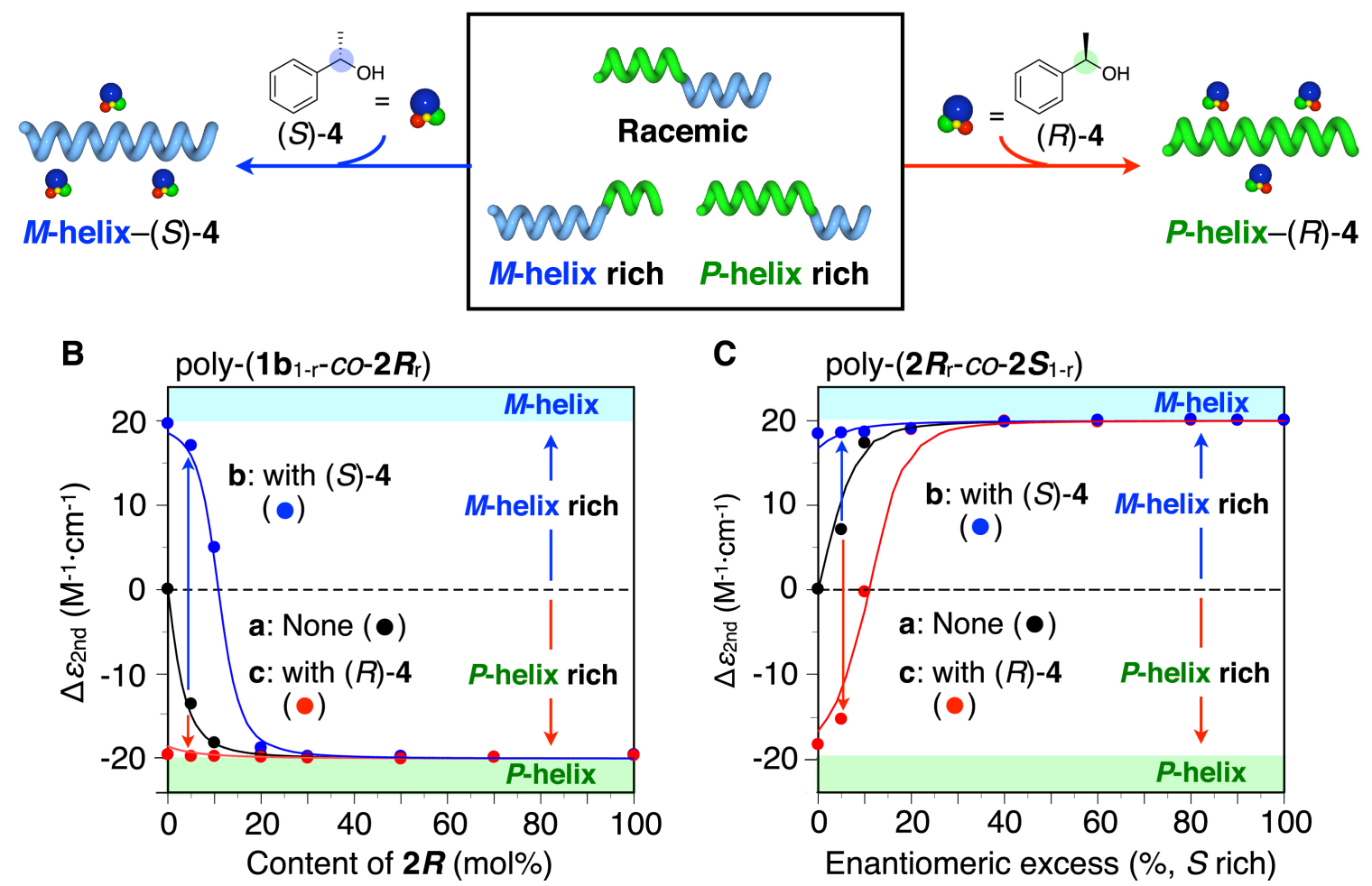

Figure 5. (A) Schematic illustration of helix-sense excess enhancement and inversion of the helicity of poly- $\left(\mathbf{1} \mathbf{b}_{1-\mathrm{r}}-\mathrm{co}-\mathbf{2} \boldsymbol{R}_{\mathbf{r}}\right)$ and poly- $\left(\mathbf{2} \boldsymbol{R}_{\mathbf{r}^{-}}\right.$ $\left.c o-2 S_{1-\mathrm{r}}\right)$ through noncovalent interactions with a chiral alcohol $((S)$ - or $(R)-\mathbf{4})$. (B and C) Plots of ICD intensity $\left(\Delta \varepsilon_{2 n d}\right.$ at $\left.380 \mathrm{~nm}\right)$ of poly$\left(\mathbf{1} \mathbf{b}_{1-\mathrm{r}}-\mathrm{Co}-\mathbf{2} \boldsymbol{R}_{\mathrm{r}}\right)$ and poly- $\left(\mathbf{2} \boldsymbol{R}_{\mathrm{r}}-\mathrm{Co}-\mathbf{2} S_{1-\mathrm{r}}\right)$ versus the content of $\mathbf{2 R}(\mathrm{B})$ and \%ee of $\mathbf{2}(\mathrm{C})$, respectively, in the absence (a) and presence of $(S)-\mathbf{4}$ (b) and $(R)-4(\mathrm{c})$ in $\mathrm{MCH}(\mathrm{MCH} / 4=80 / 20, \mathrm{v} / \mathrm{v})$ measured at $25^{\circ} \mathrm{C}$ after standing at $25^{\circ} \mathrm{C}$ for 5 days. [Polymer] $=1.0 \mathrm{mM}$; $[4]=1.65 \mathrm{M}$. Solid curves (blue and red lines) represent theoretical values calculated by the Ising model theory with the same mismatch penalty $J=0.29$ $\mathrm{kJ} / \mathrm{mol}$, and helix reversal penalty $F=14.6 \mathrm{~kJ} / \mathrm{mol}$ as in Figure 3 (D and E) and one additional mismatch penalty $K=0.032 \mathrm{~kJ} / \mathrm{mol}$ for a 4 complexed to a monomer in the unpreferred helical sense. The black solid curves (B and C) are taken from Figure 3D and E, respectively. 


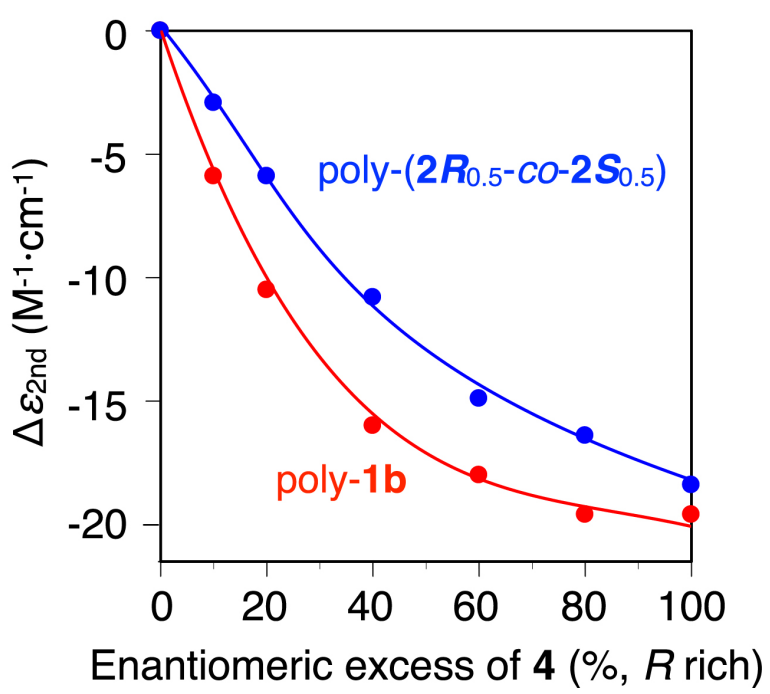

Figure 6. Plots of ICD intensity $\left(\Delta \varepsilon_{2 n d}\right.$ at $\left.380 \mathrm{~nm}\right)$ of poly-1b and poly- $\left(2 \boldsymbol{R}_{0.5}-\mathrm{co}-\mathbf{2} \boldsymbol{S}_{0.5}\right)$ versus the \%ee of $\mathbf{4}(R$ rich $)$ in $\mathrm{MCH}$ $(\mathrm{MCH} / 4=80 / 20, \mathrm{v} / \mathrm{v})$ measured at $25{ }^{\circ} \mathrm{C}$ after standing at $25{ }^{\circ} \mathrm{C}$ for 5 days. [Polymer] $=1.0 \mathrm{mM}$; [4] $=1.65 \mathrm{M}$. Solid curves (blue and red lines) represent theoretical values calculated by the Monte Carlo simulations ${ }^{24}$ (still with $J=0.29$ $\mathrm{kJ} / \mathrm{mol}, K=0.032 \mathrm{~kJ} / \mathrm{mol}$, and $F=14.6 \mathrm{~kJ} / \mathrm{mol}$ ) (see Section 6-7 in Supporting Information).

As previously reported, the nonracemic 4 ( $>40 \%$ ee) could also induce an almost one-handed helix in the dynamically racemic poly-1a as did the optically-pure 4 showing the majority rule. ${ }^{16 a}$ We then investigated the majority rule effect toward dynamically racemic helical polymers, poly- $\left(2 \boldsymbol{R}_{0.5}-\mathrm{co}-\right.$ $\mathbf{2} \boldsymbol{S}_{0.5}$ ) and poly-1b, by measuring their ICDs using nonracemic 4 in $\mathrm{MCH}$ at $25^{\circ} \mathrm{C}$ (Figure 6). The changes in the ICD intensities of these optically-inactive polymers with respect to the ee of 4 ( $R$-rich) showed moderate positive nonlinear relationships (the majority rule). Interestingly, the nonlinearity observed for poly-1b was stronger than that for poly- $\left(2 R_{0.5}-c o-2 S_{0.5}\right)$, although both polymers exist as an equal mixture of dynamic $P$ and $M$-helices in the absence of the nonracemic 4 .

Theoretical Analysis of Chiral Amplification. The strong sergeants and soldiers and majority rule effects observed in the present dynamic helical polymers through covalent and further noncovalent chiral interactions are consistent with analogous sergeants and soldiers and majority rule effects observed in polyisocyanates $^{2 \mathrm{a}, \mathrm{b}, 9-11}$ and other helical polymers, ${ }^{2,4}$ and therefore, can be quantitatively interpreted by a statistical theory using a one-dimensional (1D) Ising model developed by Lifson, Green, Teramoto, Sato, and coworkers. ${ }^{2 a-c, 19}$ According to this model, helical polymer chains consist of right- and lefthanded helical segments ( $P$ and $M$, respectively) separated by energetically unfavorable (rarely occurring) helix reversals, and each monomeric unit can have a slight imbalance in free energy between the two helical conformations. Therefore, the experimentally observed CD intensity changes that correspond to the changes in the helical sense excesses of the chiral/achiral and chiral/chiral $(R / S)$ random copolymers with respect to the chiral monomer content (sergeants and soldiers experiments) or the ee of the monomer units (majority rule experiments) (Figure 3D and E, respectively) can be expressed, in principle, as a function of two key thermodynamic stability parameters. The first parameter is the excess free energy per helix reversal and is commonly denoted as the helix reversal penalty $(F)$. The second parameter is the excess free energy difference per chiral unit in the unpreferred helical conformation, i.e., $R$ in $M$-helix or $S$ in $P$-helix, commonly denoted as the mismatch penalty $(J) .^{2 \mathrm{a}-\mathrm{c}, 19}$

According to the procedures described in the Supporting Information (Section 6), we could successfully fit the experimental CD data for both the sergeants and soldiers (Figure 3D) and majority rules (Figure $3 \mathrm{E}$ ) phenomena using a single parameter set, i.e., $J=0.29 \mathrm{~kJ} / \mathrm{mol}$ and $F=14.6 \mathrm{~kJ} / \mathrm{mol}$, based on the conventional Ising model theory using transfer-matrix techniques. The helix reversal penalty $(F=14.6 \mathrm{~kJ} / \mathrm{mol})$ value is comparable to those of typical dynamic helical polymers ${ }^{4 \mathrm{~b}}$ including substituted poly(phenylacetylene)s, ${ }^{25}$ polyisocyanates, ${ }^{2 \mathrm{a}, \mathrm{b}}$ and polysilanes, ${ }^{2 \mathrm{f}}$ whereas the mismatch penalty $(J=$ $0.29 \mathrm{~kJ} / \mathrm{mol}$ ) is significantly greater than those of the substituted poly(phenylacetylene) derivatives $(J=\text { ca. } 0.005 \mathrm{~kJ} / \mathrm{mol})^{4 \mathrm{~b}, 25}$ and roughly similar to those of poly(quinoxaline-2,3-diyl)s $(J$ $=$ ca. $0.1-1.0 \mathrm{~kJ} / \mathrm{mol}$ ) that depend on the use of certain substituents and solvents. ${ }^{26}$ The higher mismatch penalty $(J)$ of the present copolymers of biphenylylacetylenes as compared to those of the substituted poly(phenylacetylene $)^{25}$ could be explained as a result of the bulky biphenyl pendants directly linked to the main chains. The biphenyl pendants can also take an excess single-handed, axially twisted conformation induced by a preferred-handed helical structure of the polymer backbone, leading to the greater free energy difference between the $P$ - and $M$-helical states, thus showing a very strong chiral amplification behavior.

In order to gain insights into the mechanism that controls the inversion and enhancement of the helicity of poly- $\left(\mathbf{1}_{1-\mathrm{r}^{-}}\right.$ $\left.c o-2 R_{\mathrm{r}}\right)(\mathrm{r}<0.2)$ and poly- $\left(2 \boldsymbol{R}_{\mathrm{r}}-c o-2 S_{1-\mathrm{r}}\right)(<20 \%$ ee $)$ by noncovalent interactions with $(R)$ - or $(S)-4$ (Figures 4 and 5), we introduced an additional mismatch penalty $(K)$, representing the difference in gained free energy upon complexation of the chiral alcohol with a monomeric unit (1b and enantiomeric $\mathbf{2} \boldsymbol{R}$ and $\mathbf{2 S}$ ) in either a $P$ - or $M$-helical segment. As we assumed that the $(S)$ - 4 (or $(R)-4)$ used as a cosolvent in MCH quantitatively interacts with each monomer unit in a nonstereospecific manner, the chiral amplification can still be described by the 1D Ising model where the mismatch penalty of each unit comprises the sum of its mismatch penalty for the monomer ( 0 or $J)$ and that of the chiral alcohol (0 or $K)$ (see Section 6 in Supporting Information).

The experimental data of poly- $\left(\mathbf{1} \mathbf{b}_{1-\mathrm{r}}-\mathrm{co}-\mathbf{2} \boldsymbol{R}_{\mathrm{r}}\right)$ and poly- $\left(\mathbf{2} \boldsymbol{R}_{\mathrm{r}}-\right.$ $\left.c o-2 S_{1-\mathrm{r}}\right)$ measured in $\mathrm{MCH}$ in the presence of $(S)$ - and $(R)-4$ are shown in Figure 5B and $\mathrm{C}$ (blue and red colors), respectively, along with the fitted model results. We obtained a good fit for these copolymers using the same helix reversal penalty $(F=14.6 \mathrm{~kJ} / \mathrm{mol})$ and mismatch penalty $(J=0.29 \mathrm{~kJ} / \mathrm{mol})$ as found in the absence of the chiral solvent, and an approximately ten-fold lower value for the additional mismatch penalty for the chiral alcohols $(K=0.032 \mathrm{~kJ} / \mathrm{mol})$. These results suggest that the inversion and enhancement of the helicity of poly$\left(\mathbf{1} \mathbf{b}_{1-\mathrm{r}}-\mathrm{CO}-\mathbf{2} \boldsymbol{R}_{\mathrm{r}}\right)(\mathrm{r}<0.2)$ and poly- $\left(\mathbf{2} \boldsymbol{R}_{\mathrm{r}}-\mathrm{Co}-\mathbf{2} \boldsymbol{S}_{1-\mathrm{r}}\right)(<20 \%$ ee $)$ observed in the presence of $(R)$ - or $(S)-4$ can be explained by the competing and cooperative helical sense preferences of the chirality of the covalently bonded pendants and that of the noncovalently interacting $(R)$ - and $(S)-4$. We emphasize that a series of covalent and further noncovalent chiral amplification processes in the chiral/achiral and chiral/chiral $(R / S)$ copolymers in the absence and presence of chiral alcohols were fully explained using a single set of thermodynamic stability pa- 
rameters $(F, J$, and $K)$, i.e., one parameter for the excess free energy per helix reversal and two for the excess free energy of a chiral monomer and that of a noncovalently bound chiral alcohol in a helix with an unpreferred helical sense.

To quantify the preferred-handed helix formation in the optically-inactive poly-1b and poly- $\left(2 \boldsymbol{R}_{0.5}-\mathrm{co}-\mathbf{2} \boldsymbol{S}_{0.5}\right)$ accompanied by amplification of the chirality upon complexation with the nonracemic 4, we applied the Markov chain Monte Carlo simulation, which, though computationally more demanding, has the advantage over the transfer-matrix approach that it remains applicable when the model is extended with exchange of $(R)$ and $(S)-4$ (for detailed procedures, see Section 6-7 in Supporting Information). ${ }^{24}$ The simulated curves in Figure 6 , still with the same parameter set $(F=14.6 \mathrm{~kJ} / \mathrm{mol}, J=0.29 \mathrm{~kJ} / \mathrm{mol}$ and $K=0.032 \mathrm{~kJ} / \mathrm{mol}$ ), resulted in a good fit of both positive nonlinear relationships between the ICD intensities of the polymers with respect to the ee of 4 ( $R$-rich) when the maximum $\Delta \varepsilon_{2 \text { nd }}$ value of the polymers is assumed to be 21.5 . The stronger nonlinearity observed for poly-1b than for poly- $\left(2 \boldsymbol{R}_{0.5}-\mathrm{CO}-\right.$ $\mathbf{2} \boldsymbol{S}_{0.5}$ ) may be explained by the model predicting, for the same helix reversal penalty, less helix reversals in a polymer built of achiral units than in one built of totally racemic repeating units, such that to obtain the same total free energy difference due to the complexed 4 per helical segment for poly- $\left(2 \boldsymbol{R}_{0.5}-\mathrm{Co}-\mathbf{2} \boldsymbol{S}_{0.5}\right)$ with shorter segments a greater bias in nonracemic $\mathbf{4}$ is needed.

Chiral Amplification through Helicity Memory. We finally investigated whether both the $P$ - and $M$-helical conformations of the optically-active poly- $\left(\mathbf{1 b}_{1-\mathrm{r}}-\mathrm{CO}-\mathbf{2} \boldsymbol{R}_{\mathrm{r}}\right)$ and poly- $\left(\mathbf{2} \boldsymbol{R}_{\mathrm{r}}-\mathrm{CO}-\right.$ $\left.\mathbf{2} \boldsymbol{S}_{1-\mathrm{r}}\right)$ and optically-inactive poly- $\left(2 \boldsymbol{R}_{0.5}-\mathrm{co}-\mathbf{2} \boldsymbol{S}_{0.5}\right)(0 \%$ ee) induced by $(R)$ - or $(S)-4$ could be preserved after removing the optically-active 4 . First, the solutions of poly- $\left(2 R_{0.5}-c o-2 S_{0.5}\right)$ with $(R)$ - and $(S)-4$ in $\mathrm{MCH}(\mathrm{MCH} / 4=80 / 20$, v/v) were prepared, and after standing at $25{ }^{\circ} \mathrm{C}$ for 5 days (b and $\mathrm{d}$ in Figure $4 \mathrm{C}$ and Figure S23A) the copolymers were isolated by precipitation into a large amount of methanol at $-10^{\circ} \mathrm{C}$, followed by washing with methanol. The complete removal of $\mathbf{4}$ was confirmed by ${ }^{1} \mathrm{H}$ NMR analysis of the isolated copolymers (Figure $\mathrm{S} 24)$. The isolated poly- $\left(2 \boldsymbol{R}_{0.5}-\mathrm{Co}-\mathbf{2} \boldsymbol{S}_{0.5}\right)$ dissolved in $\mathrm{MCH}$ at $10{ }^{\circ} \mathrm{C}$ exhibited a full ICD as intense as that before the isolation, despite the absence of the optically-active 4 (c and e in Figure $4 \mathrm{C}$ and Figure S26). Therefore, it was concluded that the $M$ - and $P$-helices of poly- $\left(2 R_{0.5}-c o-2 S_{0.5}\right)$ induced by $(S)$ and $(R)-4$, respectively, were undoubtedly memorized. ${ }^{27}$ To the best of our knowledge, this is the first example of the helix-sense-selective synthesis of a pair of enantiomeric helical polymers from an optically-inactive polymer consisting of racemic pendants assisted by the helicity memory. In the same way, the diastereomeric $M$ - and $P$-helices of the poly- $\left(\mathbf{1 b}_{1-\mathrm{r}^{-}}\right.$ $\left.c o-2 \boldsymbol{R}_{\mathrm{r}}\right)(\mathrm{r}=0.05,0.1)$ and poly- $\left(2 \boldsymbol{R}_{\mathrm{r}}-c o-2 S_{1-\mathrm{r}}\right)(5 \%$ and $10 \%$ ee) induced by $(S)$ - or $(R)-4$ in $\mathrm{MCH}(\mathrm{MCH} / 4=80 / 20, \mathrm{v} / \mathrm{v})$ after standing at $25{ }^{\circ} \mathrm{C}$ for 5 days, were successfully memorized (Figures $4 \mathrm{~A}, \mathrm{~B}$, and D and S26). ${ }^{28}$

\section{CONCLUSION}

We have demonstrated an unexpectedly strong chiral amplification in dynamic helical copolymers of chiral/achiral and chiral/chiral $(R / S)$ biphenylylacetylenes that most likely relies on the dynamic axial chirality of the biphenyl pendants through which an excess one-handed main chain helicity is induced by the covalently-bonded remote chiral residues, resulting in the strong chiral amplification. We also found unprecedented chiral amplification phenomena based on the he- licity memory effect through noncovalent chiral interactions that allows the covalent helical copolymers with an imperfect helical sense excess to take the almost fully one-handed helices or opposite helices. The observed hierarchical amplification of the helicity through covalent (sergeants and soldiers and majority rule phenomena) and further noncovalent chiral interactions accompanied by the helicity memory was quantitatively interpreted on the basis of the 1D Ising model, which allowed us to describe both the covalent and noncovalent chiral amplifications in terms of a unique set of three key thermodynamic stability parameters; i.e., the helix reversal penalty $(F)$, the mismatch penalty $(J)$ for covalently bonded chiral residues, and an additional mismatch penalty $(K)$ for the noncovalently complexed additives.

These findings provide a versatile method to produce onehanded helical polymers with the desired handedness (either a $P$ - or $M$-helix) through the chiral amplification by combining the covalent and subsequent noncovalent bond interactions in dynamic helical polymers. We emphasize that either a $P$ - or $M$-static helical polymer can be produced in dynamically racemic helical polymers composed of totally racemic as well as achiral repeating units assisted by the helicity memory concept, thus providing emerging opportunities for applications as practically useful chiral materials, such as switchable chiral catalysts $^{29}$ and a helical polymer-based switchable CSP for separating enantiomers in which the elution order can be reversibly switched. ${ }^{16 a}$

\section{ASSOCIATED CONTENT}

\section{Supporting Information}

The Supporting Information is available free of charge on the ACS Publications website at DOI: xxx.

Experimental procedures, characterizations of polymers and copolymers, details of the chiral amplification model and modeling procedures, and supporting data (PDF).

\section{AUTHOR INFORMATION}

\section{Corresponding Author \\ *yashima@chembio.nagoya-u.ac.jp}

\section{ORCID}

Albert Jan Markvoort: 0000-0001-6025-9557

Katsuhiro Maeda: 0000-0002-5341-8799

Eiji Yashima: 0000-0001-6307-198X

\section{Notes}

The authors declare no competing financial interest.

\section{ACKNOWLEDGMENT}

We thank Prof. E. W. Meijer (Eindhoven University of Technology) for fruitful discussions and invaluable comments on the chiral amplification. This work was supported in part by JSPS KAKENHI (Grant-in-Aid for Specially Promoted Research, no. 18H05209 (E.Y. and K.M.). R.I. expresses his thanks for a JSPS Research Fellowship for Young Scientists (no. 270)). 


\section{REFERENCES}

(1) (a) Girard, C.; Kagan, H. B. Nonlinear Effects in Asymmetric Synthesis and Stereoselective Reactions: Ten Years of Investigation. Angew. Chem., Int. Ed. 1998, 37, 2923-2959. (b) Satyanarayana, T.; Abraham, S.; Kagan, H. B. Nonlinear Effects in Asymmetric Catalysis. Angew. Chem., Int. Ed. 2009, 48, 456-494. (c) Bissette, A. J.; Fletcher, S. P. Mechanisms of Autocatalysis. Angew. Chem., Int. Ed. 2013, 52, 12800-12826. (d) Soai, K.; Kawasaki, T.; Matsumoto, A. Asymmetric Autocatalysis of Pyrimidyl Alkanol and Its Application to the Study on the Origin of Homochirality. Acc. Chem. Res. 2014, 47, 3643-3654. (e) Gellman, A.; Ernst, K.-H. Chiral Autocatalysis and Mirror Symmetry Breaking. Catal. Lett. 2018, 148, 1610-1621.

(2) (a) Green, M. M.; Peterson, N. C.; Sato, T.; Teramoto, A.; Cook, R.; Lifson, S. Helical Polymer with a Cooperative Response to Chiral Information. Science 1995, 268, 1860-1866. (b) Green, M. M.; Park, J. W.; Sato, T.; Teramoto, A.; Lifson, S.; Selinger, R. L. B.; Selinger, J. V. The Macromolecular Route to Chiral Amplification. Angew. Chem., Int. Ed. 1999, 38, 3139-3154. (c) Teramoto, A. Cooperative Conformational Transitions in Linear Macromolecules Undergoing Chiral Perturbations. Prog. Polym. Sci. 2001, 26, 667-720. (d) Fujiki, M. Optically Active Polysilylenes: State-of-the-Art Chiroptical Polymers. Macromol. Rapid Commun. 2001, 22, 539-563. (e) Cornelissen, J. J. L. M.; Rowan, A. E.; Nolte, R. J. M.; Sommerdijk, N. A. J. M. Chiral Architectures from Macromolecular Building Blocks. Chem. Rev. 2001, 101, 4039-4070. (f) Sato, T.; Terao, K.; Teramoto, A.; Fujiki, M. Molecular Properties of Helical Polysilylenes in Solution. Polymer 2003, 44, 5477-5495. (g) Pijper, D.; Feringa, B. L. Control of Dynamic Helicity at the Macro- and Supramolecular Level. Soft Matter 2008, 4, 1349-1372. (h) Jain, V.; Cheon, K. S.; Tang, K.; Jha, S.; Green, M. M. Chiral Cooperativity in Helical Polymers. Isr. J. Chem. 2011, 51, 1067-1074. (i) Freire, F.; Quiñoá, E.; Riguera, R. Supramolecular Assemblies from Poly(Phenylacetylene)s. Chem. Rev. 2016, 116, 1242-127.

(3) (a) Feringa, B. L.; van Delden, R. A. Absolute Asymmetric Synthesis: The Origin, Control, and Amplification of Chirality. Angew. Chem., Int. Ed. 1999, 38, 3418-3438. (b) Mateos-Timoneda, M. A.; Crego-Calama, M.; Reinhoudt, D. N. Supramolecular Chirality of Self-Assembled Systems in Solution. Chem. Soc. Rev. 2004, 33, 363372. (c) Palmans, A. R. A.; Meijer, E. W. Amplification of Chirality in Dynamic Supramolecular Aggregates. Angew. Chem., Int. Ed. 2007, 46, 8948-8968. (d) Zhang, D. W.; Zhao, X.; Li, Z. T. Aromatic Amide and Hydrazide Foldamer-Based Responsive Host-Guest Systems. Acc. Chem. Res. 2014, 47, 1961-1970.

(4) (a) Maeda, K.; Yashima, E. Dynamic Helical Structures: Detection and Amplification of Chirality. Top. Curr. Chem. 2006, 265, 4788. (b) Yashima, E.; Maeda, K.; Iida, H.; Furusho, Y.; Nagai, K. Helical Polymers: Synthesis, Structures, and Functions. Chem. Rev. 2009, 109, 6102-6211. (c) Yashima, E.; Ousaka, N.; Taura, D.; Shimomura, K.; Ikai, T.; Maeda, K. Supramolecular Helical Systems: Helical Assemblies of Small Molecules, Foldamers, and Polymers with Chiral Amplification and Their Functions. Chem. Rev. 2016, 116, 1375213990.

(5) (a) Bonner, W. A. The Origin and Amplification of Biomolecular Chirality. Origins Life Evol. Biospheres 1991, 21, 59-111. (b) Weissbuch, I.; Leiserowitz, L.; Lahav, M. Stochastic "Mirror Symmetry Breaking" via Self-Assembly, Reactivity and Amplification of Chirality: Relevance to Abiotic Conditions. Top. Curr. Chem. 2005, 259, 123-165. (c) Blanco, C.; Hochberg, D. Stochastic Mirror Symmetry Breaking: Theoretical Models and Simulation of Experiments. Top. Curr. Chem. 2013, 333, 157-212.

(6) Pauling, L.; Corey, R. B.; Branson, H. R. The Structure of Proteins: Two Hydrogen-Bonded Helical Configurations of the Polypeptide Chain. Proc. Natl. Acad. Sci. U. S. A. 1951, 37, 205-211.

(7) Watson, J. D.; Crick, F. H. C. Molecular Structure of Nucleic Acids: A Structure for Deoxyribose Nucleic Acid. Nature 1953, 171, 737-738.

(8) Green, M. M.; Andreola, C.; Munoz, B.; Reidy, M. P.; Zero, K. Macromolecular Stereochemistry: A Cooperative Deuterium Isotope Effect Leading to a Large Optical Rotation. J. Am. Chem. Soc. 1988, 110, 4063-4065.
(9) Green, M. M.; Reidy, M. P.; Johnson, R. J.; Darling, G.; Oleary, D. J.; Willson, G. Macromolecular Stereochemistry: The Out-ofProportion Influence of Optically Active Comonomers on the Conformational Characteristics of Polyisocyanates. The Sergeants and Soldiers Experiment. J. Am. Chem. Soc. 1989, 111, 6452-6454.

(10) Green, M. M.; Garetz, B. A.; Munoz, B.; Chang, H. P.; Hoke, S.; Cooks, R. G. Majority Rules in the Copolymerization of MirrorImage Isomers. J. Am. Chem. Soc. 1995, 117, 4181-4182.

(11) Jha, S. K.; Cheon, K. S.; Green, M. M.; Selinger, J. V. Chiral Optical Properties of a Helical Polymer Synthesized from Nearly Racemic Chiral Monomers Highly Diluted with Achiral Monomers. $J$. Am. Chem. Soc. 1999, 121, 1665-1673.

(12) For reviews, see ref 4 and (a) Yashima, E.; Maeda, K.; Nishimura, T. Detection and Amplification of Chirality by Helical Polymers. Chem. - Eur. J. 2004, 10, 42-51. (b) Yashima, E.; Maeda, K.; Furusho, Y. Single- and Double-Stranded Helical Polymers: Synthesis, Structures, and Functions. Acc. Chem. Res. 2008, 41, 1166-1180. (c) Fujiki, M. Supramolecular Chirality: Solvent Chirality Transfer in Molecular Chemistry and Polymer Chemistry. Symmetry 2014, 6, 677-703. (d) Maeda, K.; Yashima, E. Helical Polyacetylenes Induced via Noncovalent Chiral Interactions and Their Applications as Chiral Materials. Top. Curr. Chem. 2017, 375, 72. For leading references, see (e) Green, M. M.; Khatri, C.; Peterson, N. C. A Macromolecular Conformational Change Driven by a Minute Chiral Solvation Energy. J. Am. Chem. Soc. 1993, 115, 4941-4942. (f) Yashima, E.; Matsushima, T.; Okamoto, Y. Poly((4-carboxyphenyl)acetylene) as a Probe for Chirality Assignment of Amines by Circular Dichroism. J. Am. Chem. Soc. 1995, 117, 11596-11597. (g) Yashima, E.; Matsushima, T.; Okamoto, Y. Chirality Assignment of Amines and Amino Alcohols Based on Circular Dichroism Induced by Helix Formation of a Stereoregular Poly((4-carboxyphenyl)acetylene) through Acid-Base Complexation. J. Am. Chem. Soc. 1997, 119, 6345-6359 (h) Inai, Y.; Tagawa, K.; Takasu, A.; Hirabayashi, T.; Oshikawa, T.; Yamashita, M. Induction of One-Handed Helical Screw Sense in Achiral Peptide Through the Domino Effect Based on Interacting Its N-Terminal Amino Group with Chiral Carboxylic Acid. J. Am. Chem. Soc. 2000, 122, 11731-11732. (i) Nonokawa, R.; Yashima, E. Detection and Amplification of a Small Enantiomeric Imbalance in $\alpha$-Amino Acids by a Helical Poly(phenylacetylene) with Crown Ether Pendants. $J$. Am. Chem. Soc. 2003, 125, 1278-1283. (j) Maeda, K.; Takeyama, Y.; Sakajiri, K.; Yashima, E. Nonracemic Dopant-Mediated Hierarchical Amplification of Macromolecular Helicity in a Charged Polyacetylene Leading to a Cholesteric Liquid Crystal in Water. J. Am. Chem. Soc. 2004, 126, 16284-16285. (k) Saxena, A.; Guo, G.; Fujiki, M.; Yang, Y.; Ohira, A.; Okoshi, K.; Naito, M. Helical Polymer Command Surface: Thermodriven Chiroptical Transfer and Amplification in Binary Polysilane Film System. Macromolecules 2004, 37, 30813083. (1) Makiguchi, W.; Kobayashi, S.; Furusho, Y.; Yashima, E. Formation of a Homo Double Helix of a Conjugated Polymer with Carboxy Groups and Amplification of the Macromolecular Helicity by Chiral Amines Sandwiched between the Strands. Angew. Chem., Int. Ed. 2013, 52, 5275-5279.

(13) (a) Palmans, A. R. A.; Vekemans, J.; Havinga, E. E.; Meijer, E. W. Sergeants-and-Soldiers Principle in Chiral Columnar Stacks of Disc-Shaped Molecules with $C_{3}$ Symmetry. Angew. Chem., Int. Ed. 1997, 36, 2648-2651. (b) van Gestel, J.; Palmans, A. R.; Titulaer, B.; Vekemans, J. A.; Meijer, E. W. "Majority-Rules" Operative in Chiral Columnar Stacks of $C_{3}$-Symmetrical Molecules. J. Am. Chem. Soc. 2005, 127, 5490-5494. (c) Jin, W.; Fukushima, T.; Niki, M.; Kosaka, A.; Ishii, N.; Aida, T. Self-Assembled Graphitic Nanotubes with OneHanded Helical Arrays of a Chiral Amphiphilic Molecular Graphene. Proc. Natl. Acad. Sci. U. S. A. 2005, 102, 10801-10806. (d) Cai, W.; Wang, G.-T.; Du, P.; Wang, R.-X.; Jiang, X.-K.; Li, Z.-T. Foldamer Organogels: A Circular Dichroism Study of Glucose-Mediated Dynamic Helicity Induction and Amplification. J. Am. Chem. Soc. 2008, 130, 13450-13459. (e) Yamamoto, T.; Fukushima, T.; Kosaka, A.; Jin, W.; Yamamoto, Y.; Ishii, N.; Aida, T. Conductive One-Handed Nanocoils by Coassembly of Hexabenzocoronenes: Control of Morphology and Helical Chirality. Angew. Chem., Int. Ed. 2008, 47, 1672-1675. (f) Isare, B.; Linares, M.; Zargarian, L.; Fermandjian, S.; Miura, M.; Motohashi, S.; Vanthuyne, N.; Lazzaroni, R.; Bouteiller, L. 
Chirality in Dynamic Supramolecular Nanotubes Induced by a Chiral Solvent. Chem. - Eur. J. 2010, 16, 173-177. (g) Helmich, F.; Smulders, M. M. J.; Lee, C. C.; Schenning, A.; Meijer, E. W. Effect of Stereogenic Centers on the Self-Sorting, Depolymerization, and Atropisomerization Kinetics of Porphyrin-Based Aggregates. J. Am. Chem Soc. 2011, 133, 12238-12246. (h) Kang, J.; Miyajima, D.; Mori, T.; Inoue, Y.; Itoh, Y.; Aida, T. A Rational Strategy for the Realization of Chain-Growth Supramolecular Polymerization. Science 2015, 347, 646-651. (i) Kim, T.; Mori, T.; Aida, T.; Miyajima, D. Dynamic Propeller Conformation for the Unprecedentedly High Degree of Chiral Amplification of Supramolecular Helices. Chem. Sci. 2016, 7, 6689-6694. (j) Karunakaran, S. C.; Cafferty, B. J.; Weigert-Muñoz, A.; Schuster, G. B.; Hud, N. V. Spontaneous Symmetry Breaking in the Formation of Supramolecular Polymers: Implications for the Origin of Biological Homochirality. Angew. Chem., Int. Ed. 2019, 58, 1453-1457.

(14) (a) Yashima, E.; Maeda, K.; Okamoto, Y. Memory of Macromolecular Helicity Assisted by Interaction with Achiral Small Molecules. Nature 1999, 399, 449-451. (b) Maeda, K.; Morino, K.; Okamoto, Y.; Sato, T.; Yashima, E. Mechanism of Helix Induction on a Stereoregular Poly((4-carboxyphenyl)acetylene) with Chiral Amines and Memory of the Macromolecular Helicity Assisted by Interaction with Achiral Amines. J. Am. Chem. Soc. 2004, 126, 4329-4342. (c) Onouchi, H.; Miyagawa, T.; Furuko, A.; Maeda, K.; Yashima, E. Enantioselective Esterification of Prochiral Phosphonate Pendants of a Polyphenylacetylene Assisted by Macromolecular Helicity: Storage of a Dynamic Macromolecular Helicity Memory. J. Am. Chem. Soc. 2005, 127, 2960-2965. (d) Miyagawa, T.; Furuko, A.; Maeda, K.; Katagiri, H.; Furusho, Y.; Yashima, E. Dual Memory of Enantiomeric Helices in a Polyacetylene Induced by a Single Enantiomer. $J$. Am. Chem. Soc. 2005, 127, 5018-5019. (e) Maeda, K.; Tamaki, S.; Tamura, K.; Yashima, E. Helicity Induction and Memory of the Macromolecular Helicity in a Polyacetylene Bearing a Biphenyl Pendant. Chem. Asian J. 2008, 3, 614-624. (f) Maeda, K.; Miyagawa, T.; Furuko, A.; Onouchi, H.; Yashima, E. Dual Memory of Enantiomeric Helices in Poly(phenylacetylene)s Induced by a Single Enantiomer through Helix Inversion and Dual Storage of the Enantiomeric Helicity Memories. Macromolecules 2015, 48, 4281-4293. For other helical polymers showing memory effects, see (g) Ishikawa, M.; Maeda, K.; Mitsutsuji, Y.; Yashima, E. An Unprecedented Memory of Macromolecular Helicity Induced in an Achiral Polyisocyanide in Water. $J$. Am Chem. Soc. 2004, 126, 732-733 (h) Kawauchi, T.; Kitaura, A.; Kumaki, J.; Kusanagi, H.; Yashima, E. Helix-Sense-Controlled Synthesis of Optically Active Poly(methyl methacrylate) Stereocomplexes. $J$. Am. Chem. Soc. 2008, 130, 11889-11891. (i) Kawauchi, T.; Kumaki, J.; Kitaura, A.; Okoshi, K.; Kusanagi, H.; Kobayashi, K.; Sugai, T.; Shinohara, H.; Yashima, E. Encapsulation of Fullerenes in a Helical PMMA Cavity Leading to a Robust Processable Complex with a Macromolecular Helicity Memory. Angew. Chem., Int. Ed. 2008, 47, 515-519. (j) Hase, Y.; Nagai, K.; Iida, H.; Maeda, K.; Ochi, N.; Sawabe, K.; Sakajiri, K.; Okoshi, K.; Yashima, E. Mechanism of Helix Induction in Poly(4-carboxyphenyl isocyanide) with Chiral Amines and Memory of the Macromolecular Helicity and Its Helical Structures. J. Am. Chem. Soc. 2009, 131, 10719-10732.

(15) (a) Furusho, Y.; Kimura, T.; Mizuno, Y.; Aida, T. ChiralityMemory Molecule: A $D_{2}$-Symmetric Fully Substituted Porphyrin as a Conceptually New Chirality Sensor. J. Am. Chem. Soc. 1997, 119, 5267-5268. (b) Prins, L. J.; De Jong, F.; Timmerman, P.; Reinhoudt, D. N. An Enantiomerically Pure Hydrogen-Bonded Assembly. Nature 2000, 408, 181-184. (c) Kubo, Y.; Ohno, T.; Yamanaka, J.; Tokita, S.; Iida, T.; Ishimaru, Y. Chirality-Transfer Control Using a Heterotopic Zinc(II) Porphyrin Dimer. J. Am. Chem. Soc. 2001, 123, 12700 12701. (d) Ziegler, M.; Davis, A. V.; Johnson, D. W.; Raymond, K. N. Supramolecular Chirality: A Reporter of Structural Memory. Angew. Chem., Int. Ed. 2003, 42, 665-668. (e) Hasegawa, T.; Furusho, Y.; Katagiri, H.; Yashima, E. Enantioselective Synthesis of Complementary Double-Helical Molecules that Catalyze Asymmetric Reactions. Angew. Chem., Int. Ed. 2007, 46, 5885-5888. (f) Takashima, S.; Abe, H.; Inouye, M. Copper(II)/Phenanthroline-Mediated CDEnhancement and Chiral Memory Effect on a meta-Ethynylpyridine Oligomer. Chem. Commun. 2012, 48, 3330-3332. (g) Castilla, A. M.;
Ousaka, N.; Bilbeisi, R. A.; Valeri, E.; Ronson, T. K.; Nitschke, J. R. High-Fidelity Stereochemical Memory in a $\mathrm{Fe}^{\mathrm{II}}{ }_{4} \mathrm{~L}_{4}$ Tetrahedral Capsule. J. Am. Chem. Soc. 2013, 135, 17999-18006. For other chiral memory effects in supramolecular systems, see (h) Sugasaki, A.; Ikeda, M.; Takeuchi, M.; Robertson, A.; Shinkai, S. Efficient Chirality Transcription Utilizing a Cerium(IV) Double Decker Porphyrin: A Prototype for Development of a Molecular Memory System. J. Chem. Soc., Perkin Trans. 1 1999, 3259-3264. (i) Lauceri, R.; Raudino, A.; Scolaro, L. M.; Micali, N.; Purrello, R. From Achiral Porphyrins to Template-Imprinted Chiral Aggregates and Further. Self-Replication of Chiral Memory from Scratch. J. Am. Chem. Soc. 2002, 124, 894 895. (j) Ousaka, N.; Inai, Y.; Kuroda, R. Chain-Terminus Triggered Chiral Memory in an Optically Inactive 310 -Helical Peptide. J. Am. Chem. Soc. 2008, 130, 12266-12267. (k) Helmich, F.; Lee, C. C.; Schenning, A. P. H. J.; Meijer, E. W. Chiral Memory via Chiral Amplification and Selective Depolymerization of Porphyrin Aggregates. J. Am. Chem. Soc. 2010, 132, 16753-16755. (1) Ohta, E.; Sato, H.; Ando, S.; Kosaka, A.; Fukushima, T.; Hashizume, D.; Yamasaki, M.; Hasegawa, K.; Muraoka, A.; Ushiyama, H.; Yamashita, K.; Aida, T. Redox-Responsive Molecular Helices with Highly Condensed $\pi$ Clouds. Nat. Chem. 2011, 3, 68-73. (m) George, S. J.; de Bruijn, R.; Tomovic, Z.; Van Averbeke, B.; Beljonne, D.; Lazzaroni, R.; Schenning, A.; Meijer, E. W. Asymmetric Noncovalent Synthesis of SelfAssembled One-Dimensional Stacks by a Chiral Supramolecular Auxiliary Approach. J. Am. Chem. Soc. 2012, 134, 17789-17796. (n) Zhang, W.; Jin, W.; Fukushima, T.; Ishii, N.; Aida, T. Dynamic or Nondynamic? Helical Trajectory in Hexabenzocoronene Nanotubes Biased by a Detachable Chiral Auxiliary. J. Am. Chem. Soc. 2013, 135, 114-117. (o) Yang, D.; Zhao, Y.; Lv, K.; Wang, X.; Zhang, W.; Zhang, L.; Liu, M. A Strategy for Tuning Achiral Main-Chain Polymers into Helical Assemblies and Chiral Memory Systems. Soft Matter 2016, 12, 1170-1175.

(16) (a) Shimomura, K.; Ikai, T.; Kanoh, S.; Yashima, E.; Maeda, K. Switchable Enantioseparation Based on Macromolecular Memory of a Helical Polyacetylene in the Solid State. Nat. Chem. 2014, 6, 429-434. (b) Maeda, K.; Shimomura, K.; Ikai, T.; Kanoh, S.; Yashima, E. Static Memory of Enantiomeric Helices Induced in a Poly(biphenylylacetylene) by a Single Enantiomer Assisted by Temperature- and Solvent-Driven Helix Inversion. Macromolecules 2017, 50, 7801-7806.

(17) Ishidate, R.; Ikai, T.; Kanoh, S.; Yashima, E.; Maeda, K. Chromatographic Enantioseparation by Poly(biphenylylacetylene) Derivatives with Memory of Both Axial Chirality and Macromolecular Helicity. Chirality 2017, 29, 120-129.

(18) Maeda, K.; Hirose, D.; Okoshi, N.; Shimomura, K.; Wada, Y.; Ikai, T.; Kanoh, S.; Yashima, E. Direct Detection of Hardly Detectable Hidden Chirality of Hydrocarbons and Deuterated Isotopomers by a Helical Polyacetylene through Chiral Amplification and Memory. $J$. Am. Chem. Soc. 2018, 140, 3270-3276.

(19) (a) Lifson, S.; Andreola, C.; Peterson, N. C.; Green, M. M. Macromolecular Stereochemistry: Helical Sense Preference in Optically Active Polyisocyanates. Amplification of a Conformational Equilibrium Deuterium Isotope Effect. J. Am. Chem. Soc. 1989, 111, 8850-8858. (b) Gu, H.; Sato, T.; Teramoto, A.; Varichon, L.; Green, M. M. Molecular Mechanisms for the Optical Activities of Polyisocyanates Induced by Intramolecular Chiral Perturbations. Polym. J. 1997, $29,77-84$.

(20) (a) Shirakawa, H.; Ito, T.; Ikeda, S. Raman-Scattering and Electronic-Spectra of Poly(acetylene). Polym. J. 1973, 4, 460-462. (b) Tabata, M.; Tanaka, Y.; Sadahiro, Y.; Sone, T.; Yokota, K.; Miura, I. Pressure-Induced Cis to Trans Isomerization of Aromatic Polyacetylenes. 2. Poly((o-ethoxyphenyl)acetylene) Stereoregularly Polymerized Using a Rh Complex Catalyst. Macromolecules 1997, 30, 5200 5204. (c) Ohsawa, S.; Sakurai, S.; Nagai, K.; Banno, M.; Maeda, K.; Kumaki, J.; Yashima, E. Hierarchical Amplification of Macromolecular Helicity of Dynamic Helical Poly(phenylacetylene)s Composed of Chiral and Achiral Phenylacetylenes in Dilute Solution, Liquid Crystal, and Two-Dimensional Crystal. J. Am. Chem. Soc. 2011, 133, 108114. (d) Tang, Z. L.; Iida, H.; Hu, H. Y.; Yashima, E. Remarkable Enhancement of the Enantioselectivity of an Organocatalyzed Asymmetric Henry Reaction Assisted by Helical Poly(phenylacetylene)s 
Bearing Cinchona Alkaloid Pendants via an Amide Linkage. ACS Macro Lett. 2012, 1, 261-265.

(21) Poly-2R also exhibited an intense CD in other solvents, such as toluene, THF, and chloroform (Figure S17). The CD intensities were almost independent of temperature $\left(-10-50{ }^{\circ} \mathrm{C}\right)$ except for polar THF and chloroform.

(22) a) Sakurai, S. I.; Okoshi, K.; Kumaki, J.; Yashima, E. TwoDimensional Hierarchical Self-Assembly of One-Handed Helical Polymers on Graphite. Angew. Chem., Int. Ed. 2006, 45, 1245-1248. (b) Sakurai, S. I.; Okoshi, K.; Kumaki, J.; Yashima, E. TwoDimensional Surface Chirality Control by Solvent-Induced Helicity Inversion of a Helical Polyacetylene on Graphite. J. Am. Chem. Soc. 2006, 128, 5650-5651. (c) Sakurai, S. I.; Ohsawa, S.; Nagai, K.; Okoshi, K.; Kumaki, J.; Yashima, E. Two-Dimensional Helix-Bundle Formation of a Dynamic Helical Poly(phenylacetylene) with Achiral Pendant Groups on Graphite. Angew. Chem., Int. Ed. 2007, 46, 76057608. (d) Kumaki, J.; Sakurai, S. I.; Yashima, E. Visualization of Synthetic Helical Polymers by High-Resolution Atomic Force Microscopy. Chem. Soc. Rev. 2009, 38, 737-746.

(23) (a) Percec, V.; Obata, M.; Rudick, J. G.; De, B. B.; Glodde, M.; Bera, T. K.; Magonov, S. N.; Balagurusamy, V. S. K.; Heiney, P. A. Synthesis, Structural Analysis, and Visualization of Poly(2-ethynyl-9substituted carbazole)s and Poly(3-ethynyl-9-substituted carbazole)s Containing Chiral and Achiral Minidendritic Substituents. J. Polym. Sci., Part A: Polym. Chem. 2002, 40, 3509-3533. (b) Onouchi, H.; Miyagawa, T.; Furuko, A.; Maeda, K.; Yashima, E. Enantioselective Esterification of Prochiral Phosphonate Pendants of a Polyphenylacetylene Assisted by Macromolecular Helicity: Storage of a Dynamic Macromolecular Helicity Memory. J. Am. Chem. Soc. 2005, 127, 2960-2965. (c) Liu, L. J.; Mottate, K.; Zhang, G.; Aoki, T.; Kaneko, T.; Teraguchi, M. Chiral Amplification during Asymmetric-Induced Copolymerization of Phenylacetylenes with Tight Cis-Cisoidal Main Chains. Macromol. Rapid Commun. 2013, 34, 1140-1144. (d) Bergueiro, J.; Freire, F.; Wendler, E. P.; Seco, J. M.; Quinoa, E.; Riguera, R. The On/Off Switching by Metal Ions of the "Sergeants and Soldiers" Chiral Amplification Effect on Helical Poly(phenylacetylene)s. Chem. Sci. 2014, 5, 2170-2176. (e) Maeda, K.; Wakasone, S.; Shimomura, K.; Ikai, T.; Kanoh, S. Chiral Amplification in Polymer Brushes Consisting of Dynamic Helical Polymer Chains through the Long-Range Communication of Stereochemical Information. Macromolecules 2014, 47, 6540-6546. (f) Arias, S.; Bergueiro, J.; Freire, F.; Quiñoá, E.; Riguera, R., Chiral Nanostructures from Helical Copolymer-Metal Complexes: Tunable Cation- $\pi$ Interactions and Sergeants and Soldiers Effect. Small 2016, 12, 238244. For aliphatic polyacetylenes, see (g) Nomura, R.; Fukushima, Y.; Nakako, H.; Masuda, T. Conformational Study of Helical Poly(propiolic esters) in Solution. J. Am. Chem. Soc. 2000, 122, 8830-8836. (h) Nomura, R.; Tabei, J.; Masuda, T. Effect of Side Chain Structure on the Conformation of Poly( $N$-propargylalkylamide). Macromolecules 2002, 35, 2955-2961. (i) Gao, G. Z.; Sanda, F.;
Masuda, T. Copolymerization of Chiral Amino Acid-Based Acetylenes and Helical Conformation of the Copolymers. Macromolecules 2003, 36, 3938-3943. (j) Deng, J. P.; Tabei, J.; Shiotsuki, M.; Sanda, F.; Masuda, T. Variation of Helical Pitches Driven by the Composition of $\mathrm{N}$-Propargylamide Copolymers. Macromolecules 2004, 37, 9715-9721.

(24) Newman, M. E. J.; Barkema, G. T., Monte Carlo Methods in Statistical Physics; Oxford University Press: Oxford, 1999.

(25) (a) Morino, K.; Maeda, K.; Okamoto, Y.; Yashima, E.; Sato, T. Temperature Dependence of Helical Structures of Poly(phenylacetylene) Derivatives Bearing an Optically Active Substituent. Chem. - Eur. J. 2002, 8, 5112-5120. (b) Maeda, K.; Muto, M.; Sato, T.; Yashima, E. Effect of Polyelectrolyte Function on Helical Structures of Optically Active Poly(phenylacetylene) Derivatives Bearing Basic or Acidic Functional Pendant Groups. Macromolecules 2011, 44, 8343-8349.

(26) (a) Nagata, Y.; Yamada, T.; Adachi, T.; Akai, Y.; Yamamoto, T.; Suginome, M. Solvent-Dependent Switch of Helical Main-Chain Chirality in Sergeants-and-Soldiers-Type Poly(quinoxaline-2,3-diyl)s: Effect of the Position and Structures of the "Sergeant" Chiral Units on the Screw-Sense Induction. J. Am. Chem. Soc. 2013, 135, 1010410113. (b) Ke, Y. Z.; Nagata, Y.; Yamada, T.; Suginome, M. Majority-Rules-Type Helical Poly(quinoxaline-2,3-diyl)s as Highly Efficient Chirality-Amplification Systems for Asymmetric Catalysis. Angew. Chem., Int. Ed. 2015, 54, 9333-9337. (c) Nagata, Y.; Nishikawa, T.; Suginome, M. Exerting Control over the Helical Chirality in the Main Chain of Sergeants-snd-Soldiers-Type Poly(quinoxaline-2,3-diyl)s by Changing from Random to Block Copolymerization Protocols. J. Am. Chem. Soc. 2015, 137, 4070-4073.

(27) The $M$ - and $P$-helical poly- $\left(\mathbf{2 R}_{0.5}-c o-2 S_{0.5}\right) \mathrm{s}$ with helicity memory were quite stable in the solid state at least for six months, while in solution the optical activities very slowly decreased as anticipated (Figure S25A)

(28) For the stabilities of a series of copolymers with helicity memory in $\mathrm{MCH}$ at $-10{ }^{\circ} \mathrm{C}$, see Figures $\mathrm{S} 21$ and $\mathrm{S} 25$.

(29) (a) Yamamoto, T.; Yamada, T.; Nagata, Y.; Suginome, M. High-Molecular-Weight Polyquinoxaline-Based Helically Chiral Phosphine (PQXphos) as Chirality-Switchable, Reusable, and Highly Enantioselective Monodentate Ligand in Catalytic Asymmetric Hydrosilylation of Styrenes. J. Am. Chem. Soc. 2010, 132, 7899-7901. (b) Yoshinaga, Y.; Yamamoto, T.; Suginome, M. ChiralitySwitchable 2,2'-Bipyridine Ligands Attached to Helical Poly(quinoxaline-2,3-diyl)s for Copper-Catalyzed Asymmetric Cyclopropanation of Alkenes. ACS Macro Lett. 2017, 6, 705-710. 
Table of Contents Artwork

Strong Chiral Amplification




\title{
Unexpectedly Strong Chiral Amplification of Chiral/Achiral and Chiral/Chiral Copolymers of Biphenylylacetylenes and Further Enhancement/Inversion and Memory of the Macromolecular Helicity
}

\author{
Ryoma Ishidate, ${ }^{\dagger}$ Albert J. Markvoort, ${ }^{\ddagger}$ Katsuhiro Maeda, ${ }^{\S}, \|$ and Eiji Yashima ${ }^{* \dagger, \perp}$ \\ 'Department of Molecular Design and Engineering, Graduate School of Engineering, Nagoya \\ University, Chikusa-ku, Nagoya 464-8603, Japan \\ Institute for Complex Molecular Systems and Computational Biology Group, Eindhoven University \\ of Technology, P.O. Box 513, 5600 MB Eindhoven, The Netherlands \\ ${ }^{\S}$ Graduate School of Natural Science and Technology and "WPI Nano Life Science Institute (WPI- \\ NanoLSI), Kanazawa University, Kakuma-machi, Kanazawa 920-1192, Japan \\ ${ }^{\perp}$ Department of Molecular and Macromolecular Chemistry, Graduate School of Engineering, Nagoya \\ University, Chikusa-ku, Nagoya 464-8603, Japan
}




\section{Table of Contents}

1. Instruments and Materials

2. Synthetic Procedures

3. CD Spectral Changes of Optically-Active Poly- $\left(\mathbf{1 b}_{1-\mathrm{r}-}-\mathrm{co}-\mathbf{2} \boldsymbol{R}_{\mathrm{r}}\right) \mathrm{s}$ and Poly- $\left(\mathbf{2} \boldsymbol{R}_{\mathrm{r}-}-c o-\mathbf{2} \boldsymbol{S}_{1-\mathrm{r}}\right) \mathrm{s}$ with $(R)$ - or $(S)-\mathbf{4}$ in Solution

4. Helicity Induction in Optically-Inactive Poly-1b and Poly-(2R $\left.\boldsymbol{R}_{0.5}-\mathbf{c o}-\mathbf{2} \boldsymbol{S}_{0.5}\right)$ with Nonracemic 4 in Solution

5. Memory of the Macromolecular Helicity in Preferred-Handed Helical Poly-1b, Poly-(1) $\mathbf{b}_{1-\mathrm{r}^{-}}$ co-2 $\left.\boldsymbol{R}_{\mathrm{r}}\right) \mathrm{s}$, and Poly- $\left(2 \boldsymbol{R}_{\mathrm{r}}-c o-2 \boldsymbol{S}_{1-\mathrm{r}}\right) \mathrm{s}$ in Solution

6. Theoretical Model for Chiral Amplification Accompanied by CD Spectral Changes of Poly$\left(1 b_{1-\mathrm{r}}-C O-2 R_{\mathrm{r}}\right) \mathrm{s}$ and Poly-(2R $\left.\boldsymbol{R}_{\mathrm{r}}-c o-2 S_{1-\mathrm{r}}\right) \mathrm{s}$ in the Absence and Presence of $(R)$ - and/or $(S)-4$ in Solution

6-1. General Description Model and Matrix-Transfer Approach

6-2. Model for Sergeants and Soldiers and Majority Rule Effects S16

6-2A. Chiral Amplification of Poly-(1 $\left.\mathbf{b}_{1-\mathrm{r}}-\mathrm{Co}-\mathbf{2} \boldsymbol{R}_{\mathrm{r}}\right) \mathrm{s}$ - Sergeants and Soldiers Effect S17

6-2B. Chiral Amplification of Poly-(2 $\left.\boldsymbol{R}_{\mathrm{r}-}-\mathrm{Co}-\mathbf{2} \boldsymbol{S}_{1-\mathrm{r}}\right) \mathrm{s}$ - Majority Rule

6-3. Preferred-Handed Helicity Induction in Optically-Inactive Poly-1b with $(R)-\mathbf{4}$ and $(S)-\mathbf{4}$

6-4. CD Spectral Changes of Poly-(1 $\left.\mathbf{b}_{1-\mathrm{r}}-c o-2 \boldsymbol{R}_{\mathrm{r}}\right) \mathrm{s}$ with $(S)-\mathbf{4}$

6-5. CD Spectral Changes of Poly-(2 $\left.\boldsymbol{R}_{\mathrm{r}}-\mathrm{co}-2 \boldsymbol{S}_{1-\mathrm{r}}\right) \mathrm{s}$ with $(R)-4$

6-6. Summary of Sergeants and Soldiers and Majority Rule with/without $(R)-4$ and/or $(S)-4$

6-7. Monte Carlo Simulations for Preferred-Handed Helicity Induction in Optically-Inactive Poly-1b and Poly-(2R $\left.\boldsymbol{R}_{0.5}-\mathrm{co}-\mathbf{2} \boldsymbol{S}_{0.5}\right)$ with Nonracemic 4

7. Supporting Data

8. Supporting References

9. ${ }^{1} \mathrm{H}$ and ${ }^{13} \mathrm{C}$ NMR Spectra of Monomers and Polymers 


\section{Instruments and Materials}

Instruments. The melting points were measured on a Yanako melting point apparatus (Yanako, Kyoto, Japan) and were uncorrected. The NMR spectra were measured using a Varian 500AS spectrometer (Varian, Palo Alto, CA) operating at $500 \mathrm{MHz}$ for ${ }^{1} \mathrm{H}$ and $125 \mathrm{MHz}$ for ${ }^{13} \mathrm{C}$ using tetramethylsilane (TMS) or a solvent residual peak as the internal standard. The IR spectra were recorded on a JASCO FT/IR-680 spectrophotometer (JASCO, Tokyo, Japan). The absorption and CD spectra were measured in a $0.1-\mathrm{cm}$ quartz cell using a JASCO V-750 spectrophotometer and a JASCO J-820 spectropolarimeter, respectively. The temperature was controlled with a JASCO ETCS-900 apparatus. The Raman spectra were measured on a confocal Raman microscope (Renishaw inVia Raman system, Renishaw, Inc., Gloucestershire, UK) with a 532-nm excitation laser. The electrospray ionization mass spectra (ESI-MS) were recorded using a JEOL JMS-T100CS spectrometer (JEOL, Akishima, Japan). The size exclusion chromatography (SEC) measurements were performed with a JASCO PU-980 liquid chromatograph equipped with a UV-visible detector (JASCO UV-2070, $254 \mathrm{~nm}$ ) and a column oven (JASCO CO-2060). The number-average molecular weight $\left(M_{\mathrm{n}}\right)$ and its distribution $\left(M_{\mathrm{w}} / M_{\mathrm{n}}\right)$ were determined at $40{ }^{\circ} \mathrm{C}$ using a Tosoh TSKgel Multipore $\mathrm{H}_{\mathrm{XL}}-\mathrm{M}(30 \mathrm{~cm}) \mathrm{SEC}$ column (Tosoh, Tokyo, Japan), and THF was used as the eluent at a flow rate of $1.0 \mathrm{~mL} / \mathrm{min}$. The molecular weight calibration curve was obtained with polystyrene standards (Tosoh). The elemental analyses were performed by the laboratory of elemental analyses in the Department of Agriculture, Nagoya University.

Materials. All starting materials were purchased from Sigma-Aldrich (St. Louis, MO), Wako Pure Chemical Industries (Osaka, Japan), or Tokyo Kasei (TCI, Tokyo, Japan) and were used as received, except for triethylamine ( $\left.\mathrm{NEt}_{3}\right)$ and THF. $\mathrm{NEt}_{3}$ was dried over $\mathrm{KOH}$ pellets and distilled onto $\mathrm{KOH}$ under nitrogen. THF was dried and deoxygenized by passing through purification columns (Glass Contour Solvent System, Nikko Hansen, Osaka, Japan), further dried over $\mathrm{LiAlH}_{4}$ under nitrogen, and distilled under high vacuum just before use. (2,2'-Bis(methoxymethoxy)-4'-carboxyl-4biphenylyl)acetylene, ${ }^{1} \quad$ and $\quad\left(2,2^{2}\right.$-bis(methoxymethoxy)-4'-dodecyloxycarbonyl-4biphenylyl)acetylene $(\mathbf{1 b})^{2}$ were synthesized according to the previously reported methods. $(R)$ - and $(S)$-2-methyldodecane-1-ol were synthesized according to the literature using $(R)$ - and (S)-3-bromo2-methyl-1-propanol, respectively. ${ }^{3}$

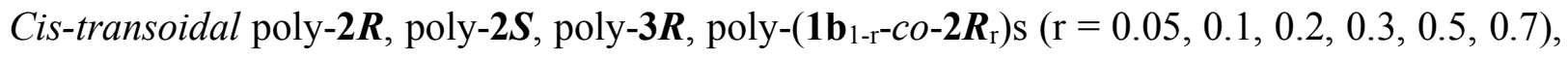
and poly- $\left(2 \boldsymbol{R}_{\mathrm{r}}-c o-2 S_{1-\mathrm{r}}\right) \mathrm{s}(\mathrm{r}=0.05,0.1,0.2,0.3,0.4,0.45,0.475,0.5,0.7)$ were prepared by the polymerization or copolymerization of the corresponding monomers $(\mathbf{1 b}, \mathbf{2} \boldsymbol{R}, \mathbf{2 S}$, and $\mathbf{3 R})$ according to the previously reported method. ${ }^{2,4}$ Their number-average molecular weights $\left(M_{\mathrm{n}}\right)$ and molecular weight distributions $\left(M_{\mathrm{w}} / M_{\mathrm{n}}\right)$ are summarized in Tables S1-S3. 
<smiles>C#Cc1ccc(-c2ccc(C(=O)O)cc2OC)c(OC)c1</smiles>

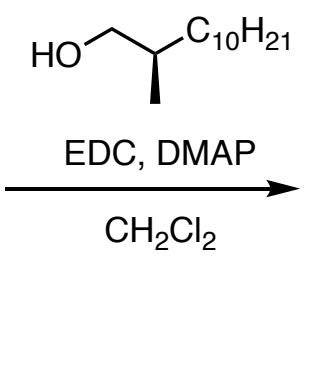

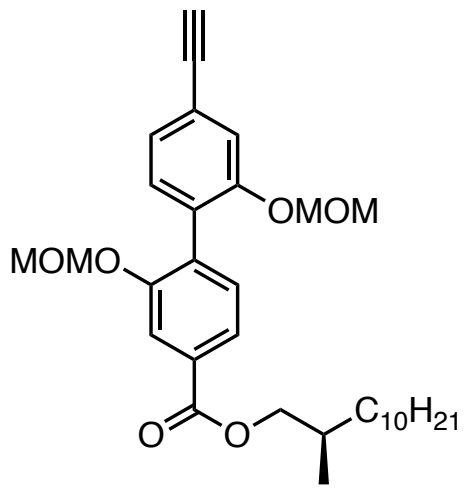

$2 R$<smiles>C#Cc1ccc(-c2ccc(C(=O)O)cc2OC)c(OC)c1</smiles>

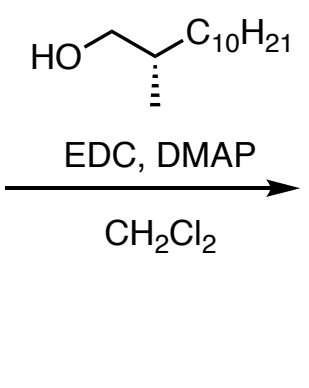

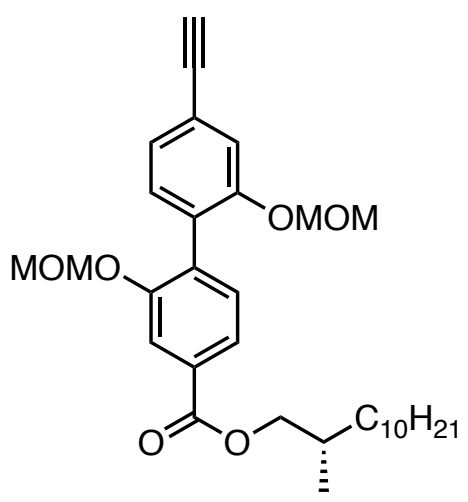

$2 S$<smiles>C#Cc1ccc(C(=O)O)cc1</smiles>

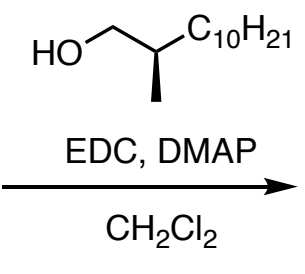

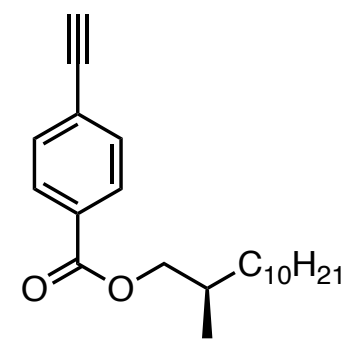

$3 R$

Scheme S1. Synthesis of $\mathbf{2 R}, \mathbf{2 S}$, and $\mathbf{3 R}$.

(2,2'-Bis(methoxymethoxy)-4'-((R)-2-methyldodecyloxycarbonyl)-4-biphenylyl)acetylene (2R), (2,2'-bis(methoxymethoxy)-4'-((S)-2-methyldodecyloxycarbonyl)-4-biphenylyl)acetylene (2S), and (4-((R)-2-methyldodecyloxycarbonyl)phenyl)acetylene (3R) were prepared according to Scheme S1.

\section{Synthesis of (2,2'-bis(methoxymethoxy)-4'-((R)-2-methyldodecyloxycarbonyl)-4-} biphenylyl)acetylene (2R). (2,2'-Bis(methoxymethoxy)-4'-carboxyl-4-biphenylyl)acetylene (700 mg, $2.04 \mathrm{mmol}$ ), (R)-2-methyldodecane-1-ol (414 mg, $2.07 \mathrm{mmol}$ ), and $N, N$-dimethyl-4aminopyridine (DMAP) (299 mg, $2.45 \mathrm{mmol}$ ) were dissolved in anhydrous dichloromethane (7.1 $\mathrm{mL}$ ) and the solution was cooled to $0{ }^{\circ} \mathrm{C}$. To this was added 1-ethyl-3-(3-dimethylaminopropyl)- 
carbodiimide hydrochloride $(\mathrm{EDC} \cdot \mathrm{HCl})(470 \mathrm{mg}, 2.45 \mathrm{mmol})$ and the mixture was stirred at room temperature for $3 \mathrm{~h}$. After evaporating the solvent, the residue was diluted with ethyl acetate and the solution was washed with water, and then dried over $\mathrm{Na}_{2} \mathrm{SO}_{4}$. The solvent was removed under reduced pressure and the crude product was purified by silica gel chromatography using $n$-hexaneethyl acetate $(95 / 5, \mathrm{v} / \mathrm{v})$ as the eluent to give the desired product as a white solid (990 $\mathrm{mg}, 92 \%$ yield). Mp: 30.8-31.5 ${ }^{\circ} \mathrm{C}$. IR $\left(\mathrm{KBr}, \mathrm{cm}^{-1}\right): 3254(\equiv \mathrm{CH}), 2110(\mathrm{C} \equiv \mathrm{C}), 1719(\mathrm{C}=\mathrm{O}) .{ }^{1} \mathrm{H}$ NMR $(500 \mathrm{MHz}$, $\left.\mathrm{CDCl}_{3}, 25^{\circ} \mathrm{C}\right): \delta 7.86(\mathrm{~d}, J=1.5 \mathrm{~Hz}, 1 \mathrm{H}, \mathrm{Ar}-\mathrm{H}), 7.76-7.74(\mathrm{dd}, J=1.5,6.0 \mathrm{~Hz}, 1 \mathrm{H}, \mathrm{Ar}-\mathrm{H}), 7.37(\mathrm{~d}$, $J=1.0 \mathrm{~Hz}, 1 \mathrm{H}, \mathrm{Ar}-\mathrm{H}), 7.30$ (d, $J=8.0 \mathrm{~Hz}, 1 \mathrm{H}, \mathrm{Ar}-\mathrm{H}), 7.23-7.18(\mathrm{~m}, 2 \mathrm{H}, \mathrm{Ar}-\mathrm{H}), 5.09$ (d, $J=21.0$ $\left.\mathrm{Hz}, 4 \mathrm{H}, 2 \mathrm{OCH}_{2} \mathrm{O}\right), 4.23-4.20\left(\mathrm{~m}, 1 \mathrm{H}, \mathrm{COCH}_{2}\right), 4.14-4.10\left(\mathrm{~m}, 1 \mathrm{H}, \mathrm{COCH}_{2}\right), 3.34(\mathrm{~d}, J=6.5 \mathrm{~Hz}, 6 \mathrm{H}$, $\left.2 \mathrm{OCH}_{3}\right), 3.10(\mathrm{~s}, 1 \mathrm{H}, \mathrm{C} \equiv \mathrm{C}-\mathrm{H}), 1.96-1.91\left(\mathrm{~m}, 1 \mathrm{H}, \mathrm{CHCH}_{3}\right), 1.49-1.22\left(\mathrm{~m}, 18 \mathrm{H}, \mathrm{CH}_{2}\right), 1.02(\mathrm{~d}, J=$ $\left.7.0 \mathrm{~Hz}, 3 \mathrm{H}, \mathrm{CHCH}_{3}\right), 0.88\left(\mathrm{t}, J=7.0 \mathrm{~Hz}, 3 \mathrm{H}, \mathrm{CH}_{3}\right) .{ }^{13} \mathrm{C} \mathrm{NMR}\left(125 \mathrm{MHz}, \mathrm{CDCl}_{3}, 25{ }^{\circ} \mathrm{C}\right): \delta 166.32$, $154.71,154.53,133.17,131.30,131.26,131.12$, 129.16, 125.64, 122.95, 122.81, 118.85, 116.33, 95.21, 95.11, 83.41, 77.44, 70.00, 56.08, 56.02, 33.50, 32.75, 31.92, 29.88, 29.67, 29.64, 29.63, 29.35, 26.90, 22.69, 17.07, 14.12. HRMS (ESI+): $\mathrm{m} / \mathrm{z}$ calcd for $\mathrm{C}_{32} \mathrm{H}_{44} \mathrm{O}_{6}\left(\mathrm{M}+\mathrm{Na}^{+}\right), 547.3036$; found 547.3063.

The monomer $(\mathbf{2} S)$ was also prepared from $(S)$-2-methyldodecane-1-ol in the same way for the synthesis of $\mathbf{2} \boldsymbol{R}$ in $90 \%$ yield as a white solid.

Spectroscopic data of $2 \mathrm{~S}$. Mp 30.6-31.5 ${ }^{\circ} \mathrm{C}$. IR $\left(\mathrm{KBr}, \mathrm{cm}^{-1}\right): 3248(\equiv \mathrm{CH}), 2109(\mathrm{C} \equiv \mathrm{C}), 1721$ $(\mathrm{C}=\mathrm{O}) .{ }^{1} \mathrm{H} \mathrm{NMR}\left(500 \mathrm{MHz}, \mathrm{CDCl}_{3}, 25^{\circ} \mathrm{C}\right): \delta 7.87(\mathrm{~d}, J=1.5 \mathrm{~Hz}, 1 \mathrm{H}, \mathrm{Ar}-\mathrm{H}), 7.76-7.74(\mathrm{dd}, J=1.5$, $6.0 \mathrm{~Hz}, 1 \mathrm{H}, \mathrm{Ar}-\mathrm{H}), 7.37$ (d, $J=1.5 \mathrm{~Hz}, 1 \mathrm{H}, \mathrm{Ar}-\mathrm{H}), 7.30$ (d, J=8.0 Hz, 1H, Ar-H), 7.23-7.18 (m, $2 \mathrm{H}, \mathrm{Ar}-\mathrm{H}), 5.09$ (d, $\left.J=21.0 \mathrm{~Hz}, 4 \mathrm{H}, 2 \mathrm{OCH}_{2} \mathrm{O}\right), 4.23-4.20\left(\mathrm{~m}, 1 \mathrm{H}, \mathrm{COCH}_{2}\right), 4.14-4.10(\mathrm{~m}, 1 \mathrm{H}$, $\left.\mathrm{COCH}_{2}\right), 3.34\left(\mathrm{~d}, J=6.5 \mathrm{~Hz}, 6 \mathrm{H}, 2 \mathrm{OCH}_{3}\right), 3.10$ (s, 1H, C $\left.\equiv \mathrm{C}-\mathrm{H}\right), 1.97-1.91\left(\mathrm{~m}, 1 \mathrm{H}, \mathrm{CHCH}_{3}\right), 1.49-$ $1.22\left(\mathrm{~m}, 18 \mathrm{H}, \mathrm{CH}_{2}\right), 1.02\left(\mathrm{~d}, J=6.5 \mathrm{~Hz}, 3 \mathrm{H}, \mathrm{CHCH}_{3}\right), 0.88\left(\mathrm{t}, J=7.0 \mathrm{~Hz}, 3 \mathrm{H}, \mathrm{CH}_{3}\right) .{ }^{13} \mathrm{C} \mathrm{NMR}(125$ $\left.\mathrm{MHz}, \mathrm{CDCl}_{3}, 25^{\circ} \mathrm{C}\right): \delta 166.32,154.70,154.51,133.16,131.28,131.25,131.11,129.14,125.63$, 122.94, 122.81, 118.82, 116.31, 95.19, 95.09, 83.40, 77.46, 70.00, 56.07, 56.01, 33.49, 32.74, 31.92, 29.88, 29.67, 29.64, 29.63, 29.36, 26.90, 22.69, 17.07, 14.13. HRMS (ESI+): m/z calcd for $\mathrm{C}_{32} \mathrm{H}_{44} \mathrm{O}_{6}$ $\left(\mathrm{M}+\mathrm{Na}^{+}\right), 547.3036$; found 547.3063.

\section{Synthesis of (4-((R)-2-methyldodecyloxycarbonyl)phenyl)acetylene $\quad(3 R)$. (4-} Carboxyphenyl)acetylene (51.1 mg, $0.350 \mathrm{mmol}),(R)$-2-methyldodecane-1-ol (70.1 mg, 0.350 mmol), and DMAP (51.3 mg, $0.420 \mathrm{mmol})$ were dissolved in anhydrous dichloromethane $(1.2 \mathrm{~mL})$ and the solution was cooled to $0{ }^{\circ} \mathrm{C}$. To this was added EDC $(80.5 \mathrm{mg}, 0.420 \mathrm{mmol})$ and the mixture was stirred at room temperature for $3 \mathrm{~h}$. After evaporating the solvent, the residue was diluted with ethyl acetate and the solution was washed with water, and then dried over $\mathrm{Na}_{2} \mathrm{SO}_{4}$. The solvent was removed under reduced pressure and the crude product was purified by silica gel chromatography 
using $n$-hexane-ethyl acetate $(95 / 5, \mathrm{v} / \mathrm{v})$ as the eluent to give the desired product as a colorless oil (98.4 mg, 85\% yield). IR (KBr, cm $\left.{ }^{-1}\right): 3261(\equiv \mathrm{CH}), 2109(\mathrm{C} \equiv \mathrm{C}), 1716(\mathrm{C}=\mathrm{O}) .{ }^{1} \mathrm{H}$ NMR $(500 \mathrm{MHz}$, $\left.\mathrm{CDCl}_{3}, 25^{\circ} \mathrm{C}\right): \delta 8.00(\mathrm{~d}, J=8.5 \mathrm{~Hz}, 2 \mathrm{H}, \mathrm{Ar}-\mathrm{H}), 7.55(\mathrm{~d}, J=8.5 \mathrm{~Hz}, 2 \mathrm{H}, \mathrm{Ar}-\mathrm{H}), 4.22-4.19(\mathrm{~m}, 1 \mathrm{H}$, $\left.\mathrm{COCH}_{2}\right), 4.12-4.09\left(\mathrm{~m}, 1 \mathrm{H}, \mathrm{COCH}_{2}\right), 3.23$ (s, 1H, C $\left.\equiv \mathrm{C}-\mathrm{H}\right), 1.95-1.89$ (m, 1H, $\left.\mathrm{CHCH}_{3}\right), 1.48-1.22$ $\left(\mathrm{m}, 18 \mathrm{H}, \mathrm{CH}_{2}\right), 1.01\left(\mathrm{~d}, J=6.5 \mathrm{~Hz}, 3 \mathrm{H}, \mathrm{CHCH}_{3}\right), 0.88\left(\mathrm{t}, J=6.5 \mathrm{~Hz}, 3 \mathrm{H}, \mathrm{CH}_{3}\right) .{ }^{13} \mathrm{C} \mathrm{NMR}(125 \mathrm{MHz}$, $\left.\mathrm{CDCl}_{3}, 25{ }^{\circ} \mathrm{C}\right): \delta 166.01,132.07,130.55,129.41,126.62,82.85,79.95,70.14,33.45,32.68,31.92$, 29.83, 29.65, 29.61, 29.35, 26.86, 22.70, 17.05, 14.13. HRMS (ESI+): m/z calcd for $\mathrm{C}_{22} \mathrm{H}_{32} \mathrm{O}_{2}$ $\left(\mathrm{M}+\mathrm{Na}^{+}\right), 351.2300$; found 351.2283 .

Polymerization. Homopolymerization of $2 R, 2 S$, and $3 R$ and copolymerization of $\mathbf{1 b}$ with $\mathbf{2 R}$ and $2 \boldsymbol{R}$ with $2 S$ were carried out in a dry glass ampule under a dry nitrogen atmosphere using $[\mathrm{Rh}(\mathrm{nbd}) \mathrm{Cl}]_{2}$ as a catalyst in the same way as reported previously (Scheme S2). ${ }^{2,4}$ The results of the homo- and copolymerizations are summarized in Tables S1-S3, respectively. 
<smiles>C#Cc1ccc(-c2ccc(C(=O)OCC(C)CCCCCC)cc2OC)c(OC)c1</smiles>

$2 R$<smiles>C#Cc1ccc(-c2ccc(C(=O)OCC(C)CCCCC)cc2OC)c(OC)c1</smiles>

$2 S$

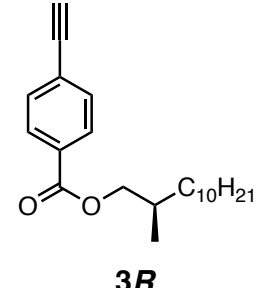<smiles>CCN(CC)CC</smiles>

$3 R$<smiles>C#Cc1ccc(-c2ccc(C(=O)OCC)cc2OC)c(OC)c1</smiles>

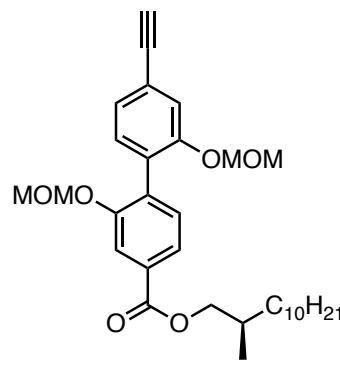

$2 R$

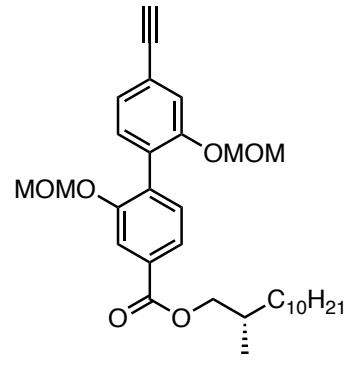

$2 S$

1b

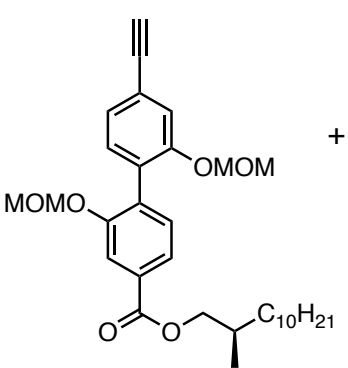

2R

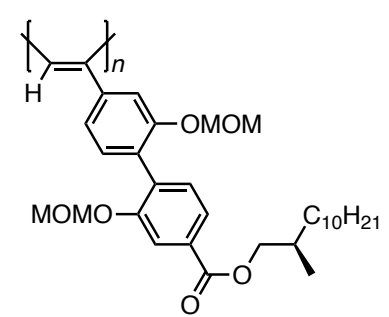

poly-2R<smiles>CCCCCC[C@H](C)COC(=O)c1ccc(-c2ccc(C(C)C)cc2OC)c(OC)c1</smiles>

poly-2S

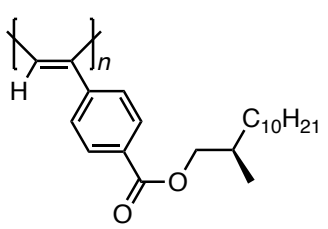

poly-3R
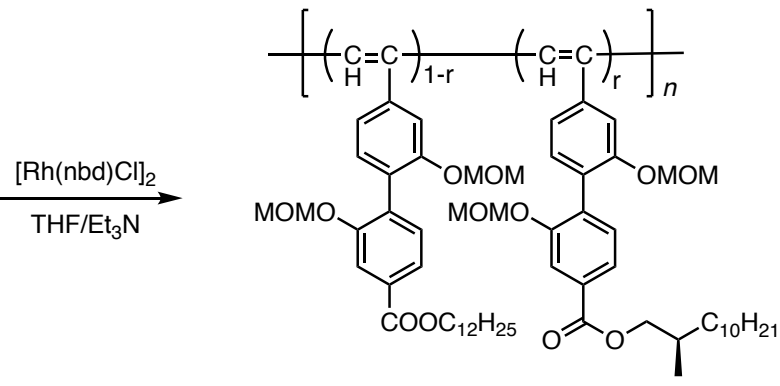

poly-(1 $\left.\mathbf{b}_{1-\mathrm{r}}-\mathrm{CO}-\mathbf{2} \boldsymbol{R}_{\mathrm{r}}\right)$

$(r=0.05,0.1,0.2,0.3,0.5,0.7)$

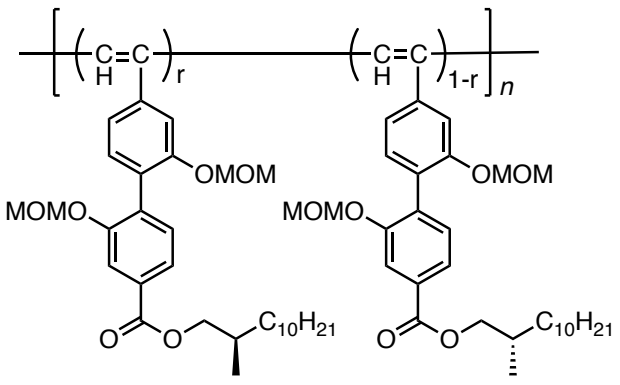

poly- $\left(2 \boldsymbol{R}_{\mathrm{r}}-\mathrm{CO}^{-2} \boldsymbol{S}_{1-\mathrm{r}}\right)$

$(r=0.05,0.1,0.2,0.3,0.4,0.45,0.475,0.5,0.7)$

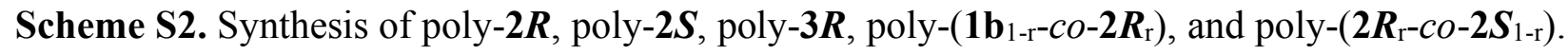


Table S1. Polymerization results of $\mathbf{2} \boldsymbol{R}, \mathbf{2} \boldsymbol{S}$, and $\mathbf{3 R}$ with $[\mathrm{Rh}(\mathrm{nbd}) \mathrm{Cl}]_{2}$ in THF/Et ${ }_{3} \mathrm{~N}$ at $30{ }^{\circ} \mathrm{C}$ for $3 \mathrm{~h}^{a}$

\begin{tabular}{ccccc}
\hline \multirow{2}{*}{ monomer } & \multicolumn{4}{c}{ polymer } \\
\cline { 2 - 5 } & sample code & yield $(\%)^{b}$ & $M_{\mathrm{n}} \times 10^{-5 c}$ & $M_{\mathrm{w}} / M_{\mathrm{n}}{ }^{c}$ \\
\hline $\mathbf{2} \boldsymbol{R}$ & poly-2R & 93 & 3.6 & 1.6 \\
$\mathbf{2 S}$ & poly-2S & 95 & 5.0 & 1.6 \\
$\mathbf{3 R}$ & poly-3R & 96 & 3.9 & 1.6
\end{tabular}

$\overline{{ }^{a}}[$ Monomer $]=0.5 \mathrm{M},\left[[\mathrm{Rh}(\mathrm{nbd}) \mathrm{Cl}]_{2}\right]=0.005 \mathrm{M},\left[\mathrm{Et}_{3} \mathrm{~N}\right] /[$ monomer $]=3 .{ }^{b}$ Methanol insoluble part. ${ }^{c}$ Determined by SEC (polystyrene standards) with THF as the eluent.

Table S2. Copolymerization results of $\mathbf{1 b}$ with $\mathbf{2 R}$ using $[\mathrm{Rh}(\mathrm{nbd}) \mathrm{Cl}]_{2}$ in $\mathrm{THF} / \mathrm{Et}_{3} \mathrm{~N}$ at $30{ }^{\circ} \mathrm{C}$ for 3 $\mathrm{h}^{a}$

\begin{tabular}{|c|c|c|c|c|c|c|}
\hline \multirow{2}{*}{\multicolumn{2}{|c|}{$\begin{array}{l}\text { monomer in feed } \\
(\mathrm{mol} \%)\end{array}$}} & \multicolumn{5}{|c|}{ copolymer } \\
\hline & & \multirow{2}{*}{ 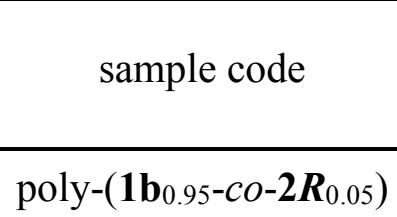 } & \multirow{2}{*}{$\frac{\text { yield }(\%)^{b}}{97}$} & \multirow{2}{*}{$\frac{M_{\mathrm{n}} \times 10^{-5 c}}{6.5}$} & \multirow{2}{*}{$\frac{M_{\mathrm{w}} / M_{\mathrm{n}}{ }^{c}}{1.7}$} & \multirow{2}{*}{$\begin{array}{c}\begin{array}{c}2 \boldsymbol{R} \\
(\mathrm{mol} \%)^{d}\end{array} \\
5.0\end{array}$} \\
\hline $\mathbf{1 b}(95)$ & $2 R(5)$ & & & & & \\
\hline $\mathbf{1 b}(90)$ & $2 \boldsymbol{R}(10)$ & poly-($\left(\mathbf{1} \mathbf{b}_{0.9}-c o-\mathbf{2} \boldsymbol{R}_{0.1}\right)$ & 91 & 5.9 & 1.5 & 10 \\
\hline $\mathbf{1 b}(80)$ & $\mathbf{2} \boldsymbol{R}(20)$ & poly-( $\left.\mathbf{1} \mathbf{b}_{0.8}-c o-\mathbf{2} \boldsymbol{R}_{0.2}\right)$ & 94 & 6.3 & 1.7 & 20 \\
\hline $1 b(70)$ & $\mathbf{2 R}(30)$ & poly-(1 $\left.\mathbf{b}_{0.7}-c o-2 R_{0.3}\right)$ & 93 & 7.2 & 1.6 & 29 \\
\hline $1 \mathrm{~b}(50)$ & $2 R(50)$ & poly-( $\left.\mathbf{1} \mathbf{b}_{0.5}-c o-\mathbf{2} \boldsymbol{R}_{0.5}\right)$ & 94 & 5.2 & 1.8 & 50 \\
\hline $\mathbf{1 b}(30)$ & $2 \boldsymbol{R}(70)$ & poly-(1 $\left.\mathbf{b}_{0.3}-c o-\mathbf{2} \boldsymbol{R}_{0.7}\right)$ & 95 & 6.9 & 1.7 & 71 \\
\hline
\end{tabular}


$\underline{\text { Table S3. Copolymerization results of } \mathbf{2} \boldsymbol{R} \text { with } \mathbf{2 S} \text { using }[\mathrm{Rh}(\mathrm{nbd}) \mathrm{Cl}]_{2} \text { in } \mathrm{THF} / \mathrm{Et}_{3} \mathrm{~N} \text { at } 30{ }^{\circ} \mathrm{C} \text { for } 3 \mathrm{~h}^{a}}$ monomer in feed $(\mathrm{mol} \%)$

\begin{tabular}{|c|c|c|c|c|c|c|}
\hline \multirow{2}{*}{\multicolumn{2}{|c|}{$(\mathrm{mol} \%)$}} & \multirow{3}{*}{\multicolumn{2}{|c|}{$\begin{array}{c}\begin{array}{c}\text { yield } \\
(\%)^{b}\end{array} \\
95\end{array}$}} & \multirow{3}{*}{$\frac{M_{\mathrm{n}} \times 10^{-5 c}}{5.0}$} & \multirow{3}{*}{$\frac{M_{\mathrm{w}} / M_{\mathrm{n}}{ }^{c}}{1.6}$} & \multirow{3}{*}{$\frac{\% \text { ee of } \mathbf{2}^{d}}{90(S \text { rich })}$} \\
\hline & & & & & & \\
\hline $2 R(5)$ & $2 S(95)$ & & & & & \\
\hline $\mathbf{2 R}(10)$ & $2 S(90)$ & poly- $\left(\mathbf{2} \boldsymbol{R}_{0.1}-c o-\mathbf{2} \boldsymbol{S}_{0.9}\right)$ & 94 & 5.2 & 1.6 & 80 ( $S$ rich $)$ \\
\hline $\boldsymbol{2} \boldsymbol{R}(20)$ & $2 S(80)$ & poly- $\left(2 \boldsymbol{R}_{0.2}-\mathrm{co}-\mathbf{2} \boldsymbol{S}_{0.8}\right)$ & 95 & 4.9 & 1.6 & $60(S$ rich $)$ \\
\hline $\mathbf{2 R}(30)$ & $2 S(70)$ & poly- $\left(\mathbf{2} \boldsymbol{R}_{0.3}-\mathrm{co}-\mathbf{2} \boldsymbol{S}_{0.7}\right)$ & 95 & 4.5 & 1.7 & 40 ( $S$ rich $)$ \\
\hline $\mathbf{2 R}(40)$ & $2 S(60)$ & poly- $\left(2 \boldsymbol{R}_{0.4}-\mathrm{co}-\mathbf{2} \boldsymbol{S}_{0.6}\right)$ & 96 & 4.2 & 1.8 & $20(S$ rich $)$ \\
\hline $2 \boldsymbol{R}(45)$ & $2 S(55)$ & poly- $\left(\mathbf{2} \boldsymbol{R}_{0.45}-c o-\mathbf{2} \boldsymbol{S}_{0.55}\right)$ & 94 & 5.2 & 1.6 & $10(S$ rich $)$ \\
\hline $2 \boldsymbol{R}(47.5)$ & $2 S(52.5)$ & poly-( $\left(2 \boldsymbol{R}_{0.475}-c o-\mathbf{2} \boldsymbol{S}_{0.525}\right)$ & 91 & 4.6 & 1.6 & 5 (S rich) \\
\hline $\mathbf{2 R}(50)$ & $2 S(50)$ & poly- $\left(\mathbf{2} \boldsymbol{R}_{0.5}-\mathrm{co}-\mathbf{2} \boldsymbol{S}_{0.5}\right)$ & 97 & 6.0 & 1.5 & 0 \\
\hline $2 R(70)$ & $2 S(30)$ & poly- $\left(2 \boldsymbol{R}_{0.7}-\mathrm{co}-\mathbf{2} \boldsymbol{S}_{0.3}\right)$ & 94 & 4.6 & 1.7 & 40 ( $R$ rich) \\
\hline
\end{tabular}

${ }_{c}^{a}[$ Monomer $\left.]=0.5 \mathrm{M},[[\mathrm{Rh}(\mathrm{nbd}) \mathrm{Cl}]]_{2}\right]=0.005 \mathrm{M},\left[\mathrm{Et}_{3} \mathrm{~N}\right] /[$ monomer $]=3 .{ }^{b}$ Methanol insoluble part. the monomers in feed.

Spectroscopic data of poly-2R: IR $\left(\mathrm{KBr}, \mathrm{cm}^{-1}\right): 1718\left(\mathrm{v}_{\mathrm{C}=0}\right) .{ }^{1} \mathrm{H}$ NMR $\left(500 \mathrm{MHz}, \mathrm{CDCl}_{3}, 50{ }^{\circ} \mathrm{C}\right)$ : $\delta 7.80-7.70$ (br, 1H, Ar-H), 7.58-7.48 (br, 1H, Ar-H), 7.02-6.78 (br, 3H, Ar-H), 6.58-6.42 (br, 1H, $\mathrm{Ar}-\mathrm{H}), 6.07-5.92(\mathrm{br}, 1 \mathrm{H}, \mathrm{C}=\mathrm{CH}), 4.95-4.58\left(\mathrm{br}, 4 \mathrm{H}, 2 \mathrm{OCH}_{2} \mathrm{O}\right), 4.25-4.10\left(\mathrm{~m}, 1 \mathrm{H}, \mathrm{COCH}_{2}\right), 4.05-$ $3.90\left(\mathrm{~m}, 1 \mathrm{H}, \mathrm{COCH}_{2}\right), 3.15-2.90\left(\mathrm{br}, 6 \mathrm{H}, 2 \mathrm{OCH}_{3}\right), 1.92-1.80\left(\mathrm{br}, 1 \mathrm{H}, \mathrm{CHCH}_{3}\right), 1.42-1.15$ (br, $18 \mathrm{H}$, $\mathrm{CH}_{2}$ ), 0.98-0.91 (br, 3H, $\mathrm{CHCH}_{3}$ ), 0.90-0.82 (br, 3H, $\mathrm{CH}_{3}$ ). Anal. Calcd for $\mathrm{C}_{32} \mathrm{H}_{44} \mathrm{O}_{6}: \mathrm{C}, 72.25 ; \mathrm{H}$, 8.45. Found: C, 72.23; H, 8.50.

Spectroscopic data of poly-2S: IR $\left(\mathrm{KBr}, \mathrm{cm}^{-1}\right): 1719\left(v_{\mathrm{C}=\mathrm{O}}\right) .{ }^{1} \mathrm{H} \mathrm{NMR}\left(500 \mathrm{MHz}, \mathrm{CDCl}_{3}, 50{ }^{\circ} \mathrm{C}\right)$ : $\delta 7.80-7.70$ (br, 1H, Ar-H), 7.58-7.48 (br, 1H, Ar-H), 7.02-6.78 (br, 3H, Ar-H), 6.58-6.42 (br, 1H, $\mathrm{Ar}-\mathrm{H}), 6.07-5.92(\mathrm{br}, 1 \mathrm{H}, \mathrm{C}=\mathrm{CH}), 4.95-4.58\left(\mathrm{br}, 4 \mathrm{H}, 2 \mathrm{OCH}_{2} \mathrm{O}\right), 4.25-4.10\left(\mathrm{~m}, 1 \mathrm{H}, \mathrm{COCH}_{2}\right), 4.05-$ $3.90\left(\mathrm{~m}, 1 \mathrm{H}, \mathrm{COCH}_{2}\right), 3.15-2.90\left(\mathrm{br}, 6 \mathrm{H}, 2 \mathrm{OCH}_{3}\right), 1.92-1.80\left(\mathrm{br}, 1 \mathrm{H}, \mathrm{CHCH}_{3}\right), 1.42-1.15$ (br, $18 \mathrm{H}$, $\mathrm{CH}_{2}$ ), 0.98-0.91 (br, 3H, $\mathrm{CHCH}_{3}$ ), 0.90-0.82 (br, 3H, $\mathrm{CH}_{3}$ ). Anal. Calcd for $\mathrm{C}_{32} \mathrm{H}_{44} \mathrm{O}_{6}: \mathrm{C}, 72.25 ; \mathrm{H}$, 8.45. Found: C, 72.26; H, 8.41.

Spectroscopic data of poly-3R: IR (KBr, cm $\left.{ }^{-1}\right): 1719\left(v_{\mathrm{C}=0}\right) .{ }^{1} \mathrm{H} \mathrm{NMR}\left(500 \mathrm{MHz}, \mathrm{CDCl}_{3}, 50{ }^{\circ} \mathrm{C}\right)$ : $\delta 7.70-7.55$ (br, 2H, Ar-H), 6.75-6.60 (br, 2H, Ar-H), 5.78-5.65 (br, 1H, C=CH), 4.20-4.07 (m, 1H, $\mathrm{COCH}_{2}$ ), 4.00-3.85 (m, 1H, $\left.\mathrm{COCH}_{2}\right), 1.90-1.75$ (br, $\left.1 \mathrm{H}, \mathrm{CHCH}_{3}\right), 1.42-1.10$ (br, $18 \mathrm{H}, \mathrm{CH}_{2}$ ), 0.970.87 (br, $3 \mathrm{H}, \mathrm{CHCH}_{3}$ ), 0.90-0.80 (br, $3 \mathrm{H}, \mathrm{CH}_{3}$ ). Anal. Calcd for $\mathrm{C}_{22} \mathrm{H}_{32} \mathrm{O}_{2}$ : C, 80.44; H, 9.82. Found: C, 80.43; H, 9.95. 


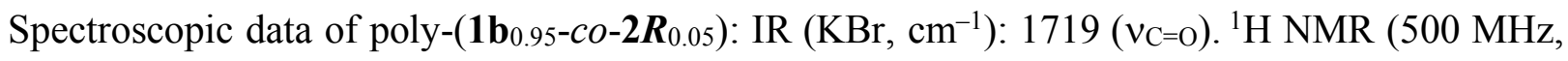
$\mathrm{CDCl}_{3}, 50{ }^{\circ} \mathrm{C}$ ): $\delta 7.80-7.68$ (br, $\left.1 \mathrm{H}, \mathrm{Ar}-\mathrm{H}\right), 7.60-7.46$ (br, $\left.1 \mathrm{H}, \mathrm{Ar}-\mathrm{H}\right), 7.06-6.75$ (br, 3H, Ar-H), 6.58-6.40 (br, 1H, Ar-H), 6.10-5.90 (br, 1H, C=CH), 4.95-4.60 (br, 4H, 2OCH $\mathrm{O}_{2} \mathrm{O}$ ), 4.35-4.10 (br, $1.95 \mathrm{H}, \mathrm{COCH}_{2}$ ), 4.01-3.92 (m, 0.05H, $\mathrm{COCH}_{2}$ ), 3.18-2.88 (br, $6 \mathrm{H}, 2 \mathrm{OCH}_{3}$ ), 1.90-1.82 (br, 0.05H, $\mathrm{CHCH}_{3}$ ), 1.80-1.62 (br, 1.9H, $\mathrm{CH}_{2}$ ), 1.45-1.10 (br, 18H, $\left.\mathrm{CH}_{2}\right), 0.97-0.93$ (br, 0.15H, CHCH3), 0.930.81 (br, $3 \mathrm{H}, \mathrm{CH}_{3}$ ). Anal. Calcd for $0.95 \mathrm{C}_{31} \mathrm{H}_{42} \mathrm{O}_{6} \cdot 0.05 \mathrm{C}_{32} \mathrm{H}_{44} \mathrm{O}_{6}$ : C, 72.93; H, 8.30. Found: C, 72.92; H, 8.36.

Spectroscopic data of poly-(1 $\left.\mathbf{b}_{0.9}-c o-2 \boldsymbol{R}_{0.1}\right): \operatorname{IR}\left(\mathrm{KBr}, \mathrm{cm}^{-1}\right): 1718\left(v_{\mathrm{C}=0}\right) .{ }^{1} \mathrm{H}$ NMR $(500 \mathrm{MHz}$, $\mathrm{CDCl}_{3}, 50{ }^{\circ} \mathrm{C}$ ): $\delta 7.80-7.68$ (br, $\left.1 \mathrm{H}, \mathrm{Ar}-\mathrm{H}\right), 7.60-7.46$ (br, $\left.1 \mathrm{H}, \mathrm{Ar}-\mathrm{H}\right), 7.06-6.75$ (br, 3H, Ar-H), 6.58-6.40 (br, 1H, Ar-H), 6.10-5.90 (br, 1H, C=CH), 4.96-4.58 (br, 4H, 2OCH $\mathrm{O}_{2} \mathrm{O}$ ), 4.35-4.12 (br, $\left.1.90 \mathrm{H}, \mathrm{COCH}_{2}\right), 4.02-3.92\left(\mathrm{~m}, 0.1 \mathrm{H}, \mathrm{COCH}_{2}\right), 3.18-2.88\left(\mathrm{br}, 6 \mathrm{H}, 2 \mathrm{OCH}_{3}\right), 1.90-1.82(\mathrm{br}, 0.1 \mathrm{H}$, $\mathrm{CHCH}_{3}$ ), 1.80-1.62 (br, 1.8H, $\mathrm{CH}_{2}$ ), 1.45-1.14 (br, 18H, $\mathrm{CH}_{2}$ ), 0.98-0.93 (br, 0.3H, $\mathrm{CHCH}_{3}$ ), 0.920.83 (br, $3 \mathrm{H}, \mathrm{CH}_{3}$ ). Anal. Calcd for $0.90 \mathrm{C}_{31} \mathrm{H}_{42} \mathrm{O}_{6} \cdot 0.10 \mathrm{C}_{32} \mathrm{H}_{44} \mathrm{O}_{6}$ : C, 72.94; H, 8.31. Found: C, 72.96; H, 8.21.

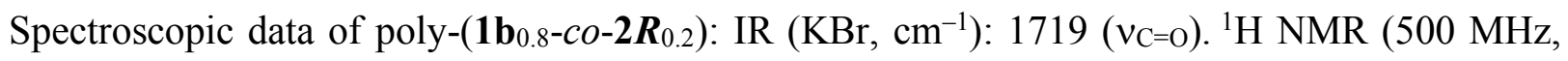
$\mathrm{CDCl}_{3}, 50{ }^{\circ} \mathrm{C}$ ): $\delta 7.80-7.68$ (br, $\left.1 \mathrm{H}, \mathrm{Ar}-\mathrm{H}\right), 7.60-7.46(\mathrm{br}, 1 \mathrm{H}, \mathrm{Ar}-\mathrm{H}), 7.06-6.75$ (br, 3H, Ar-H), 6.58-6.40 (br, 1H, Ar-H), 6.10-5.90 (br, 1H, C=CH), 4.95-4.60 (br, 4H, 2OCH $2 \mathrm{O}), 4.35-4.10$ (br, $\left.1.8 \mathrm{H}, \mathrm{COCH}_{2}\right), 4.02-3.92\left(\mathrm{~m}, 0.2 \mathrm{H}, \mathrm{COCH}_{2}\right), 3.18-2.88\left(\mathrm{br}, 6 \mathrm{H}, 2 \mathrm{OCH}_{3}\right), 1.90-1.82(\mathrm{br}, 0.2 \mathrm{H}$, $\mathrm{CHCH}_{3}$ ), 1.80-1.62 (br, 1.6H, $\mathrm{CH}_{2}$ ), 1.45-1.10 (br, 18H, $\mathrm{CH}_{2}$ ), 0.98-0.92 (br, 0.6H, CHCH $), 0.93-$ 0.80 (br, $3 \mathrm{H}, \mathrm{CH}_{3}$ ). Anal. Calcd for $0.80 \mathrm{C}_{31} \mathrm{H}_{42} \mathrm{O}_{6} \cdot 0.20 \mathrm{C}_{32} \mathrm{H}_{44} \mathrm{O}_{6}$ : C, 72.98; H, 8.32. Found: C, 72.97; $\mathrm{H}, 8.28$.

Spectroscopic data of poly-(1 $\left.\mathbf{b}_{0.7}-c o-2 \boldsymbol{R}_{0.3}\right):$ IR $\left(\mathrm{KBr}, \mathrm{cm}^{-1}\right): 1719\left(v_{\mathrm{C}=0}\right) .{ }^{1} \mathrm{H}$ NMR $(500 \mathrm{MHz}$, $\mathrm{CDCl}_{3}, 50{ }^{\circ} \mathrm{C}$ ): $\delta 7.80-7.68$ (br, $\left.1 \mathrm{H}, \mathrm{Ar}-\mathrm{H}\right), 7.60-7.45$ (br, $\left.1 \mathrm{H}, \mathrm{Ar}-\mathrm{H}\right), 7.05-6.75$ (br, 3H, Ar-H), 6.58-6.40 (br, 1H, Ar-H), 6.10-5.90 (br, 1H, C=CH), 4.95-4.60 (br, 4H, 2OCH $\mathrm{OC}_{2} \mathrm{O}, 4.37-4.10$ (br, $1.7 \mathrm{H}, \mathrm{OCH}_{2} \mathrm{CH}_{2}, \mathrm{COCH}_{2}$ ), 4.02-3.91 (m, 0.3H, $\mathrm{COCH}_{2}$ ), 3.18-2.86 (br, 6H, 20CH $), 1.92-1.82$ (br, 0.3H, $\mathrm{CHCH}_{3}$ ), 1.80-1.63 (br, 1.4H, $\mathrm{CH}_{2}$ ), 1.45-1.10 (br, 18H, $\mathrm{CH}_{2}$ ), 0.97-0.92 (br, 0.9H, $\mathrm{CHCH}_{3}$ ), 0.93-0.81 (br, 3H, $\mathrm{CH}_{3}$ ). Anal. Calcd for $0.71 \mathrm{C}_{31} \mathrm{H}_{42} \mathrm{O}_{6} \cdot 0.29 \mathrm{C}_{32} \mathrm{H}_{44} \mathrm{O}_{6}: \mathrm{C}, 73.01 ; \mathrm{H}, 8.34$. Found: C, $72.98 ; \mathrm{H}, 8.30$.

Spectroscopic data of poly-(1 $\left.\mathbf{b}_{0.5}-c o-2 \boldsymbol{R}_{0.5}\right)$ : IR $\left(\mathrm{KBr}, \mathrm{cm}^{-1}\right): 1719\left(v_{\mathrm{C}=0}\right) .{ }^{1} \mathrm{H}$ NMR $(500 \mathrm{MHz}$, $\mathrm{CDCl}_{3}, 50{ }^{\circ} \mathrm{C}$ ): $\delta 7.80-7.68$ (br, $\left.1 \mathrm{H}, \mathrm{Ar}-\mathrm{H}\right), 7.60-7.46$ (br, $\left.1 \mathrm{H}, \mathrm{Ar}-\mathrm{H}\right), 7.06-6.75$ (br, 3H, Ar-H), 6.58-6.40 (br, 1H, Ar-H), 6.10-5.90 (br, 1H, C=CH), 4.95-4.60 (br, 4H, 2OCH $2 \mathrm{O}$ ), 4.36-4.08 (br, $\left.1.5 \mathrm{H}, \mathrm{COCH}_{2}\right), 4.01-3.92\left(\mathrm{~m}, 0.5 \mathrm{H}, \mathrm{COCH}_{2}\right), 3.18-2.88$ (br, 6H, 2OCH 3$), 1.90-1.82(\mathrm{br}, 0.5 \mathrm{H}$, $\mathrm{CHCH}_{3}$ ), 1.80-1.62 (br, 1H, $\mathrm{CH}_{2}$ ), 1.45-1.10 (br, $18 \mathrm{H}, \mathrm{CH}_{2}$ ), 0.97-0.93 (br, 1.5H, CHCH3), 0.93- 
0.8 (br, $3 \mathrm{H}, \mathrm{CH}_{3}$ ). Anal. Calcd for $0.50 \mathrm{C}_{31} \mathrm{H}_{42} \mathrm{O}_{6} \cdot 0.50 \mathrm{C}_{32} \mathrm{H}_{44} \mathrm{O}_{6}$ : C, 73.08; H, 8.37. Found: C, 73.07; H, 8.28.

Spectroscopic data of poly-(1 $\left.\mathbf{b}_{0.3}-c o-2 \boldsymbol{R}_{0.7}\right): \operatorname{IR}\left(\mathrm{KBr}, \mathrm{cm}^{-1}\right): 1719\left(\mathrm{v}_{\mathrm{C}=\mathrm{O}}\right) .{ }^{1} \mathrm{H}$ NMR $(500 \mathrm{MHz}$, $\mathrm{CDCl}_{3}, 50{ }^{\circ} \mathrm{C}$ ): $\delta 7.80-7.68$ (br, $\left.1 \mathrm{H}, \mathrm{Ar}-\mathrm{H}\right), 7.60-7.46$ (br, $\left.1 \mathrm{H}, \mathrm{Ar}-\mathrm{H}\right), 7.06-6.75$ (br, 3H, Ar-H), 6.58-6.40 (br, 1H, Ar-H), 6.10-5.90 (br, 1H, C=CH), 4.94-4.60 (br, 4H, 2OCH $\mathrm{O}_{2} \mathrm{O}$ ), 4.35-4.10 (br, 1.3H, $\left.\mathrm{COCH}_{2}\right), 4.01-3.92\left(\mathrm{~m}, 0.7 \mathrm{H}, \mathrm{COCH}_{2}\right), 3.18-2.88\left(\mathrm{br}, 6 \mathrm{H}, 2 \mathrm{OCH}_{3}\right), 1.90-1.82(\mathrm{br}, 0.7 \mathrm{H}$, $\left.\mathrm{CHCH}_{3}\right), 1.80-1.62\left(\mathrm{br}, 0.6 \mathrm{H}, \mathrm{CH}_{2}\right), 1.45-1.10$ (br, $\left.18 \mathrm{H}, \mathrm{CH}_{2}\right), 0.97-0.93$ (br, 2.1H, $\left.\mathrm{CHCH}_{3}\right), 0.93-$ 0.80 (br, $3 \mathrm{H}, \mathrm{CH}_{3}$ ). Anal. Calcd for $0.29 \mathrm{C}_{31} \mathrm{H}_{42} \mathrm{O}_{6} \cdot 0.71 \mathrm{C}_{32} \mathrm{H}_{44} \mathrm{O}_{6}$ : C, 73.15; H, 8.40. Found: C, 73.14; H, 8.39.

Spectroscopic data of poly-(2 $\left.\boldsymbol{R}_{0.05}-\mathrm{co}-\mathbf{2 S}_{0.95}\right)$ : IR $\left(\mathrm{KBr}, \mathrm{cm}^{-1}\right): 1719\left(\mathrm{v}_{\mathrm{C}=0}\right) .{ }^{1} \mathrm{H}$ NMR $(500 \mathrm{MHz}$, $\mathrm{CDCl}_{3}, 50{ }^{\circ} \mathrm{C}$ ): $\delta 7.80-7.70$ (br, $\left.1 \mathrm{H}, \mathrm{Ar}-\mathrm{H}\right), 7.58-7.48$ (br, $\left.1 \mathrm{H}, \mathrm{Ar}-\mathrm{H}\right), 7.02-6.78$ (br, 3H, Ar-H), 6.58-6.42 (br, 1H, Ar-H), 6.07-5.92 (br, 1H, C=CH), 4.95-4.58 (br, 4H, 2OCH $\left.\mathrm{O}_{2} \mathrm{O}\right), 4.25-4.10$ (m, $1 \mathrm{H}, \mathrm{COCH}_{2}$ ), 4.05-3.90 (m, 1H, $\left.\mathrm{COCH}_{2}\right), 3.15-2.90$ (br, 6H, 2OCH $), 1.92-1.80\left(\mathrm{br}, 1 \mathrm{H}, \mathrm{CHCH}_{3}\right.$ ), 1.42-1.15 (br, $18 \mathrm{H}, \mathrm{CH}_{2}$ ), 0.98-0.91 (br, 3H, $\mathrm{CHCH}_{3}$ ), 0.90-0.82 (br, 3H, $\mathrm{CH}_{3}$ ). Anal. Calcd for $\mathrm{C}_{32} \mathrm{H}_{44} \mathrm{O}_{6}$ : C, 72.25; H, 8.45. Found: C, 72.23; H, 8.44.

Spectroscopic data of poly-(2 $\left.\boldsymbol{R}_{0.1}-c o-2 S_{0.9}\right)$ : IR $\left(\mathrm{KBr}, \mathrm{cm}^{-1}\right): 1719\left(v_{\mathrm{C}=0}\right) .{ }^{1} \mathrm{H}$ NMR $(500 \mathrm{MHz}$, $\mathrm{CDCl}_{3}, 50{ }^{\circ} \mathrm{C}$ ): $\delta 7.80-7.70$ (br, $\left.1 \mathrm{H}, \mathrm{Ar}-\mathrm{H}\right), 7.58-7.48$ (br, $\left.1 \mathrm{H}, \mathrm{Ar}-\mathrm{H}\right), 7.02-6.78$ (br, 3H, Ar-H), 6.58-6.42 (br, 1H, Ar-H), 6.07-5.92 (br, 1H, C=CH), 4.95-4.58 (br, 4H, 2OCH $\left.\mathrm{O}_{2} \mathrm{O}\right), 4.25-4.10$ (m, $\left.1 \mathrm{H}, \mathrm{COCH}_{2}\right), 4.05-3.90\left(\mathrm{~m}, 1 \mathrm{H}, \mathrm{COCH}_{2}\right), 3.15-2.90$ (br, $\left.6 \mathrm{H}, 2 \mathrm{OCH}_{3}\right), 1.92-1.80\left(\mathrm{br}, 1 \mathrm{H}, \mathrm{CHCH}_{3}\right)$, 1.42-1.15 (br, $18 \mathrm{H}, \mathrm{CH}_{2}$ ), 0.98-0.91 (br, 3H, $\mathrm{CHCH}_{3}$ ), 0.90-0.82 (br, 3H, $\mathrm{CH}_{3}$ ). Anal. Calcd for $\mathrm{C}_{32} \mathrm{H}_{44} \mathrm{O}_{6}$ : C, 72.25; H, 8.45. Found: C, 72.27; H, 8.51.

Spectroscopic data of poly-(2 $\left.\boldsymbol{R}_{0.2}-c o-2 S_{0.8}\right): \operatorname{IR}\left(\mathrm{KBr}, \mathrm{cm}^{-1}\right): 1719\left(\mathrm{v}_{\mathrm{C}=\mathrm{O}}\right) .{ }^{1} \mathrm{H}$ NMR $(500 \mathrm{MHz}$, $\mathrm{CDCl}_{3}, 50{ }^{\circ} \mathrm{C}$ ): $\delta 7.80-7.70$ (br, $\left.1 \mathrm{H}, \mathrm{Ar}-\mathrm{H}\right), 7.58-7.48$ (br, $\left.1 \mathrm{H}, \mathrm{Ar}-\mathrm{H}\right), 7.02-6.78$ (br, 3H, Ar-H), 6.58-6.42 (br, 1H, Ar-H), 6.07-5.92 (br, 1H, C=CH), 4.95-4.58 (br, 4H, 2OCH $\mathrm{O}_{2} \mathrm{O}$ ), 4.25-4.10 (m, $\left.1 \mathrm{H}, \mathrm{COCH}_{2}\right), 4.05-3.90\left(\mathrm{~m}, 1 \mathrm{H}, \mathrm{COCH}_{2}\right), 3.15-2.90$ (br, $\left.6 \mathrm{H}, 2 \mathrm{OCH}_{3}\right), 1.92-1.80\left(\mathrm{br}, 1 \mathrm{H}, \mathrm{CHCH}_{3}\right.$ ), 1.42-1.15 (br, $18 \mathrm{H}, \mathrm{CH}_{2}$ ), 0.98-0.91 (br, 3H, $\mathrm{CHCH}_{3}$ ), 0.90-0.82 (br, 3H, $\mathrm{CH}_{3}$ ). Anal. Calcd for $\mathrm{C}_{32} \mathrm{H}_{44} \mathrm{O}_{6}$ : C, 72.25; H, 8.45. Found: C, 72.20; H, 8.43.

Spectroscopic data of poly-(2 $\left.\boldsymbol{R}_{0.3}-c o-2 S_{0.7}\right)$ : IR $\left(\mathrm{KBr}, \mathrm{cm}^{-1}\right): 1719\left(v_{\mathrm{C}=0}\right) .{ }^{1} \mathrm{H}$ NMR $(500 \mathrm{MHz}$, $\mathrm{CDCl}_{3}, 50{ }^{\circ} \mathrm{C}$ ): $\delta 7.80-7.70$ (br, $\left.1 \mathrm{H}, \mathrm{Ar}-\mathrm{H}\right), 7.58-7.48$ (br, $\left.1 \mathrm{H}, \mathrm{Ar}-\mathrm{H}\right), 7.02-6.78$ (br, 3H, Ar-H), 6.58-6.42 (br, 1H, Ar-H), 6.07-5.92 (br, 1H, C=CH), 4.95-4.58 (br, 4H, 2OCH $\left.\mathrm{O}_{2} \mathrm{O}\right), 4.25-4.10(\mathrm{~m}$, $1 \mathrm{H}, \mathrm{COCH}_{2}$ ), 4.05-3.90 (m, 1H, $\left.\mathrm{COCH}_{2}\right), 3.15-2.90$ (br, 6H, 2OCH $), 1.92-1.80\left(\mathrm{br}, 1 \mathrm{H}, \mathrm{CHCH}_{3}\right.$ ), 1.42-1.15 (br, $18 \mathrm{H}, \mathrm{CH}_{2}$ ), 0.98-0.91 (br, 3H, $\mathrm{CHCH}_{3}$ ), 0.90-0.82 (br, 3H, $\mathrm{CH}_{3}$ ). Anal. Calcd for $\mathrm{C}_{32} \mathrm{H}_{44} \mathrm{O}_{6}$ : C, 72.25; H, 8.45. Found: C, 72.26; H, 8.41. 


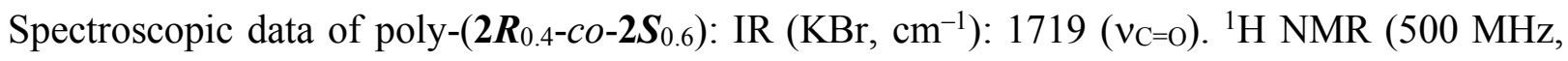
$\mathrm{CDCl}_{3}, 50{ }^{\circ} \mathrm{C}$ ): $\delta 7.80-7.70$ (br, $\left.1 \mathrm{H}, \mathrm{Ar}-\mathrm{H}\right), 7.58-7.48$ (br, $\left.1 \mathrm{H}, \mathrm{Ar}-\mathrm{H}\right), 7.02-6.78$ (br, 3H, Ar-H), 6.58-6.42 (br, 1H, Ar-H), 6.07-5.92 (br, 1H, C=CH), 4.95-4.58 (br, 4H, 2OCH $\left.{ }_{2} \mathrm{O}\right), 4.25-4.10$ (m, $\left.1 \mathrm{H}, \mathrm{COCH}_{2}\right), 4.05-3.90\left(\mathrm{~m}, 1 \mathrm{H}, \mathrm{COCH}_{2}\right), 3.15-2.90\left(\mathrm{br}, 6 \mathrm{H}, 2 \mathrm{OCH}_{3}\right), 1.92-1.80\left(\mathrm{br}, 1 \mathrm{H}, \mathrm{CHCH}_{3}\right)$, 1.42-1.15 (br, $18 \mathrm{H}, \mathrm{CH}_{2}$ ), 0.98-0.91 (br, 3H, $\mathrm{CHCH}_{3}$ ), 0.90-0.82 (br, 3H, $\mathrm{CH}_{3}$ ). Anal. Calcd for $\mathrm{C}_{32} \mathrm{H}_{44} \mathrm{O}_{6}$ : C, 72.25; H, 8.45. Found: C, 72.26; H, 8.26.

Spectroscopic data of poly-(2 $\left.\boldsymbol{R}_{0.45}-c o-2 S_{0.55}\right)$ : IR $\left(\mathrm{KBr}, \mathrm{cm}^{-1}\right): 1719\left(v_{\mathrm{C}=0}\right) .{ }^{1} \mathrm{H}$ NMR $(500 \mathrm{MHz}$, $\mathrm{CDCl}_{3}, 50{ }^{\circ} \mathrm{C}$ ): $\delta 7.80-7.70(\mathrm{br}, 1 \mathrm{H}, \mathrm{Ar}-\mathrm{H}), 7.58-7.48$ (br, $\left.1 \mathrm{H}, \mathrm{Ar}-\mathrm{H}\right), 7.02-6.78$ (br, 3H, Ar-H), 6.58-6.42 (br, 1H, Ar-H), 6.07-5.92 (br, 1H, C=CH), 4.95-4.58 (br, 4H, 2OCH $\left.\mathrm{O}_{2} \mathrm{O}\right), 4.25-4.10$ (m, $\left.1 \mathrm{H}, \mathrm{COCH}_{2}\right), 4.05-3.90\left(\mathrm{~m}, 1 \mathrm{H}, \mathrm{COCH}_{2}\right), 3.15-2.90\left(\mathrm{br}, 6 \mathrm{H}, 2 \mathrm{OCH}_{3}\right), 1.92-1.80\left(\mathrm{br}, 1 \mathrm{H}, \mathrm{CHCH}_{3}\right)$, 1.42-1.15 (br, $18 \mathrm{H}, \mathrm{CH}_{2}$ ), 0.98-0.91 (br, 3H, $\mathrm{CHCH}_{3}$ ), 0.90-0.82 (br, 3H, $\mathrm{CH}_{3}$ ). Anal. Calcd for $\mathrm{C}_{32} \mathrm{H}_{44} \mathrm{O}_{6}$ : C, 72.25; H, 8.45. Found: C, 72.26; H, 8.43.

Spectroscopic data of poly-(2 $\left.\boldsymbol{R}_{0.475}-\mathrm{co}-\mathbf{2} \boldsymbol{S}_{0.525}\right)$ : IR $\left(\mathrm{KBr}, \mathrm{cm}^{-1}\right): 1719\left(\mathrm{v}_{\mathrm{C}=\mathrm{O}}\right) .{ }^{1} \mathrm{H} \mathrm{NMR}(500 \mathrm{MHz}$, $\mathrm{CDCl}_{3}, 50{ }^{\circ} \mathrm{C}$ ): $\delta 7.80-7.70$ (br, $\left.1 \mathrm{H}, \mathrm{Ar}-\mathrm{H}\right), 7.58-7.48$ (br, $\left.1 \mathrm{H}, \mathrm{Ar}-\mathrm{H}\right), 7.02-6.78$ (br, 3H, Ar-H), 6.58-6.42 (br, 1H, Ar-H), 6.07-5.92 (br, 1H, C=CH), 4.95-4.58 (br, 4H, 2OCH $\left.\mathrm{O}_{2} \mathrm{O}\right), 4.25-4.10$ (m, $\left.1 \mathrm{H}, \mathrm{COCH}_{2}\right), 4.05-3.90\left(\mathrm{~m}, 1 \mathrm{H}, \mathrm{COCH}_{2}\right), 3.15-2.90\left(\mathrm{br}, 6 \mathrm{H}, 2 \mathrm{OCH}_{3}\right), 1.92-1.80$ (br, $\left.1 \mathrm{H}, \mathrm{CHCH}_{3}\right)$, 1.42-1.15 (br, $18 \mathrm{H}, \mathrm{CH}_{2}$ ), 0.98-0.91 (br, 3H, $\mathrm{CHCH}_{3}$ ), 0.90-0.82 (br, 3H, $\mathrm{CH}_{3}$ ). Anal. Calcd for $\mathrm{C}_{32} \mathrm{H}_{44} \mathrm{O}_{6}$ : C, 72.25; H, 8.45. Found: C, 72.23; H, 8.30.

Spectroscopic data of poly-(2 $\left.\boldsymbol{R}_{0.5}-c o-2 S_{0.5}\right): \operatorname{IR}\left(\mathrm{KBr}, \mathrm{cm}^{-1}\right): 1718\left(v_{\mathrm{C}=0}\right) .{ }^{1} \mathrm{H}$ NMR $(500 \mathrm{MHz}$, $\mathrm{CDCl}_{3}, 50{ }^{\circ} \mathrm{C}$ ): $\delta 7.80-7.70$ (br, $\left.1 \mathrm{H}, \mathrm{Ar}-\mathrm{H}\right), 7.58-7.48$ (br, $\left.1 \mathrm{H}, \mathrm{Ar}-\mathrm{H}\right), 7.02-6.78$ (br, 3H, Ar-H), 6.58-6.42 (br, 1H, Ar-H), 6.07-5.92 (br, 1H, C=CH), 4.95-4.58 (br, 4H, 2OCH $\left.\mathrm{O}_{2} \mathrm{O}\right), 4.25-4.10$ (m, $\left.1 \mathrm{H}, \mathrm{COCH}_{2}\right), 4.05-3.90\left(\mathrm{~m}, 1 \mathrm{H}, \mathrm{COCH}_{2}\right), 3.15-2.90$ (br, $\left.6 \mathrm{H}, 2 \mathrm{OCH}_{3}\right), 1.92-1.80$ (br, $1 \mathrm{H}, \mathrm{CHCH}_{3}$ ), 1.42-1.15 (br, $18 \mathrm{H}, \mathrm{CH}_{2}$ ), 0.98-0.91 (br, 3H, $\mathrm{CHCH}_{3}$ ), 0.90-0.82 (br, 3H, $\mathrm{CH}_{3}$ ). Anal. Calcd for $\mathrm{C}_{32} \mathrm{H}_{44} \mathrm{O}_{6}$ : C, 72.25; H, 8.45. Found: C, 72.24; H, 8.43.

Spectroscopic data of poly-(2 $\left.\boldsymbol{R}_{0.7}-c o-2 S_{0.3}\right): \operatorname{IR~}\left(\mathrm{KBr}, \mathrm{cm}^{-1}\right): 1718\left(v_{\mathrm{C}=0}\right) .{ }^{1} \mathrm{H}$ NMR $(500 \mathrm{MHz}$, $\mathrm{CDCl}_{3}, 50{ }^{\circ} \mathrm{C}$ ): $\delta 7.80-7.70$ (br, $\left.1 \mathrm{H}, \mathrm{Ar}-\mathrm{H}\right), 7.58-7.48$ (br, $\left.1 \mathrm{H}, \mathrm{Ar}-\mathrm{H}\right), 7.02-6.78$ (br, 3H, Ar-H), 6.58-6.42 (br, 1H, Ar-H), 6.07-5.92 (br, 1H, C=CH), 4.95-4.58 (br, 4H, 2OCH $2 \mathrm{O}), 4.25-4.10(\mathrm{~m}$, $1 \mathrm{H}, \mathrm{COCH}_{2}$ ), 4.05-3.90 (m, 1H, $\left.\mathrm{COCH}_{2}\right), 3.15-2.90$ (br, 6H, 2OCH $), 1.92-1.80$ (br, 1H, $\mathrm{CHCH}_{3}$ ), 1.42-1.15 (br, $18 \mathrm{H}, \mathrm{CH}_{2}$ ), 0.98-0.91 (br, 3H, $\mathrm{CHCH}_{3}$ ), 0.90-0.82 (br, 3H, $\mathrm{CH}_{3}$ ). Anal. Calcd for $\mathrm{C}_{32} \mathrm{H}_{44} \mathrm{O}_{6}$ : C, 72.25; H, 8.45. Found: C, 72.27; H, 8.41. 
The copolymer compositions of poly-( $\left.\mathbf{1 b}_{1-\mathrm{r}}-\mathrm{co}-\mathbf{2} \boldsymbol{R}_{\mathrm{r}}\right) \mathrm{s}$ were estimated by their ${ }^{1} \mathrm{H}$ NMR spectra (see Section 9). The stereoregularities of the newly synthesized poly-2R, poly-2S, poly-3R, poly-

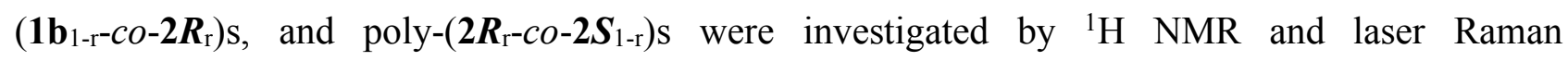
spectroscopies. The ${ }^{1} \mathrm{H}$ NMR spectra of these polymers at $50{ }^{\circ} \mathrm{C}$ showed a sharp singlet centered around $6 \mathrm{ppm}$ due to the main chain protons, indicating that the newly synthesized homopolymers and copolymers possess a highly cis-transoidal stereoregular structure (see Section 9). ${ }^{5}$ Figure S1 shows the typical Raman spectra of the homopolymers and copolymers, showing intense peaks at around 1576-1577 and $1340 \mathrm{~cm}^{-1}$ (A, C, and D), and 1541 and $1339 \mathrm{~cm}^{-1}$ (B) which can be assigned to the $\mathrm{C}=\mathrm{C}$ and $\mathrm{C}-\mathrm{C}$ bond vibrations in the cis polyacetylenes, respectively, while those in the trans polyacetylene were not observed. ${ }^{6}$ Therefore, the obtained other polymers and copolymers also likely possess highly cis-transoidal structures.

(A) poly-2R

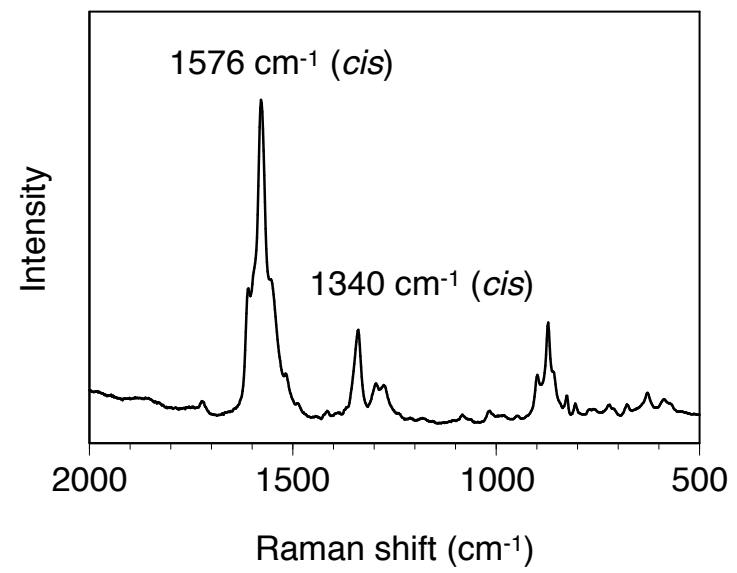

(C) poly-(1 $\left.\mathbf{b}_{0.5}-C o-\mathbf{2} \boldsymbol{R}_{0.5}\right)$

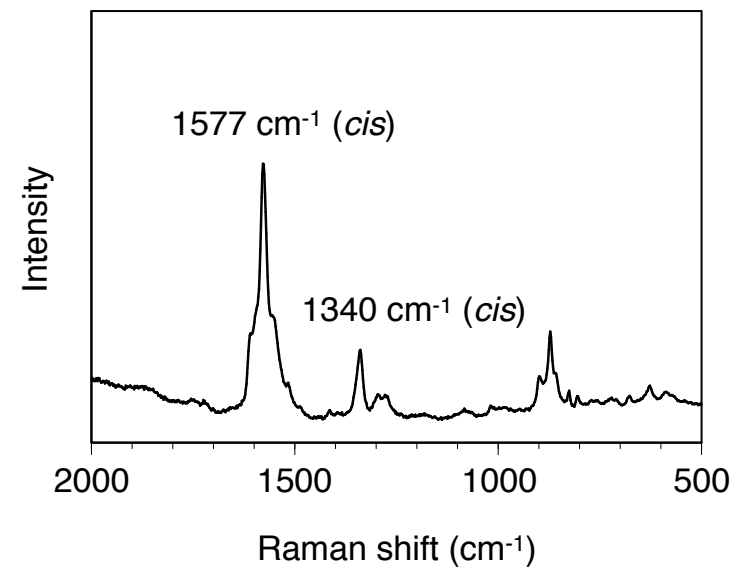

(B) poly-3R

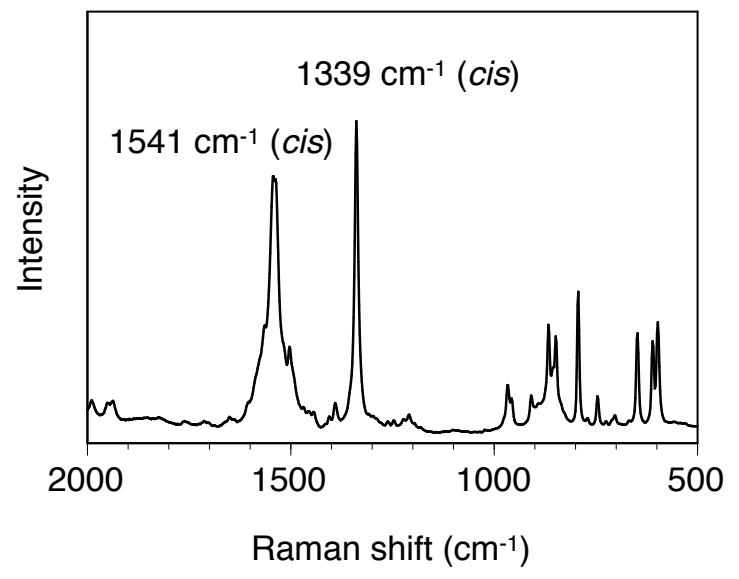

(D) poly-(2 $\left.\boldsymbol{R}_{0.5}-c o-\mathbf{2} \boldsymbol{S}_{0.5}\right)$

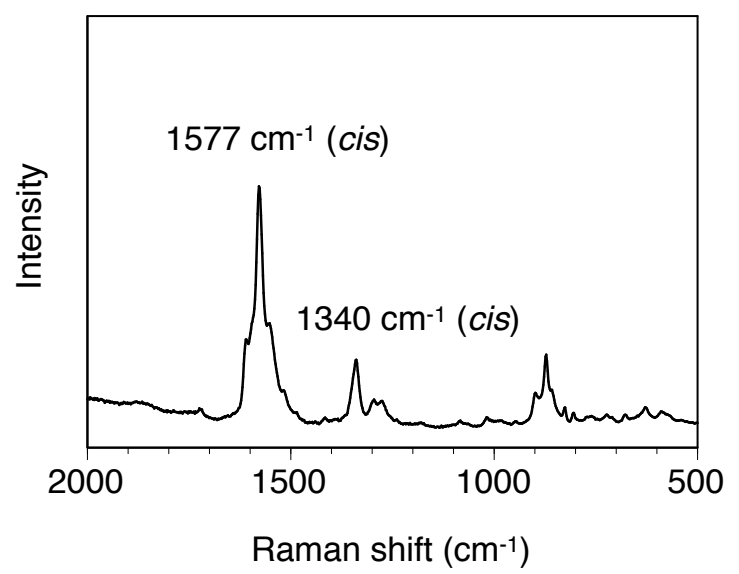

Figure S1. Laser Raman spectra of poly-2R (A), poly-3R (B), poly-(1 $\left.\mathbf{b}_{0.5-c o-2} \boldsymbol{R}_{0.5}\right)(\mathrm{C})$, and poly$\left(\mathbf{2} \boldsymbol{R}_{0.5}-\mathrm{co}-\mathbf{2} \boldsymbol{S}_{0.5}\right)(\mathrm{D})$ in the solid state at room temperature. 


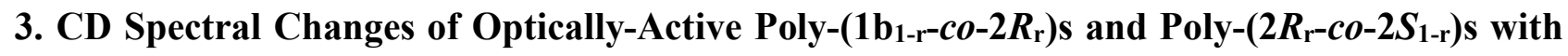
$(R)-$ or $(S)-4$ in Solution. The concentrations of poly- $\left(\mathbf{1 b}_{1-\mathrm{r}}-c o-2 R_{\mathrm{r}}\right) \mathrm{s}$ and poly- $\left(2 \boldsymbol{R}_{\mathrm{r}}-c o-2 S_{1-\mathrm{r}}\right) \mathrm{s}$ were calculated based on the monomer units and were $1.0 \mathrm{mM}$ unless otherwise stated. A typical experimental procedure was described below. Stock solution of a copolymer $(4.0 \mathrm{mM})$ in methylcyclohexane $(\mathrm{MCH})$ was prepared in a 2-mL flask equipped with a stopcock. A $250 \mu \mathrm{L}$ aliquot of the copolymer solution was transferred to a vessel equipped with a screwcap using a Hamilton microsyringe. An appropriate amount of $(R)$ - or $(S)-\mathbf{4}$ was added to the vessel and the solution was diluted with $\mathrm{MCH}$ to keep the copolymer concentration at $1.0 \mathrm{mM}$, then the solution was immediately mixed with a vibrator (IKA, Japan). After the solution was allowed to stand for appropriate time at $25{ }^{\circ} \mathrm{C}$, the absorption and $\mathrm{CD}$ spectra were recorded at 25 and $-10{ }^{\circ} \mathrm{C}$.

4. Helicity Induction in Optically-Inactive Poly-1b and Poly-(2R $\left.R_{0.5}-c o-2 S_{0.5}\right)$ with Nonracemic 4 in Solution. The nonlinear effects between the ICD intensities of poly-1b and poly- $\left(\mathbf{2} \boldsymbol{R}_{0.5}-\mathrm{co}-\mathbf{2} \boldsymbol{S}_{0.5}\right)$ against \%ee of 4 in solution were investigated in $\mathrm{MCH}$ at 25 and $-10{ }^{\circ} \mathrm{C}$. The polymer concentrations in $\mathrm{MCH} / 4(80 / 20, \mathrm{v} / \mathrm{v})$ were held constant at $1.0 \mathrm{mM}$. A typical experimental procedure was described below. Stock solutions of poly-1b $(2.0 \mathrm{mM})$ in $\mathrm{MCH}, \mathrm{MCH} /(R)-\mathbf{4}(30 / 20, \mathrm{v} / \mathrm{v})$, and MCH/(S)-4 (30/20, $\mathrm{v} / \mathrm{v})$ were prepared. Aliquots of the stock solutions of $(R)$ - and $(S)-\mathbf{4}$ were placed into six vessels so that the \%ee of the mixtures ( $R$ rich) became 10,20,40,60, 80, and 100, respectively. To the vessels was added a $500 \mu \mathrm{L}$ aliquot of the stock solution of the poly-1b, and the resulting solutions were immediately mixed using a vibrator. After the solutions were allowed to stand for appropriate time at $25{ }^{\circ} \mathrm{C}$, the absorption and $\mathrm{CD}$ spectra were then taken for each vessel at $25{ }^{\circ} \mathrm{C}$ to determine the changes in the $\mathrm{CD}$ intensity at $380 \mathrm{~nm}$ (second Cotton) (Figure 6). The same procedure was performed in the experiments with poly- $\left(\mathbf{2} \boldsymbol{R}_{0.5}-\mathrm{co}-\mathbf{2} \boldsymbol{S}_{0.5}\right)$.

5. Memory of the Macromolecular Helicity in Preferred-Handed Helical Poly-1b, Poly-(1b ${ }_{1-r^{-}}$ $\left.c o-2 R_{\mathrm{r}}\right)$ s, and Poly-(2R $\left.-c o-2 S_{1-\mathrm{r}}\right) \mathrm{s}$ in Solution. A typical experimental procedure was described

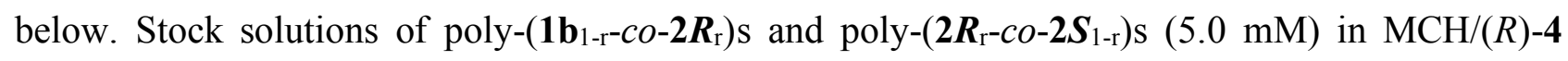
$(80 / 20, \mathrm{v} / \mathrm{v})$ were prepared. The solutions were allowed to stand for appropriate time at $25^{\circ} \mathrm{C}$. After the solutions were cooled to $-10^{\circ} \mathrm{C}$, the solutions were poured into a large amount of methanol at $10^{\circ} \mathrm{C}$ to remove $(R)-4$. The precipitated polymers were then collected by centrifugation, washed with methanol, and then dried in vacuo at room temperature overnight. Removal of $(R)-\mathbf{4}$ was confirmed by ${ }^{1} \mathrm{H}$ NMR measurements of the isolated polymers (Figure S24). After the isolated polymers were dissolved in $\mathrm{MCH}$ at $-10{ }^{\circ} \mathrm{C}$, the absorption and $\mathrm{CD}$ spectra were then recorded at $-10{ }^{\circ} \mathrm{C}$ (Figures 4 and S26). 


\section{Theoretical Model for Chiral Amplification Accompanied by CD Spectral Changes of Poly-} $\left(1 b_{1-\mathrm{r}}-c o-2 R_{\mathrm{r}}\right)$ s and Poly- $\left(2 R_{\mathrm{r}}-c o-2 S_{1-\mathrm{r}}\right) \mathrm{s}$ in the Absence and Presence of $(R)-$ and/or $(S)-4$ in

\section{Solution}

\section{6-1. General Description Model and Matrix-Transfer Approach}

The model we use to describe the helical polymers is based on the model by Green et al. ${ }^{7}$ and that of Lifson et al. ${ }^{8}$, i.e., a linear Ising model. This model consists of a polymer chain of $N$ monomers long, where the monomers can be of distinct type and each monomer is either in a left-handed or a right-handed helical conformation, resulting in alternating sequences of opposite helical sense with helix reversal points in between. The cost of a helix reversal is denoted by $\Delta G_{\mathrm{r}}$ and is typically much larger than the difference in free energy for a unit between the two helical senses. If we describe the free energy of a monomer of type $i$ in the left- and right-handed helical sense with $\Delta G_{i}^{\text {left }}$ and $\Delta G_{i}^{\text {right }}$, respectively, we can, following Green et al., ${ }^{7}$ express the partition function $Z_{N}$ of the polymer consisting of $N$ monomeric units of type $i(k)$ as

$$
Z_{N}=A \prod_{k=2}^{N} M_{i(k)} B
$$

where

$$
\begin{gathered}
M_{i(k)}=\left[\begin{array}{cc}
\exp \left(-\Delta G_{i(k)}^{\text {right }} / R T\right) & \exp \left(-\left(\Delta G_{i(k)}^{\text {left }}+\Delta G_{r}\right) / R T\right) \\
\exp \left(-\left(\Delta G_{i(k)}^{\text {right }}+\Delta G_{r}\right) / R T\right) & \exp \left(-\Delta G_{i(k)}^{\text {left }} / R T\right)
\end{array}\right], \\
A=\left[\exp \left(-\Delta G_{i(1)}^{\text {right }} / R T\right)\right. \\
\left.\exp \left(-\Delta G_{i(1)}^{\text {left }} / R T\right)\right]
\end{gathered}
$$

and

$$
B=\left[\begin{array}{l}
1 \\
1
\end{array}\right]
$$

From this partition function the average number $n_{\text {right }}$ of monomers in right-handed helices can then be derived as

$$
n_{\text {right }}=-\sum_{i} \frac{\partial\left(\ln \left(Z_{N}\right)\right)}{\partial\left(\Delta G_{i}^{r i g h t} / R T\right)}
$$

and the average number of helix reversals as

$$
n_{r e v}=-\sum_{i} \frac{\partial\left(\ln \left(Z_{N}\right)\right)}{\partial\left(\Delta G_{r, i} / R T\right)}
$$

Where in both sums $i$ runs over all different monomer types present in the polymer. 
We consider a polymer of length $N$ consisting of $N_{i}$ monomers of type $i$, where $\sum_{i} N_{i}=N$. We assume the monomers are distributed randomly on the chain, referred to as uniform random copolymer. From $n_{\text {right }}$ we calculate the net helicity as $\alpha=1-2 n_{\text {right }} / N$. For fully right-handed helices the value of $\alpha$ will thus be equal to -1 , for fully left-handed helices equal to +1 and for polymers with helix inversions a value in between. As this net helicity $\alpha$ is assumed to be proportional to the experimentally measured $\Delta \varepsilon_{2 \mathrm{nd}}$ (at $380 \mathrm{~nm}$ ), in the plots where we compare the model results with the data the experimental value of $\Delta \varepsilon_{2 n d}$ is divided by its maximal value, i.e., $20 \mathrm{M}^{-1} \mathrm{~cm}^{-1}$. In our analysis below, we calculate, for each composition of a polymer (i.e., for each combination of $N_{i}$ ), above properties for random polymers of length 5000 and average over 10 randomly generated polymers.

\section{6-2. Model for Sergeants and Soldiers and Majority Rule Effects}

To describe both the sergeants and soldiers effect and the majority rule effect, we consider the approach in section 6-1 with three different monomeric units, i.e., achiral $A$ and chiral $R$ and $S$ units. The first, i.e. achiral $A$, has no preference for either helical sense. Consequently, their free energies in the right-handed helices $\Delta G_{A}{ }^{\text {right }}$ and left-handed helices $\Delta G_{A}^{\text {left }}$ are equal, and can both be taken as 0 . The second, $R$, has a preference for the right-handed helices. Taking the preferred-handed helical state as the reference state, we describe this by $\Delta G_{R}{ }^{\text {right }}=0$ and assign a positive value $J$ to the free energy $\Delta G_{R}$ left for an $R$ in left-handed helices. The last monomer type, $S$, has a preference for the lefthanded helices. Taking again the preferred-handed state as the reference state, we describe this by $\Delta G_{S}^{\text {left }}=0$ and assign the same positive value $J$ to the free energy $\Delta G_{S}{ }^{\text {right }}$ for an $S$ in the right-handed helices. For the cost of a helix reversal $\left(\Delta G_{\mathrm{r}}\right)$ we introduce the helix reversal penalty parameter $F$. These free energies, that are thus described by only two parameters $J$ and $F$, are summarized in Figure S2.

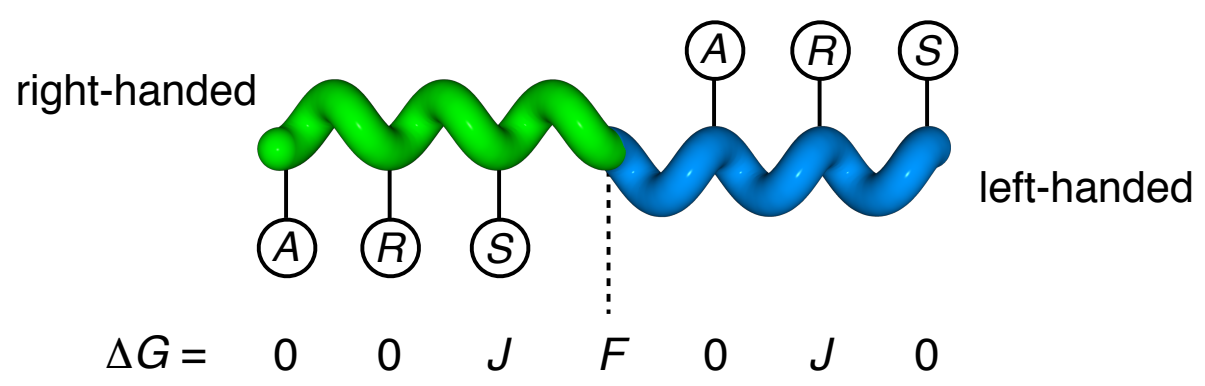

Figure S2. Schematic representation of the three monomer types in the sergeants and soldiers effect and the majority rule effect models and their free energies. For sergeants and soldiers achiral monomers $(A)$ and one of the chiral monomer types (either $R$ or $S$ ) are used. For majority rule only the two chiral monomer types $(R$ and $S)$ are used. 


\section{6-2A. Chiral Amplification of Poly-(1 $\left.b_{1-\mathrm{r}}-c o-2 R_{\mathrm{r}}\right) \mathrm{s}$ - Sergeants and Soldiers Effect}

To describe the sergeants and soldiers experiments, we consider only $R$ and $A$ monomers (with the free energies in right- and left-handed helices as depicted in Figure S2), where the fraction of $R$ monomers is denoted by $f_{R}$. This case exactly matches the model for 'type 1 polymers' in Green et al. ${ }^{7}$ We try to fit the two parameters $J$ and $F$ to the data of the chiral amplification (sergeants and soldiers) experiment. However, as both parameters are coupled (and the number of data points is limited), it is difficult to determine them with certainty. However, compared with the results by Green et al., ${ }^{7}$ we see that reasonable values for $F$ are $2.5-5.0 \mathrm{kcal} / \mathrm{mol}$, corresponding to $4.3-8.6 R T$. Figure $\mathrm{S} 3$ shows that for a smaller $F$, i.e., $F=3 R T$, the experimental data indeed cannot be fitted, even for high values of $J$. For $F=5 R T$ and $F=6 R T$, the curve can be fitted with $J=0.25 R T$ and $J=0.12 R T$, respectively.

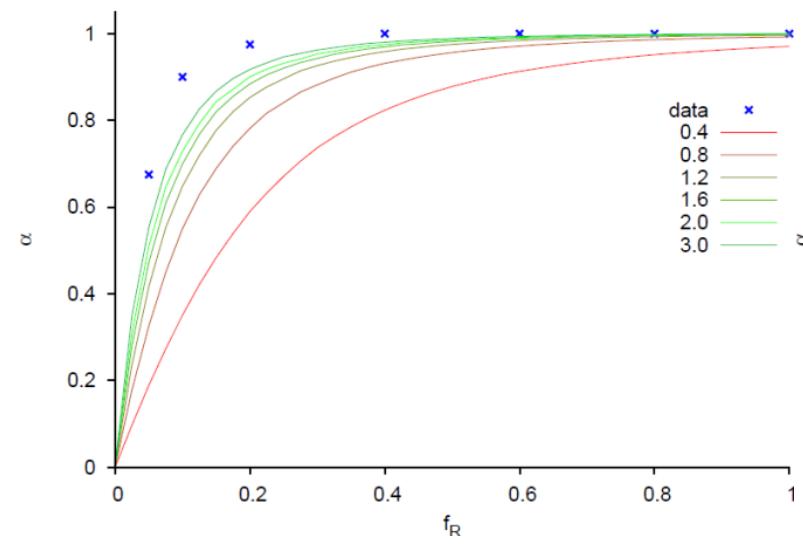

$F=3 R T$

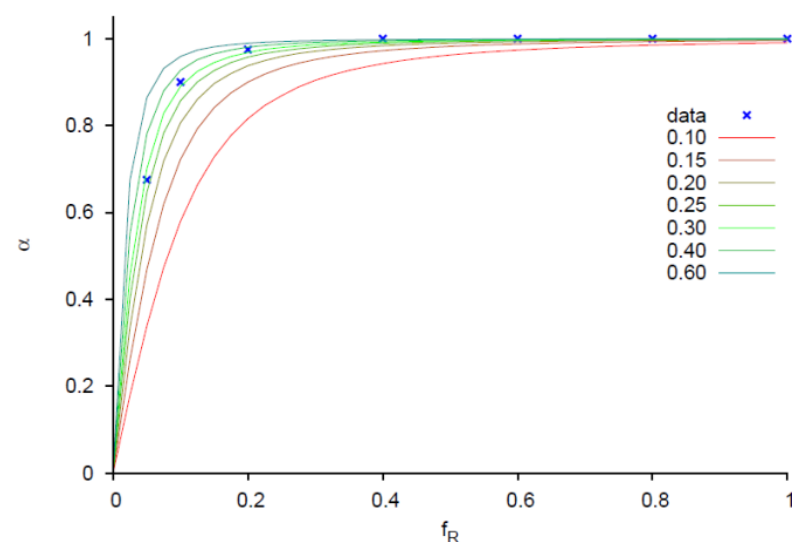

$F=5 R T$

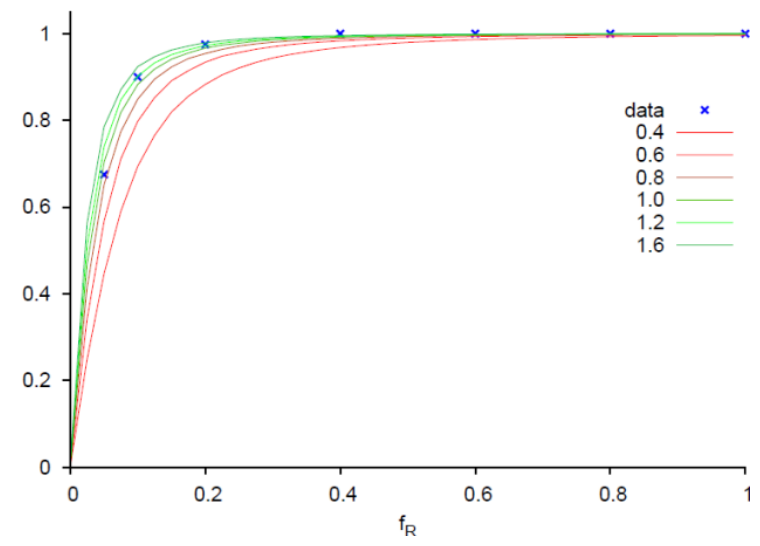

$F=4 R T$

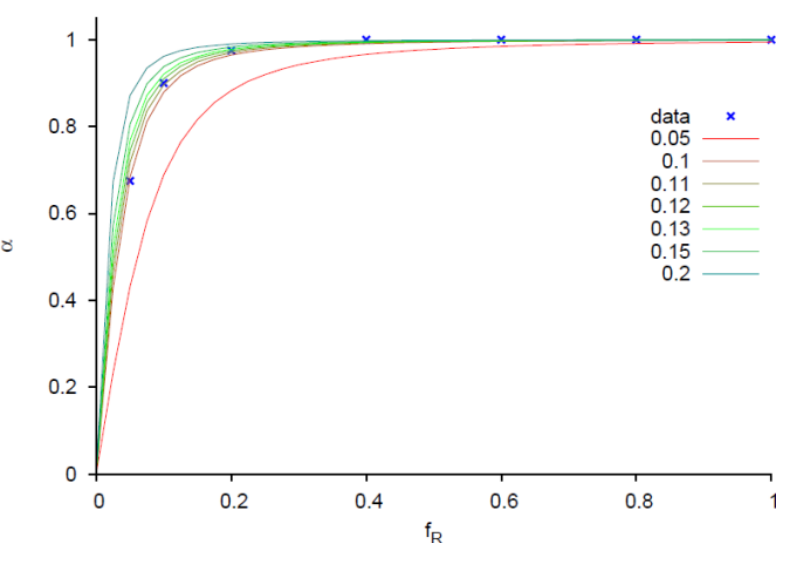

$F=6 R T$

Figure S3. Net helicity $(\alpha)$ as a function of the fraction sergeant $\left(f_{R}\right)$ for different combinations of the helix reversal penalty $F$ (different panels) and the mismatch penalty $J$ (legends, in units of $R T$ ) for a chiral unit in the unpreferred-handed helical conformation. 


\section{6-2B. Chiral Amplification of Poly-(2R $\left.R_{\mathrm{r}}-c o-2 S_{1-\mathrm{r}}\right) \mathrm{s}-$ Majority Rule}

To describe the majority rule experiments, we consider only $R$ and $S$ monomers (again with the free energies in right- and left-handed helices as depicted in Figure S2), where the fraction of $S$ monomers is denoted by $f_{S}$ and the $\left(S\right.$-rich) enantiomeric excess by ee $=\left(f_{S}-f_{R}\right) /\left(f_{S}+f_{R}\right)$. Figure S4 shows a comparison of the experimental data and the model results for $F=5 R T$ and for $F=6 R T$ for multiple values for the mismatch penalty $J$.

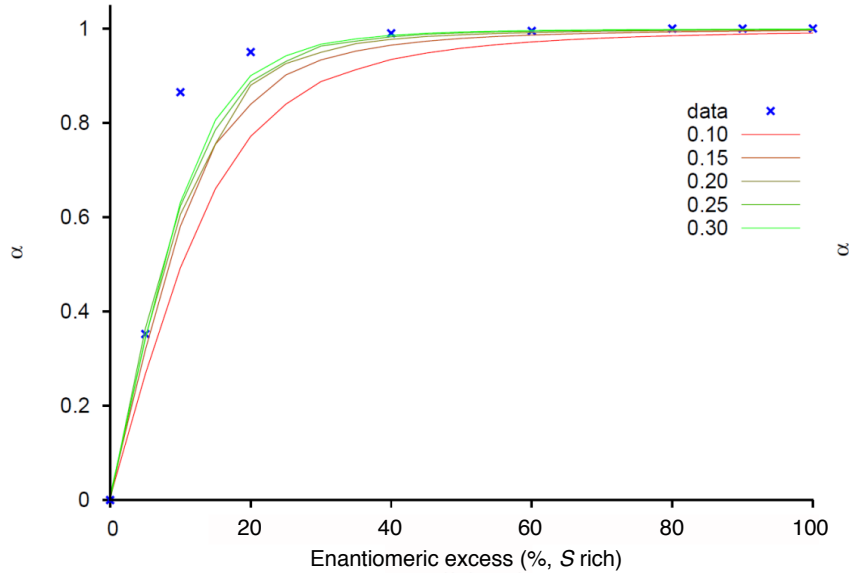

$F=5 R T$

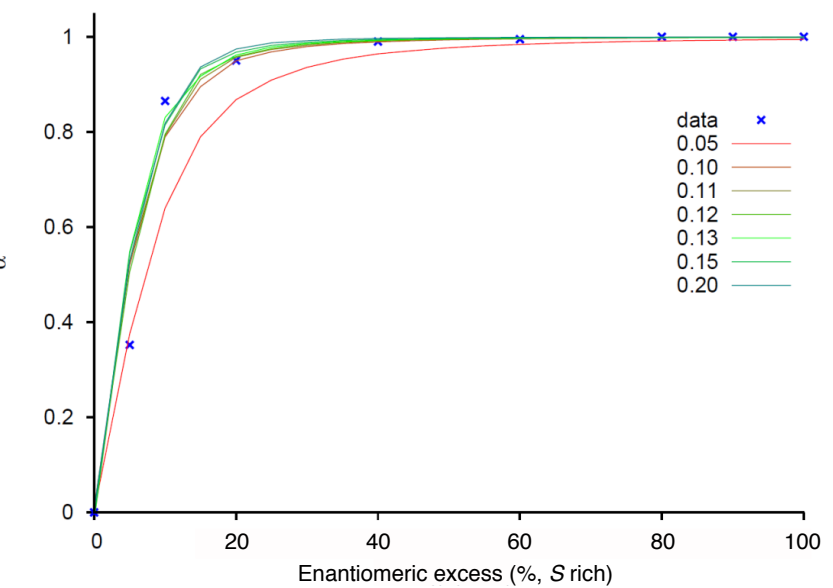

$F=6 R T$

Figure S4. Net helicity as a function of the \%ee for poly-( $\left.2 \boldsymbol{R}_{\mathrm{r}}-c o-\mathbf{2} S_{1-\mathrm{r}}\right) \mathrm{s}(S$ rich$)$, for different values of $J$ (legends, in units of $R T$ ) and two different values of the helix reversal penalty $F$.

From Figures S3 and S4 it is clear that both the majority rule data and the sergeants and soldiers data can be well described by a single set of parameters, i.e., $F=6 R T$ and $J=0.12 R T$. With $R T \approx$ $2.436 \mathrm{~kJ} / \mathrm{mol}$, this corresponds to a helix reversal penalty $(F)$ of $14.6 \mathrm{~kJ} / \mathrm{mol}$ and a mismatch penalty for chiral units $(J)$ of $0.29 \mathrm{~kJ} / \mathrm{mol}$.

\section{6-3. Preferred-Handed Helicity Induction in Optically-Inactive Poly-1b with $(R)-4$ and $(S)-4$}

To describe the addition of the guest molecules that non-covalently bind to the monomeric units, we slightly extend above model. We assume that $(R)-4$ can bind to any of the monomeric units and increases the free energy for that monomeric unit more, with an amount $K$, when it is present in a lefthanded helix $\left(\Delta G_{i}^{\text {left }}\right)$ as compared to when it is present in a right-handed helix $\left(\Delta G_{i}^{r i g h t}\right)$. Analogously we assume that $(S)-\mathbf{4}$ can bind to any monomeric unit and then increases the free energy for that monomeric unit in the right-handed helices $\Delta G_{i}{ }^{\text {right }}$ with the same amount $K$ more than when it would be present in a left-handed helix $\Delta G_{i}^{\text {left }}$.

We first consider a polymer that consists entirely of achiral monomeric units $A$ and study the effect of the addition of either $(R)-\mathbf{4}$ or $(S)-\mathbf{4}$. We thus assume these guests bind to the achiral units 
and that because the concentration of $(R)-\mathbf{4}($ or $(S)-4)$ is so high, all achiral units are saturated. Binding of (S)-4 to an $A$ monomeric unit in right-handed helices, as well as binding of $(R)-\mathbf{4}$ to an $A$ monomeric unit in left-handed helices, is assumed to result in a mismatch penalty of $K$. For the model this thus means that we have two new monomer types, which we will denote as $A_{R}$ and $A_{s}$ with free energies as summarized in Figure S5, of which only one is present at once.

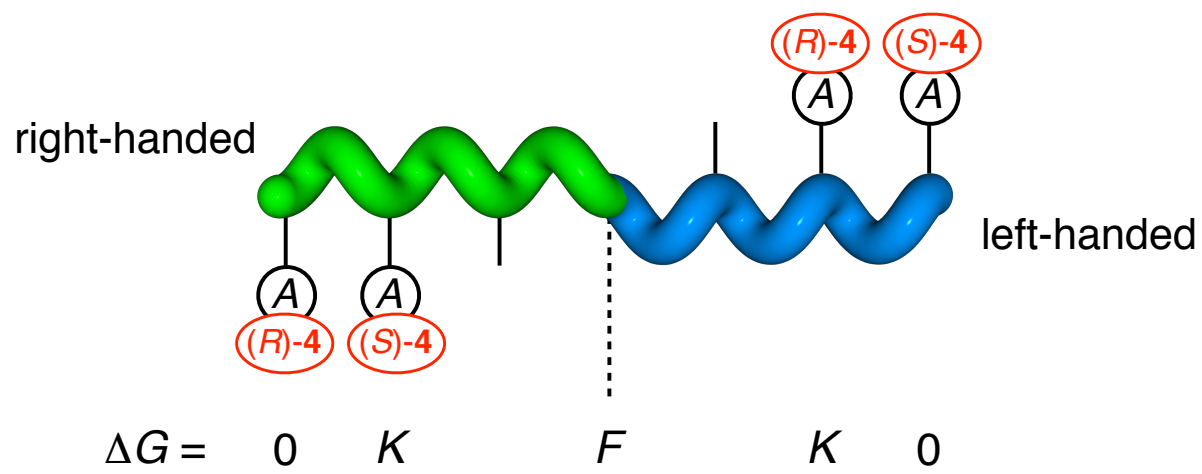

Figure S5. Schematic representation of the two monomer types in a dynamically racemic helical polymer composed of achiral monomer units in the presence of $(R)$ - or $(S)-4$ and their free energies. The achiral monomers complexed with $(R)-\mathbf{4}$ will be denoted as $A_{R}$ and those complexed with $(S)-4$ as $A_{S}$.

Figure $\mathrm{S} 6$ shows that (with $F=6 R T$ ) any mismatch penalty $K$ larger than $0.02 R T$ suffices to obtain purely right-handed helical polymers upon complexation with $(R)-\mathbf{4}$ and purely left-handed helical polymers upon complexation with $(S)-4$. That is $1 / 6^{\text {th }}$ of the mismatch penalty for the covalently bonded chiral monomers as derived in the previous section (6-2).

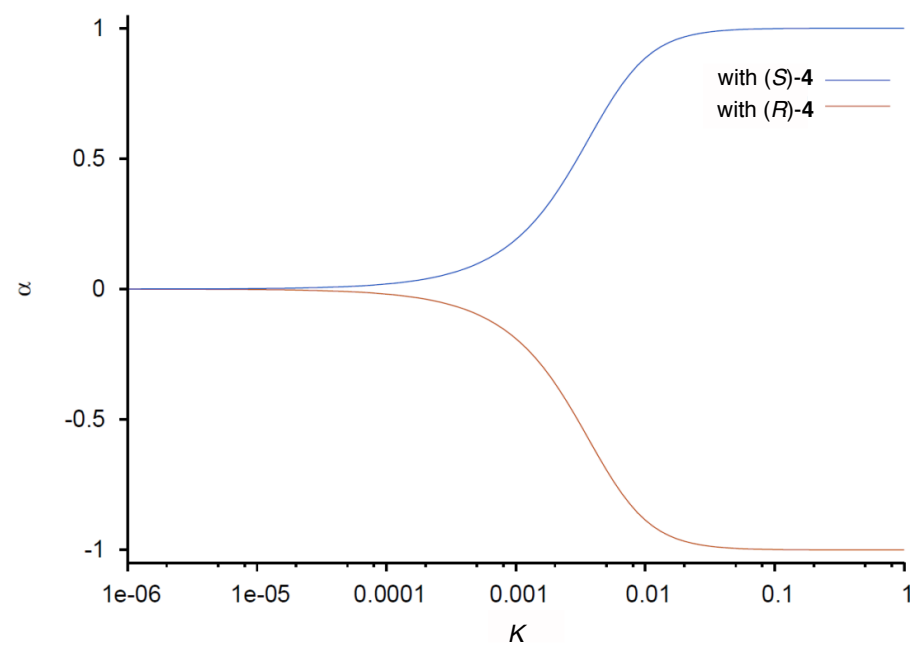

Figure S6. Net helicity for poly-1b in the presence of $(R)-\mathbf{4}$ or $(S)-\mathbf{4}$ as a function of the mismatch penalty $K$ (in units of $R T$ ) for a guest molecule in a helix with its unpreferred helical sense. 


\section{6-4. CD Spectral Changes of Poly-(1 $\left.\mathrm{b}_{1-\mathrm{r}-c o-2} R_{\mathrm{r}}\right) \mathrm{s}$ with $(S)-4$}

To investigate the helical sense excess enhancement and inversion in the sergeants and soldiers and the majority rule experiments, we next consider the case where the $(R)-\mathbf{4}$ (or $(S)-4)$ can also complex with the chiral units $R$ and $S$. In the model we thus consider four new monomer types, which we will denote as $R_{R}, R_{s}, S_{R}$ and $S_{s}$, respectively, where the subscript indicated the complexed guest.

For the new sergeants and soldiers experiments, we keep the parameters as derived in $\mathbf{6 - 2}$ for the pure sergeants and soldiers and majority rule models (i.e. $F=6 R T$ and $J=0.12 R T$ ) and add $(S)-4$. We again assume that $(S)-\mathbf{4}$ binds to any type of the monomeric units, that the concentration is so high that it saturates all monomeric units, and that $(S) \mathbf{- 4}$ results in a mismatch penalty of $K$ when present in right-handed helices instead of in left-handed helices, as schematically depicted in Figure S7. Figure S8 shows that with $K=0.013 R T$ the resulting net helicity as a function of the fraction sergeant $R$ fits the experimental data quite nice.

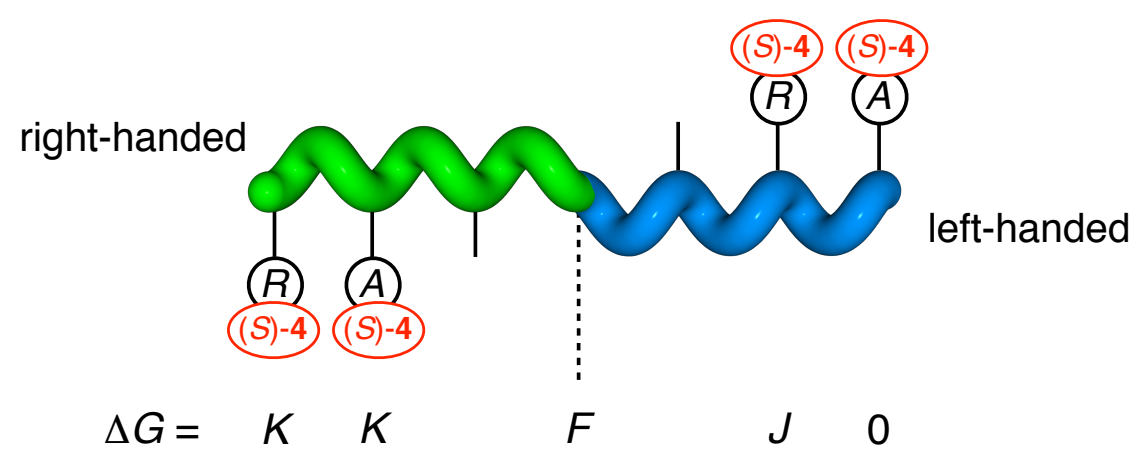

Figure S7. Schematic representation of the two monomer types in a chiral/achiral random copolymer (the sergeants and soldiers experiment) in the presence of $(S)-\mathbf{4}$ and their free energies.

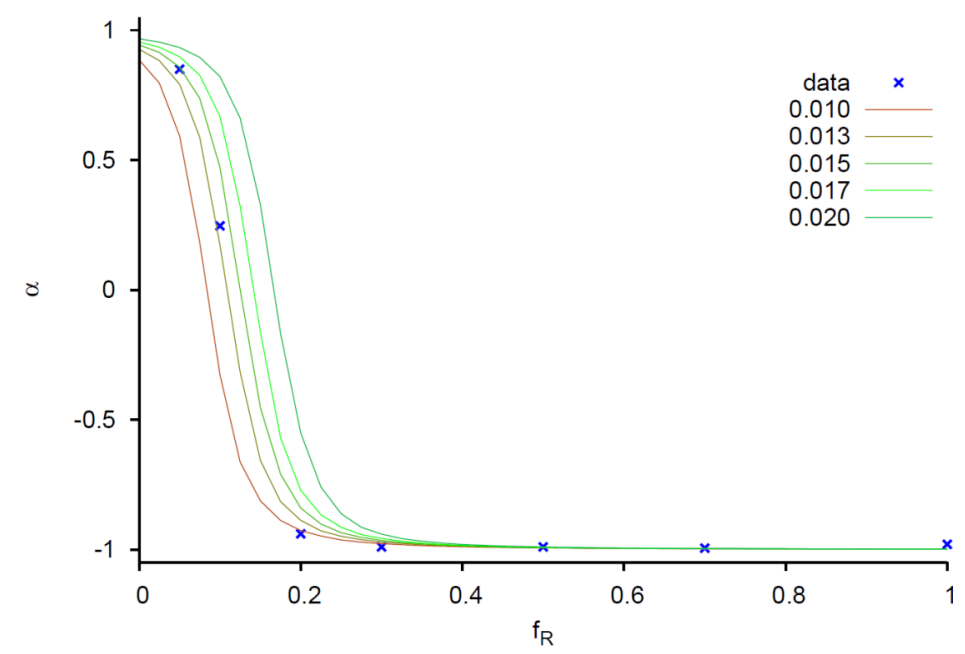

Figure S8. Net helicity as a function of the fraction sergeant $f_{R}$ in the presence of $(S)$-4, for different values of $K$ as specified by the legend (in units of $R T)$. $(F=6 R T$ and $J=0.12 R T$ ). 


\section{6-5. CD Spectral Changes of Poly-(2R $\left.-c o-2 S_{1-\mathrm{r}}\right) \mathrm{s}$ with $(R)-4$}

We then add $(R)-\mathbf{4}$ to the poly-(2 $\left.\boldsymbol{R}_{\mathrm{r}}-c o-\mathbf{2} S_{1-\mathrm{r}}\right) \mathrm{s}(S$ rich), which we again assume can bind to any of the monomeric units present and results in a mismatch penalty $K$ when bound to a monomer in lefthanded helices. Free energies for the two resulting monomer types are as summarized in Figure S9, where the mismatch penalty for an $R$ monomer with a bound $(R)-4$ thus consists of the sum of the mismatch penalties for a covalently bound chiral unit $(J)$ and that for a guest $(K)$. Figure S10 shows that (still with $F=6 R T$ and $J=0.12 R T$ ) for $K=0.013 R T$ seems to fit the data best. Interestingly, that is the again exactly the same value as the mismatch penalty for $(S)-4$ that we found in the sergeants and soldiers experiments in section 6-4.

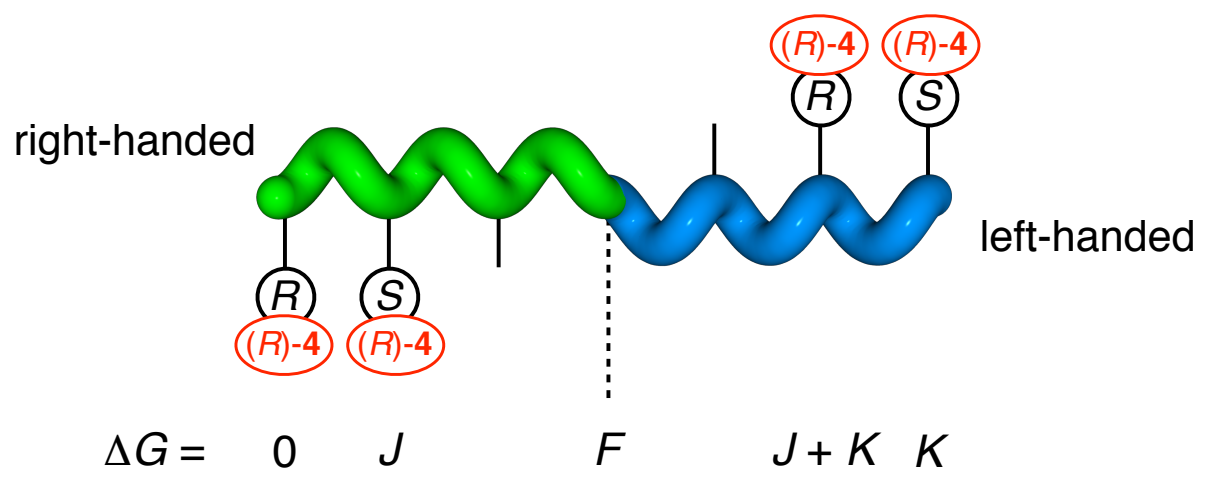

Figure S9. Schematic representation of the two monomer types in a chiral/chiral $(R / S)$ random copolymer (the majority rule experiment) in the presence of $(R)-\mathbf{4}$ and their free energies.

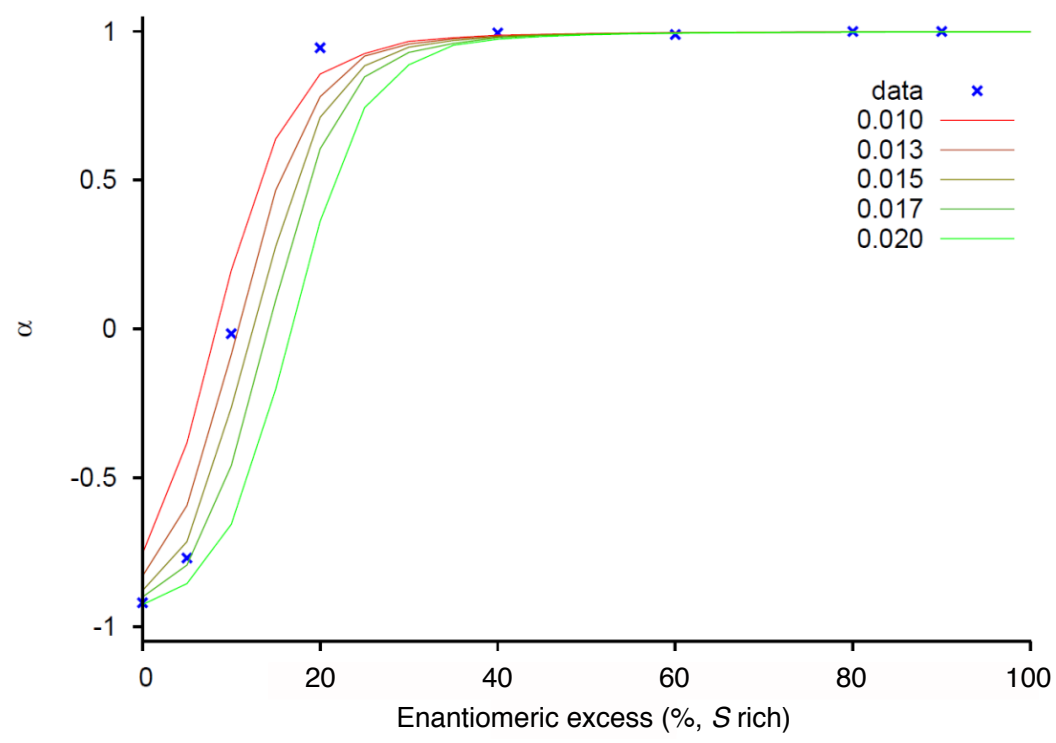

Figure S10. Net helicity as a function of the \%ee for poly- $\left(2 R_{\mathrm{r}}-c o-2 S_{1-\mathrm{r}}\right) \mathrm{s}(S$ rich $)$ in the presence of $(R)-4$ for different values of $K$ (in units of $R T$ ) as specified by the legend $(F=6 R T$ and $J=0.12 R T$ ). 


\section{6-6. Summary of Sergeants and Soldiers and Majority Rule with/without $(R)-4$ and/or $(S)-4$}

In summary, we describe the helical copolymers with the model of Green et al., ${ }^{7}$ where we extended the number of different monomers to nine, i.e., three for the different monomeric units $(R$, $A$ and $S$ ) and six additional ones for the complexes of these three monomeric units with $(R)-4$ and $(S)$ 4. For each of the nine different monomers we assign an energy penalty for not being in the preferredhanded helical sense, which consists of:

(i) a contribution $J$ for the monomeric unit $R$ or $S$ in the unpreferred-handed helical conformation.

(ii) a contribution $K$ for a $(R)-\mathbf{4}$ or $(S)-\mathbf{4}$ complexed to a monomeric unit in the unpreferredhanded helical conformation.

Finally there is a helix reversal penalty $F$. All these free energies are schematically depicted in Figure S11. With a single set of parameters, i.e. $J=0.12 R T, K=0.013 R T$, and $F=6 R T$, all (equilibrium) experiments can be explained with this model, as shown in Figures $5 \mathrm{~B}$ and $5 \mathrm{C}$ for the sergeants and soldiers and majority rule experiments, respectively.

right-handed

left-handed

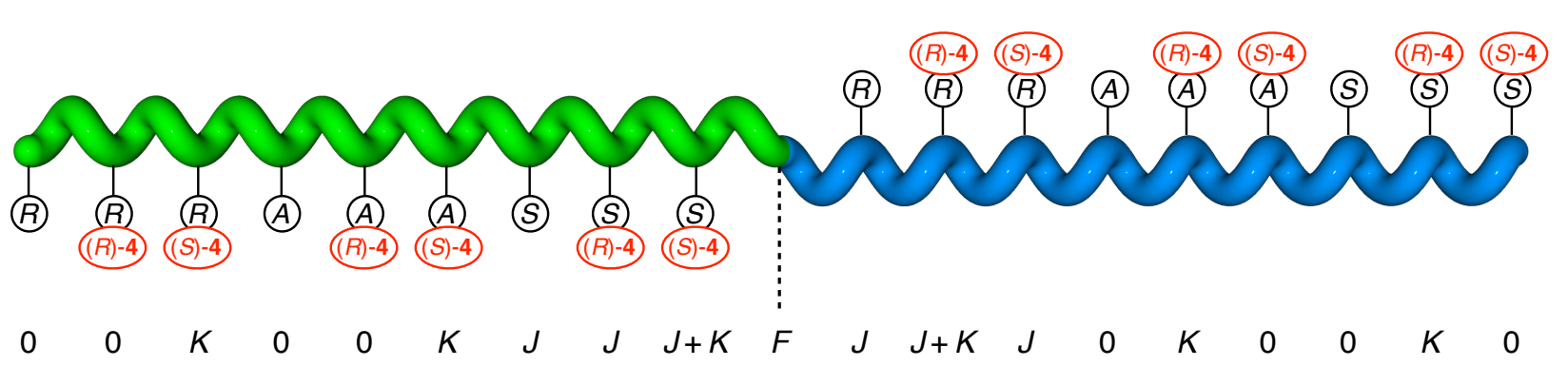

Figure S11. Schematic representation of the nine monomer types in the sergeants and soldiers and majority rule experiments with/without $(R)-\mathbf{4}$ or $(S)-\mathbf{4}$ and their free energies in the right- and lefthanded helices.

\section{6-7. Monte Carlo Simulations for Preferred-Handed Helicity Induction in Optically-Inactive} Poly-1b and Poly-(2R0.5-co-2S $\left.S_{0.5}\right)$ with Nonracemic 4

An alternative way to solve the Ising models is using Markov chain Monte Carlo simulation. ${ }^{9}$ The Hamiltonian representing the energy of our copolymer is:

$$
H=\sum_{k=1}^{N} \Delta G_{i(k)}^{\sigma(k)}-\frac{1}{2} \Delta G_{r} \sum_{k=1}^{N-1} \sigma(k) \sigma(k+1)
$$


where $i(k)$ still describes the type of the $k$-th monomeric unit and $\sigma(k)$ describes the helical sense that monomer is in, where a value of 1 for $\sigma$ corresponds to a right-handed helical sense and a value of 1 to a left-handed helical sense. In such a simulation, we start by assigning a random helical sense to each monomer, after which repeatedly trial moves are performed. In one such a trial move one randomly picks one of the monomeric units and calculates the change in energy $\Delta H$ if the helical sense for that monomer would be flipped. If the flip results in a decrease in the energy, it is always accepted. Otherwise, i.e. when $\Delta H>0$, the flip is only accepted with probability $\exp (-\Delta H / R T)$.

We performed twenty simulations with twenty different random copolymers (poly-(2 $\boldsymbol{R}_{0.5}-\mathrm{co}$ $\left.\mathbf{2} \boldsymbol{S}_{0.5}\right)$ ), each consisting of 5000 monomeric units, in the presence of $(R)-\mathbf{4}$, with energy parameters as found above with the matrix-transfer method, i.e., $\Delta G_{\mathrm{r}}=F=6 R T$ and the $\Delta G_{i(k)}{ }^{\sigma(k)}$ in terms of $J=$ $0.12 R T$ and $K=0.013 R T$ in case the monomeric unit and the complexed guests are in the unpreferredhanded helical sense (as summarized in Figure S11). The net helicity in six of these simulations, in which the polymer is followed over five billion trial moves, is shown in Figure S12 as a function of the number of trial moves. This starts at zero, as in the initial configuration a random helical sense was assigned to each monomer, and after an equilibration phase oscillates around its equilibrium value. The equilibrium value (which still depends on the exact sequence in the random copolymer) is calculated as the average of the final 90 percent of the simulation. These equilibrium values for the net helicity as well as number of helix reversals for the twenty simulations are shown in a box plot in Figure S13, where they are compared to the values calculated using the transfer matrix method for twenty different copolymers. As can be seen, the mean results are very comparable, though the variance in the values derived from the Monte Carlo simulations is higher. This can be contributed to the fact that in the Monte Carlo simulations the values do not only depend on the exact composition/sequence of the copolymer, but also on the length of the simulation. The longer the simulation, the better estimate the average gives for the equilibrium value, but these simulations already take long. 


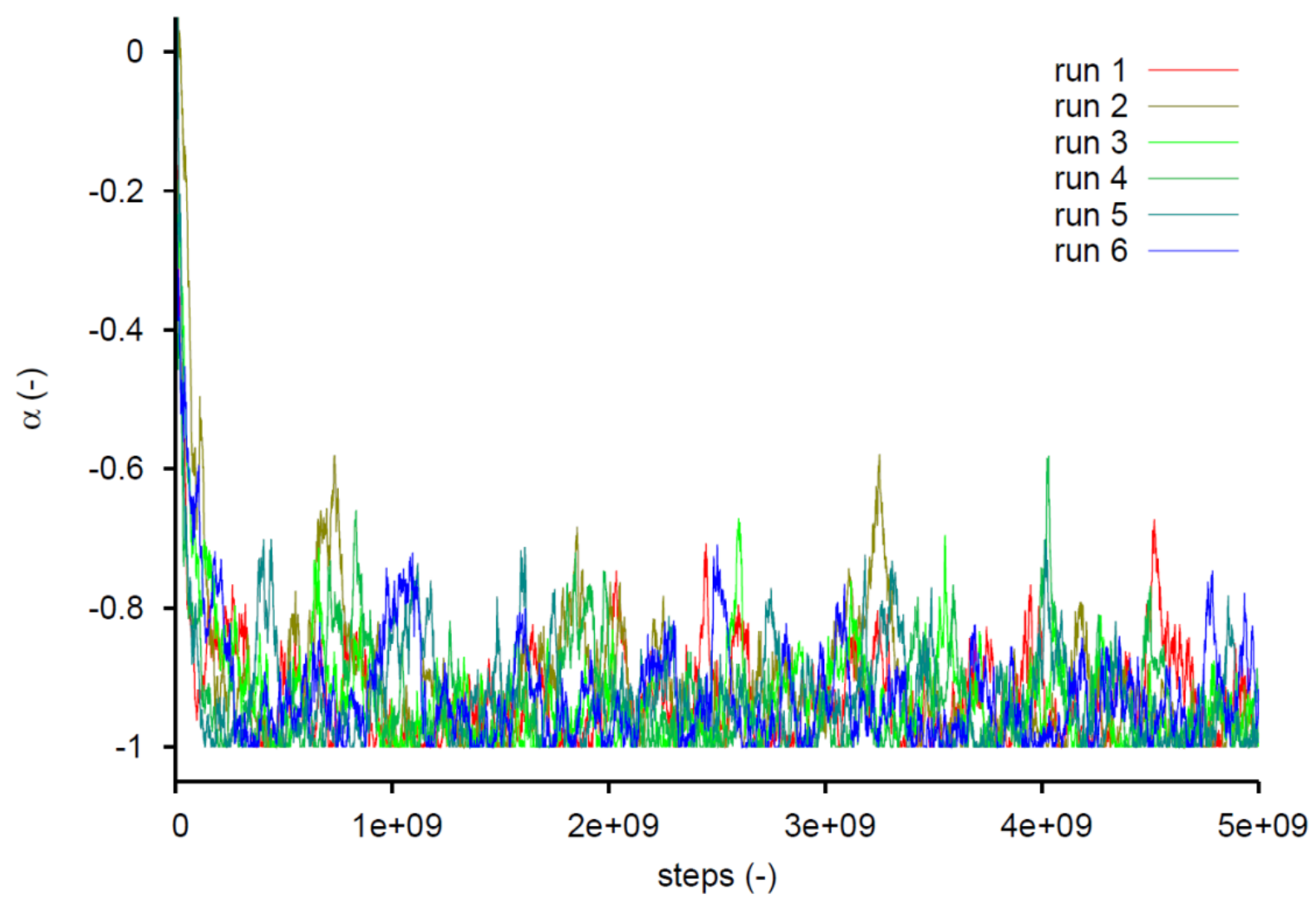

Figure S12. Net helicity as a function of the number of trial moves in six Monte Carlo simulations

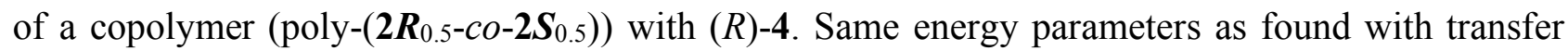
matrix method, i.e., $J=0.12 R T, K=0.013 R T$, and $F=6 R T$.
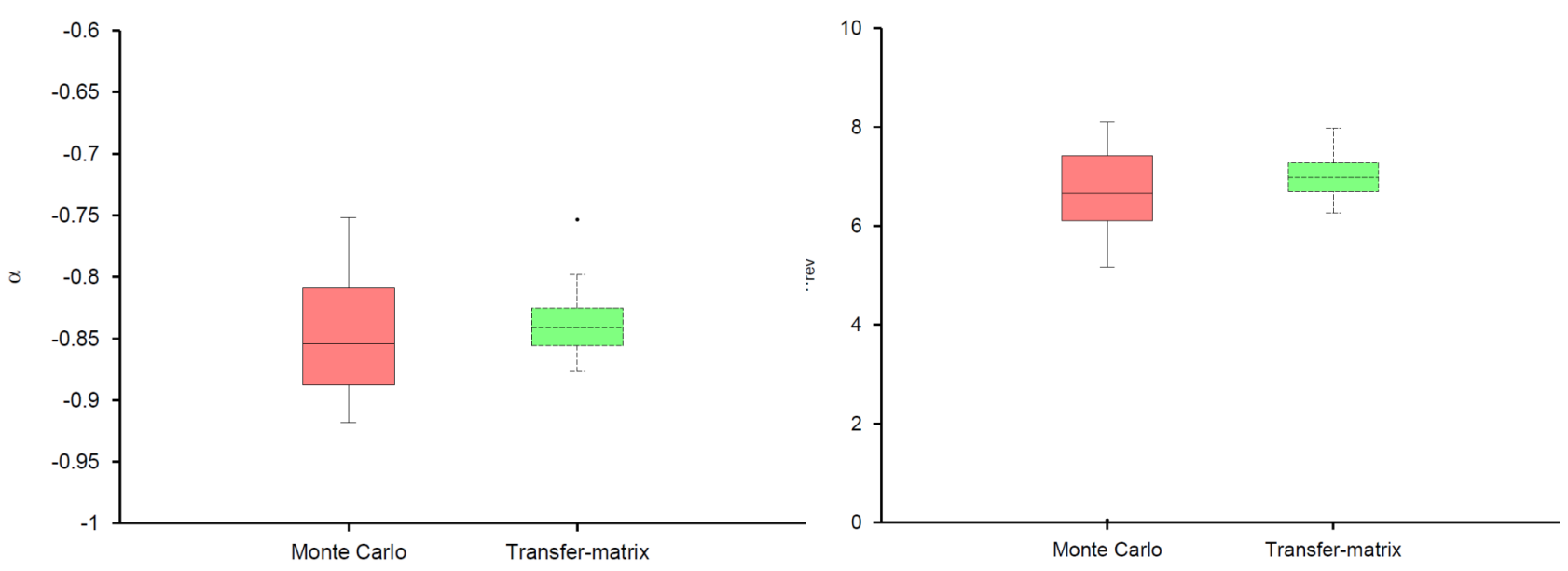

Figure S13. Boxplots of the net helicities (left) and number of helix reversals (right) as extracted from the twenty Monte Carlo simulations on twenty random copolymers (poly- $\left(\mathbf{2} \boldsymbol{R}_{0.5}-\mathrm{co}-\mathbf{2} \boldsymbol{S}_{0.5}\right)$ ) in the presence of $(R)-4$ guests compared to boxplots of the same quantities calculated with the transfer matrix method on 20 different such copolymers in the presence of $(R)-\mathbf{4}$ guests. 
Advantage of this simulation approach to solve the model is that it still works if we do not only consider $(R)-\mathbf{4}$ (or only $(S)-\mathbf{4}$ ), but mixtures of $(R)-\mathbf{4}$ and $(S)-\mathbf{4}$ instead. In the simulation approach we then only need to add additional trial moves that exchange guests. Now $50 \%$ of the trial moves is a flip of the helicity for a random monomeric unit while in the other $50 \%$ of the trial moves we remove the guest from a random monomeric unit and add a $(R)-\mathbf{4}$ or $(S) \mathbf{- 4}$ guest with propensity proportional to the \%ee of the guests. Here it is assumed that the guests are present in abundance and that the \%ee of the guests in the solution does not change on the complexation of guests with the monomeric units (though in principle the exact \%ee of the solvent could be tracked as well). For each \%ee value again twenty simulations are performed and the mean net helicity determined from those simulations is given in Figure S14. The same figure also shows the net helicity for poly-1b as a function of the guest \%ee as extracted from twenty such Monte Carlo simulations per ee value. Compared to the experimental data, which is plotted in this figure just like earlier figures as $\Delta \varepsilon_{2 n d} / 20$, the model shows the correct trend, but systematically seems to underestimate the net helicity slightly. In Figure 6 the same data is shown, but using two y-axes, i.e. one for the model and one for the experimental data. The difference in scale between the two axes here is a factor 21.5 instead of 20 . This yields a very nice fit, but thus maximum $\Delta \varepsilon$ assumed of 21.5 is slightly higher than observed in the earlier experiments where we do expect $100 \%$ net helicity. Fits could probably be improved by adding additional parameters, but we prefer the simplicity of the current model that nicely fits all experimental data with just a single set of 3 parameters $(F=6 R T, J=0.12 R T$ and $K=0.013 R T)$.

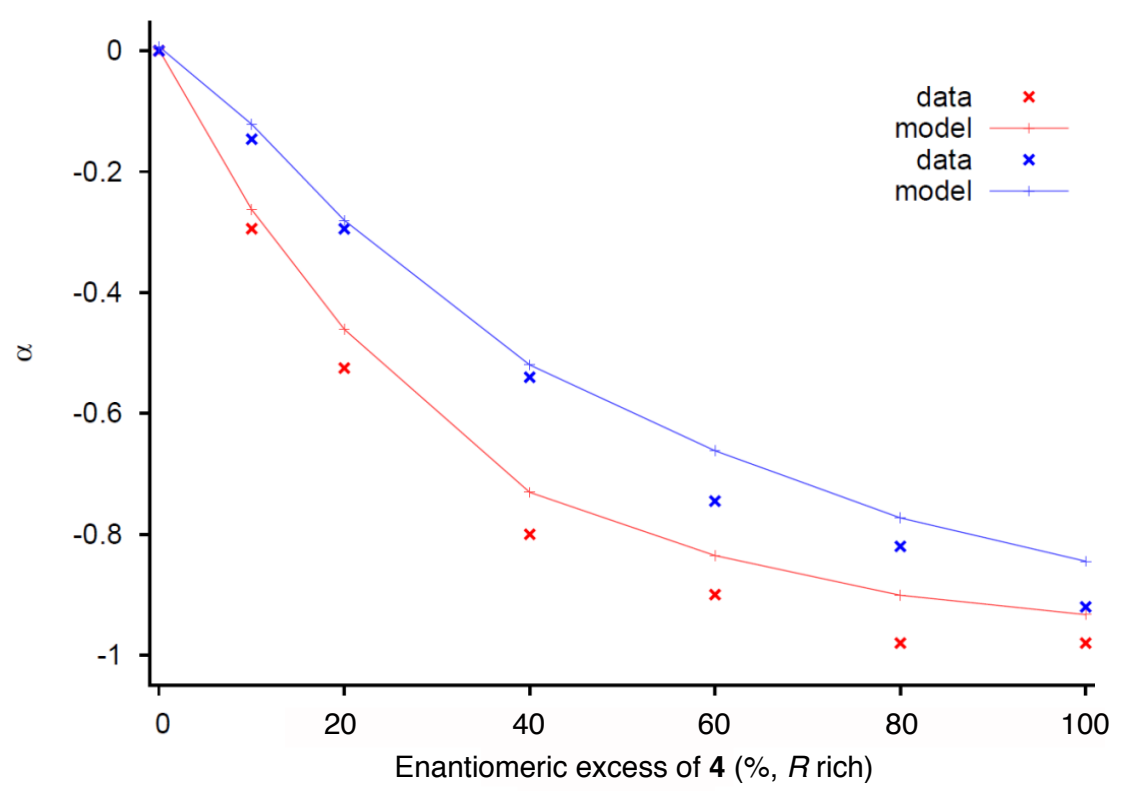

Figure S14. Net helicity estimated by $\Delta \varepsilon_{2 \text { nd }} / 20$ for poly-1b (red) and poly-(2 $\left.\boldsymbol{R}_{0.5}-c o-\mathbf{2} \boldsymbol{S}_{0.5}\right)$ (blue) as a function of the guest \%ee as derived from Monte Carlo simulations compared to the experimental value. 
Not only the net helicity, but also the number of helix reversals can be extracted from the Monte Carlo simulations. For both poly-1b and poly- $\left(\mathbf{2} \boldsymbol{R}_{0.5}-\mathrm{co}-\mathbf{2} \boldsymbol{S}_{0.5}\right)$ these are shown in Figure S15 as a function of the guest \%ee. Though the helix reversal penalty in both cases is equal, i.e. $F=6 R T$, the number of helix reversals in poly-(2 $\left.\boldsymbol{R}_{0.5}-c o-\mathbf{2} \boldsymbol{S}_{0.5}\right)$ is clearly higher than in poly-1b. The stronger nonlinearity in the net helicity as a function of the guest \%ee observed for poly-1b than for poly$\left(\mathbf{2} \boldsymbol{R}_{0.5}-\mathrm{co}-\mathbf{2} \boldsymbol{S}_{0.5}\right)$ may thus be explained by the model predicting, for the same helix reversal penalty, less helix reversals in a polymer built of achiral units than in one built of totally racemic repeating units, such that to obtain the same total free energy difference due to the complexed 4 per helical segment (needed to remove a helix reversal) for poly- $\left(\mathbf{2} \boldsymbol{R}_{0.5}-c o-\mathbf{2} \boldsymbol{S}_{0.5}\right)$ with shorter segments a larger bias in nonracemic $\mathbf{4}$ is needed.

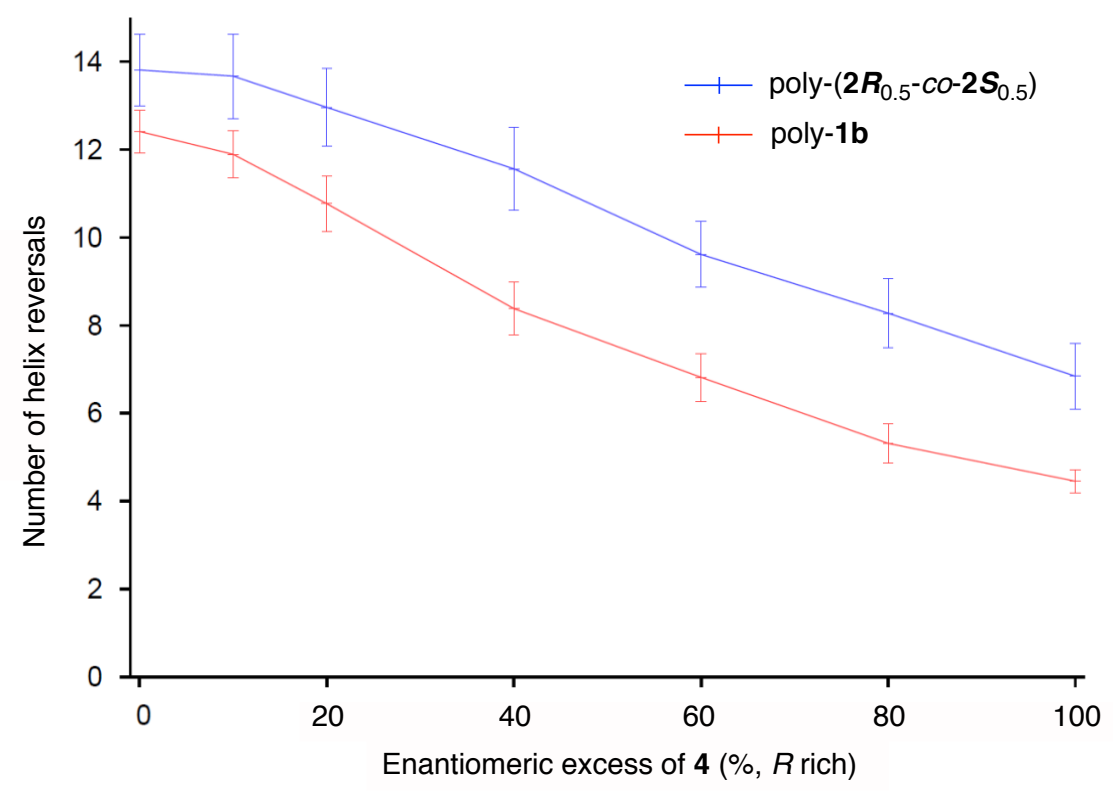

Figure S15. Average number of helix reversals per polymer of length 5000 for poly-1b (red) and poly- $\left(2 R_{0.5}-c o-2 S_{0.5}\right)$ (blue) as a function of the guest \%ee as derived from Monte Carlo simulations. Error bars show standard deviation of numbers calculated for 20 different random copolymers. 


\section{Supporting Data}

(A)
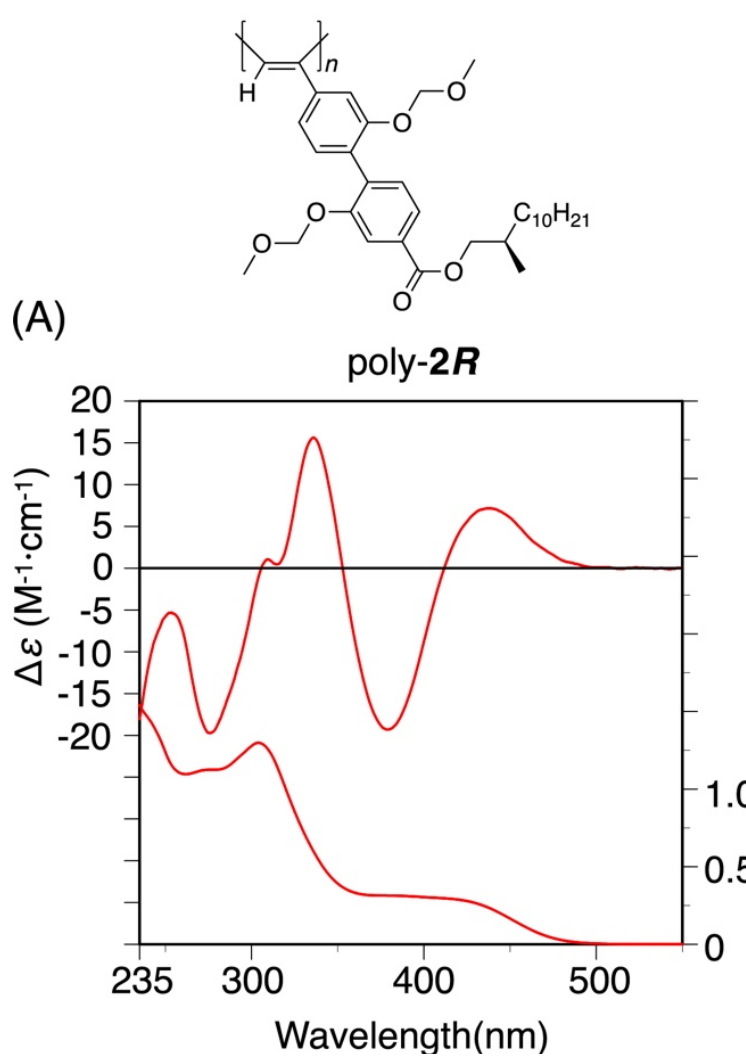

(B)
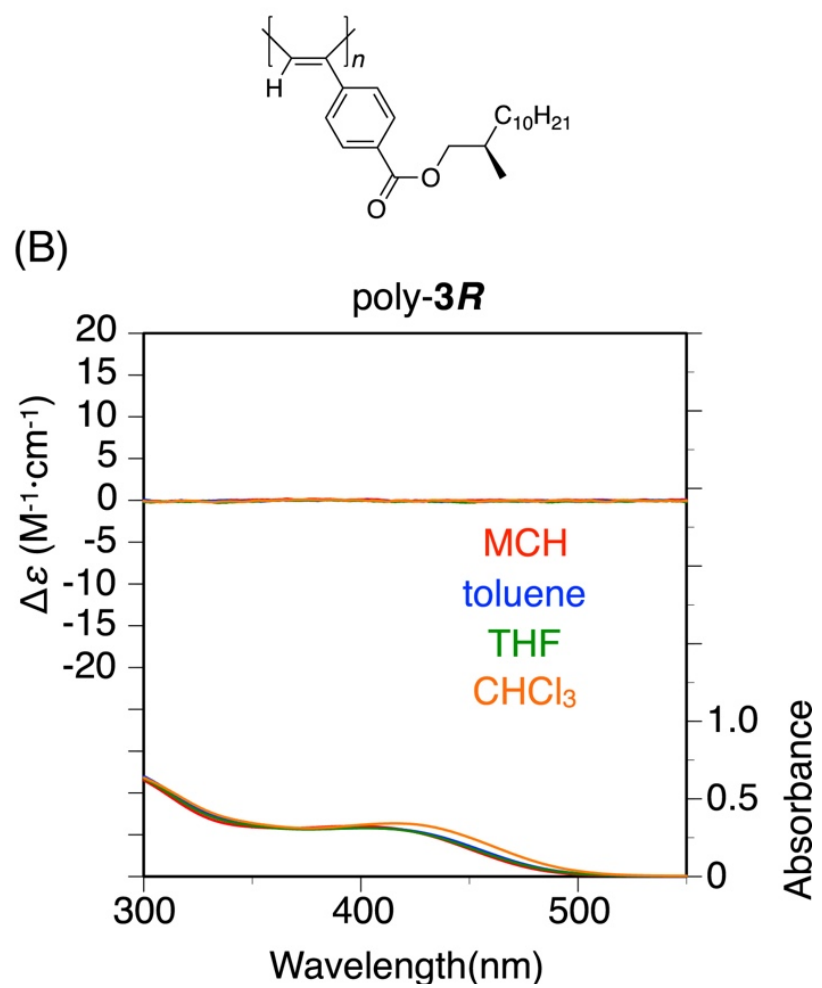

Figure S16. CD and absorption spectra of poly-2R (A) in $\mathrm{MCH}$ and poly-3R (B) in various solvents $\left(\mathrm{MCH}\right.$, toluene, $\mathrm{THF}$, and $\left.\mathrm{CHCl}_{3}\right)$ at $25^{\circ} \mathrm{C}$. [Polymer] $=1.0 \mathrm{mM}$. 

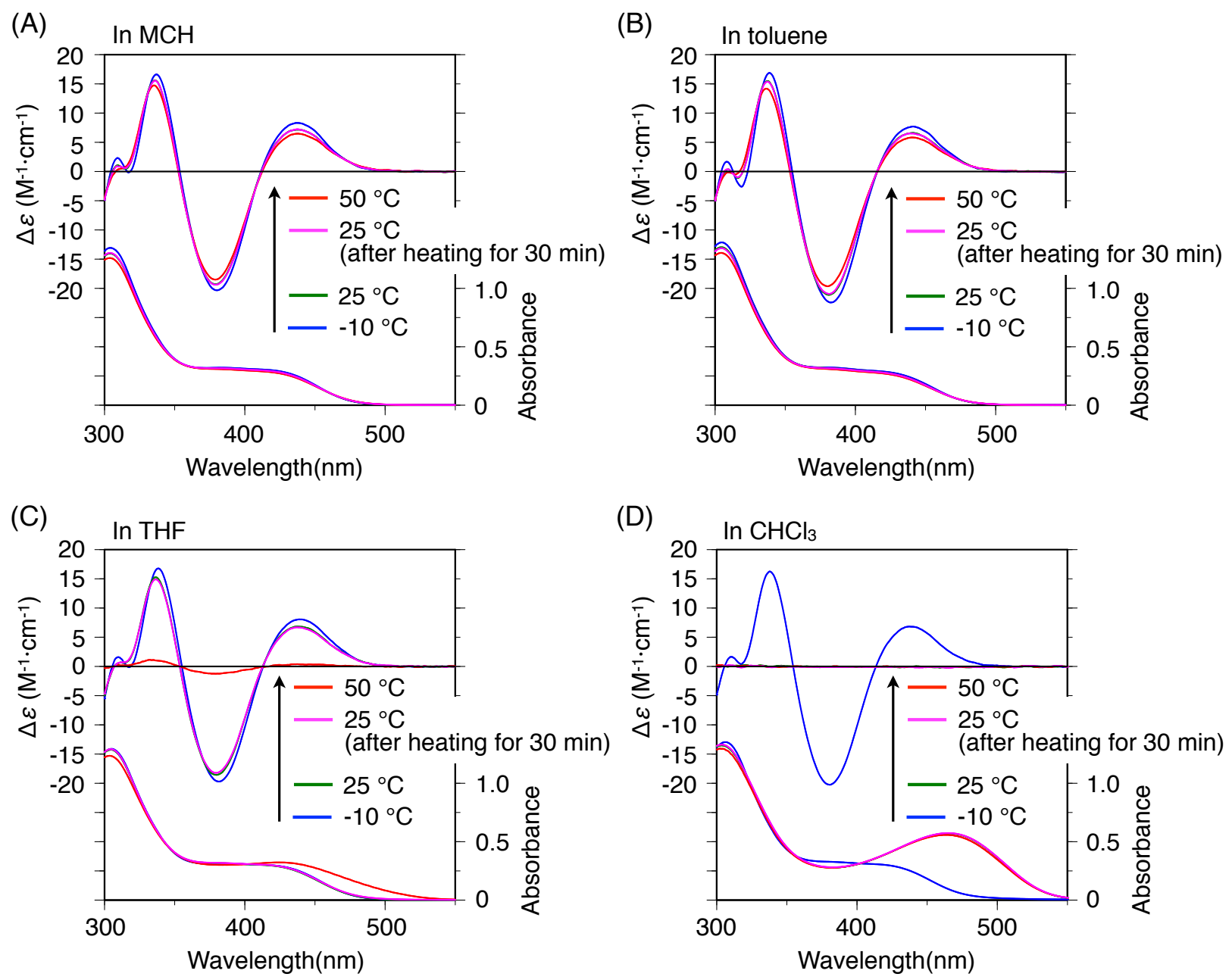

Figure S17. $\mathrm{CD}$ and absorption spectra of poly-2R in $\mathrm{MCH}(\mathrm{A})$, toluene (B), THF (C), and $\mathrm{CHCl}_{3}$ (D) at various temperatures. [Poly-2R] $=1.0 \mathrm{mM}$. 

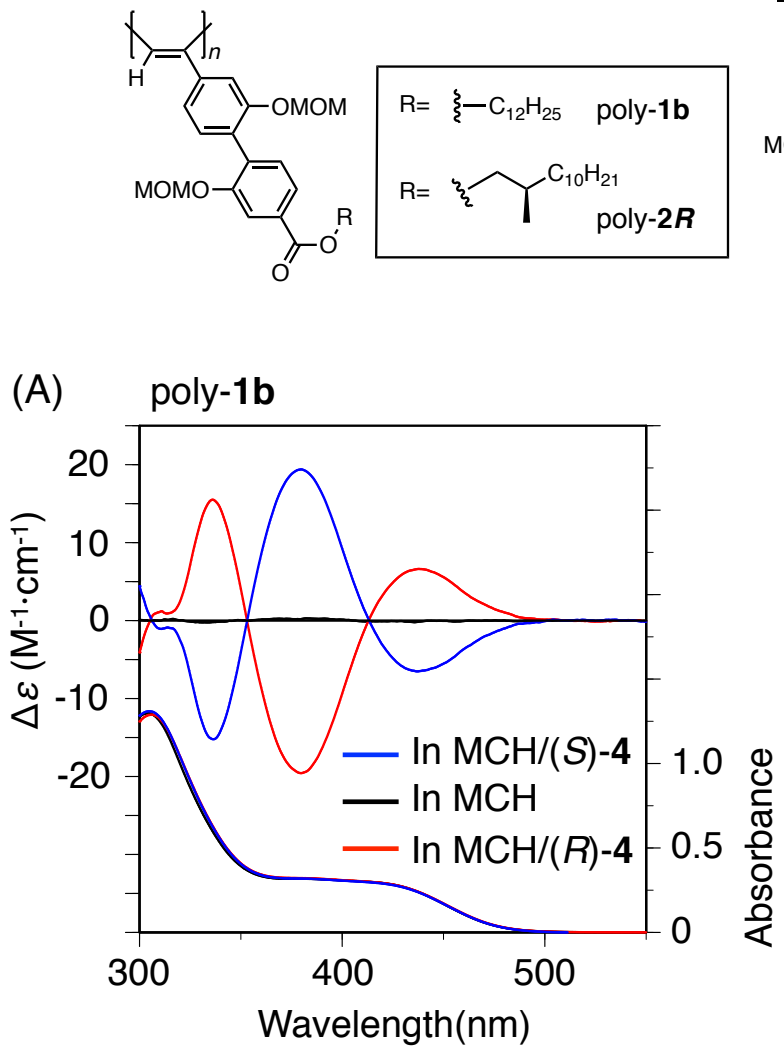

(C) poly-(1 $\left.\mathbf{b}_{0.9}-c o-2 \boldsymbol{R}_{0.1}\right)$

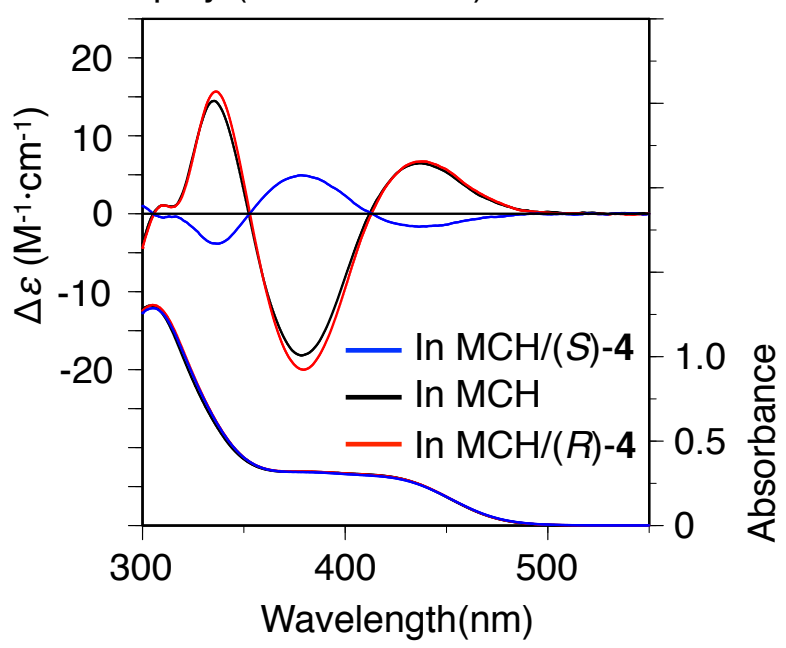

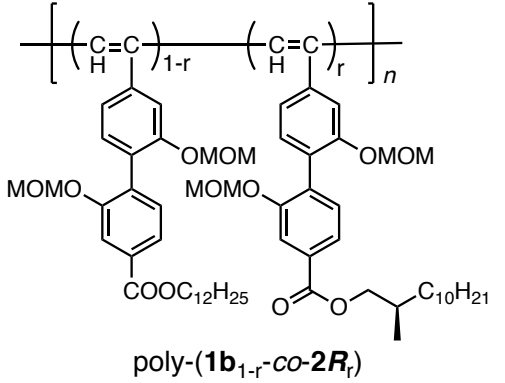
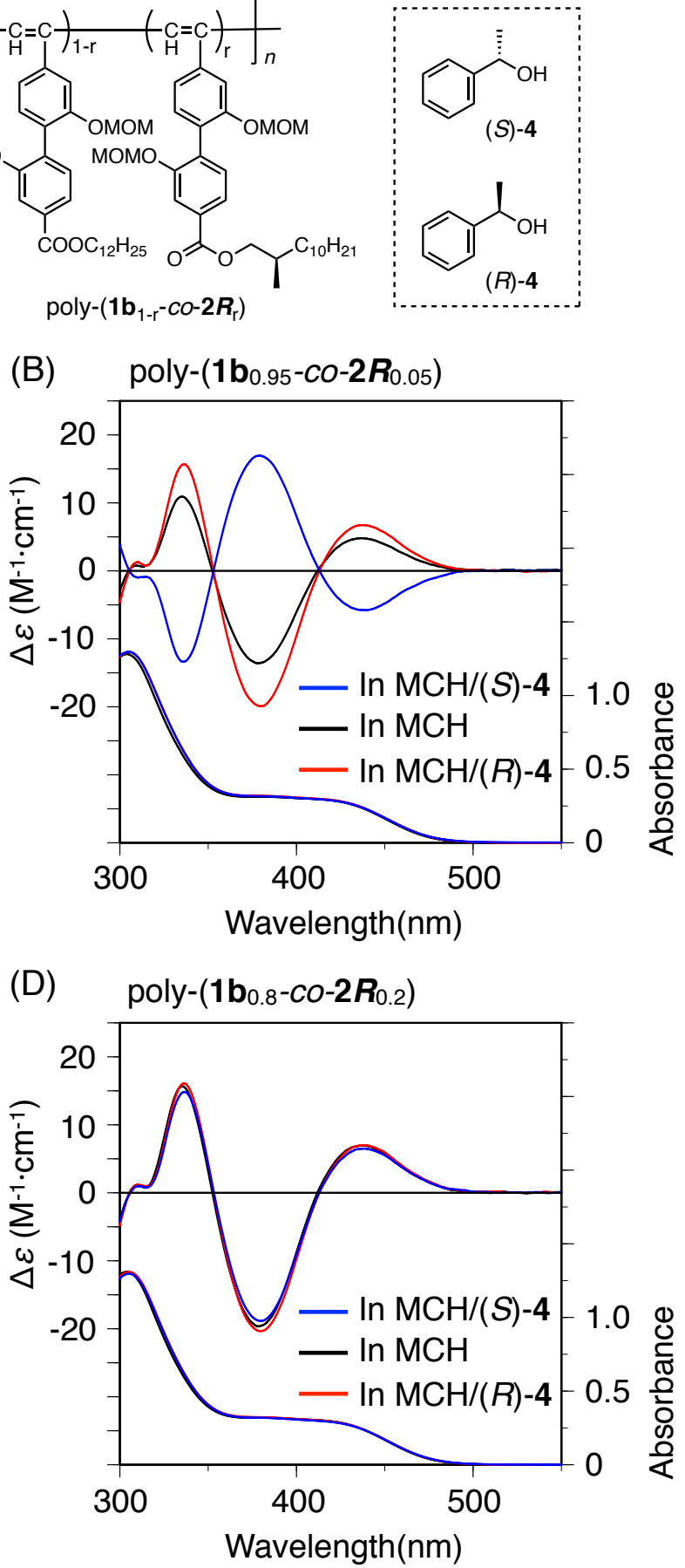

(Figure S18 to be continued) 

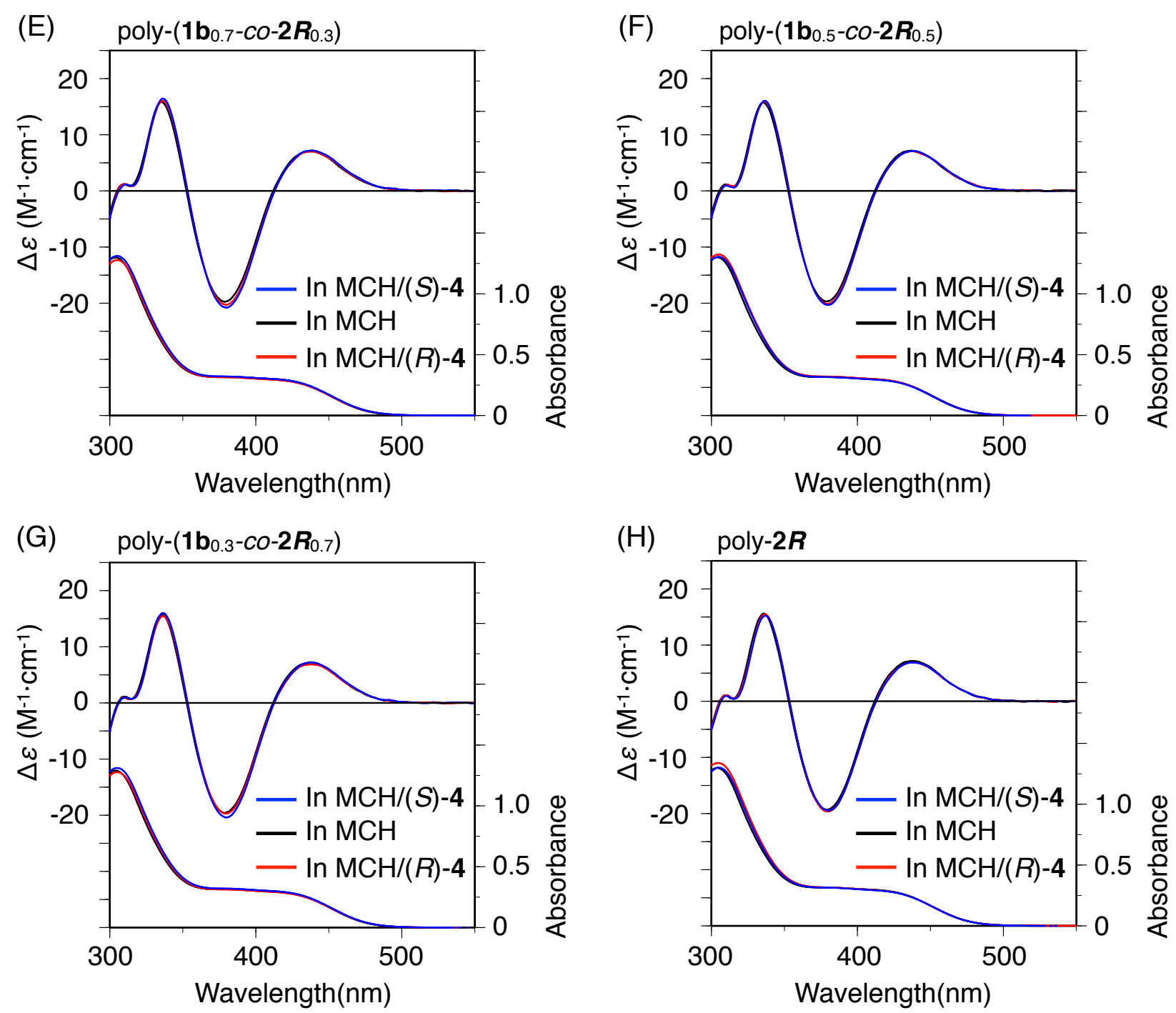

Figure S18. CD and absorption spectra of poly-1b (A), poly-(1 $\left.\mathbf{b}_{1-\mathrm{r}-c o-2} \boldsymbol{R}_{\mathrm{r}}\right)(\mathrm{r}=0.05$ (B), 0.1 (C), 0.2 (D), $0.3(\mathrm{E}), 0.5(\mathrm{~F})$, and $0.7(\mathrm{G}))$, and poly-2R $(\mathrm{H})$ in the absence and presence of $(R)$ - and $(S)-4$ in $\mathrm{MCH}(\mathrm{MCH} / 4=80 / 20, \mathrm{v} / \mathrm{v})$ at $25{ }^{\circ} \mathrm{C}$ after standing at $25{ }^{\circ} \mathrm{C}$ for 5 days. [Polymer] $=1.0 \mathrm{mM}$; [4] = $1.65 \mathrm{M}$. 

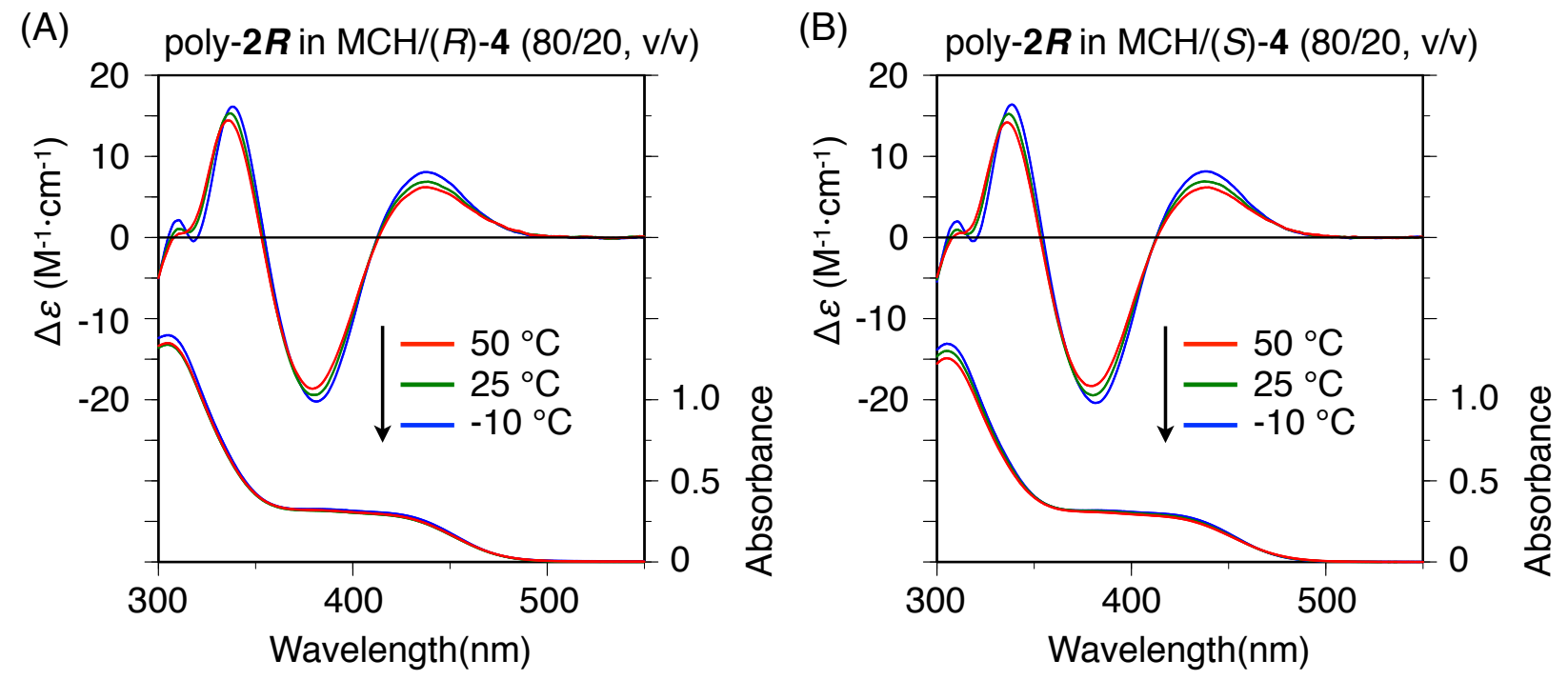

Figure S19. CD and absorption spectra of poly-2R in the presence of $(R)-4(\mathrm{~A})$ and $(S)-4(\mathrm{~B})$ in $\mathrm{MCH}$ $(\mathrm{MCH} / \mathbf{4}=80 / 20, \mathrm{v} / \mathrm{v})$ at various temperatures. [Poly-2R] $=1.0 \mathrm{mM} ; \mathbf{4}]=1.65 \mathrm{M}$.
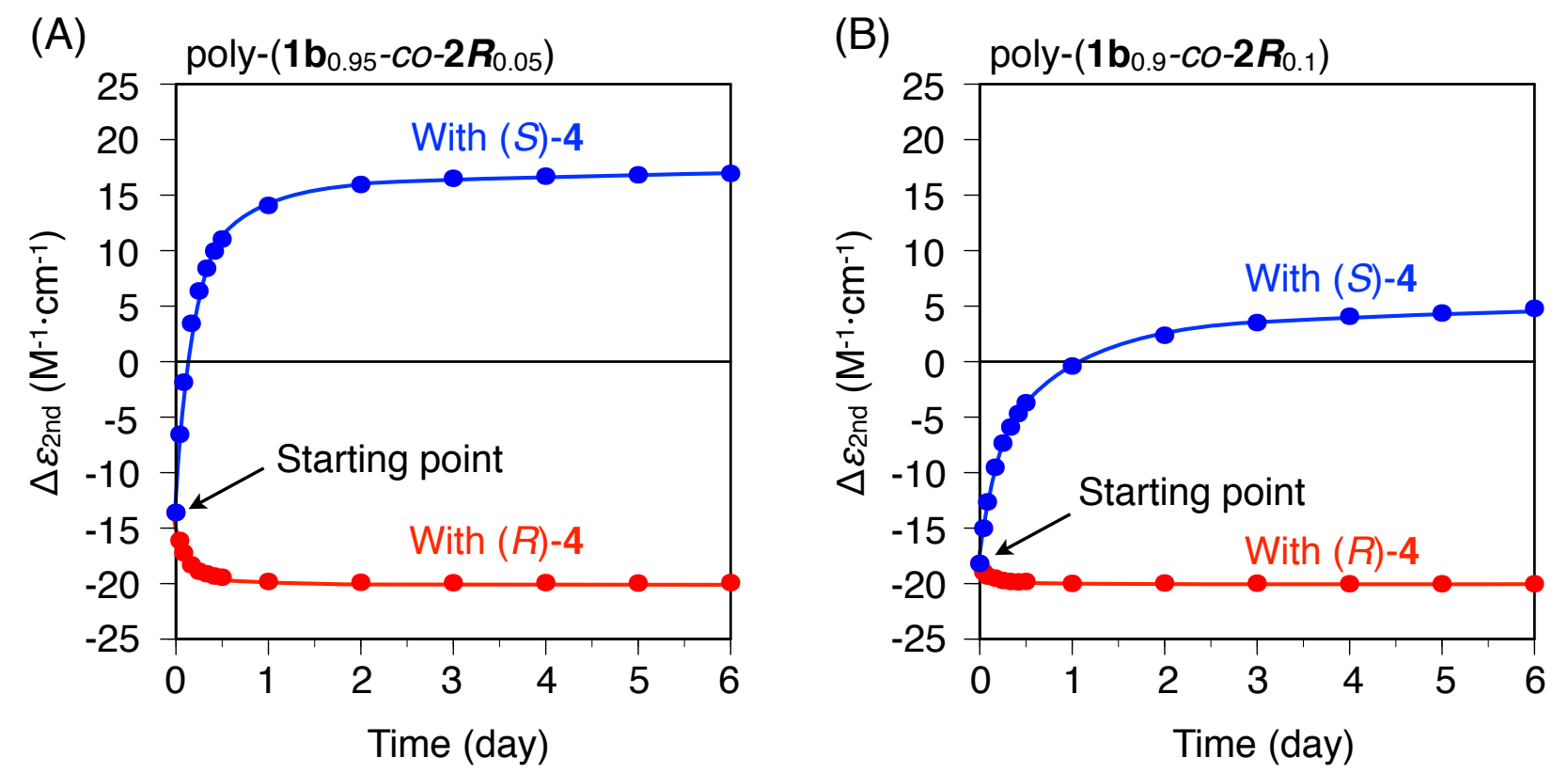

Figure S20. Time-dependent ICD intensity $\left(\Delta \varepsilon_{2 n d}\right.$ at $\left.380 \mathrm{~nm}\right)$ changes of poly-(1 $\left.\mathbf{b}_{0.95}-c o-2 \boldsymbol{R}_{0.05}\right)(\mathrm{A})$ and poly-(1 $\left.\mathbf{b}_{0.9}-c o-2 \boldsymbol{R}_{0.1}\right)$ (B) in $\mathrm{MCH} /(S)-\mathbf{4}(80 / 20, \mathrm{v} / \mathrm{v})$ and $\mathrm{MCH} /(R)-\mathbf{4}(80 / 20, \mathrm{v} / \mathrm{v})$ at $25{ }^{\circ} \mathrm{C}$. $[$ Polymer $]=1.0 \mathrm{mM} ;[4]=1.65 \mathrm{M}$. 

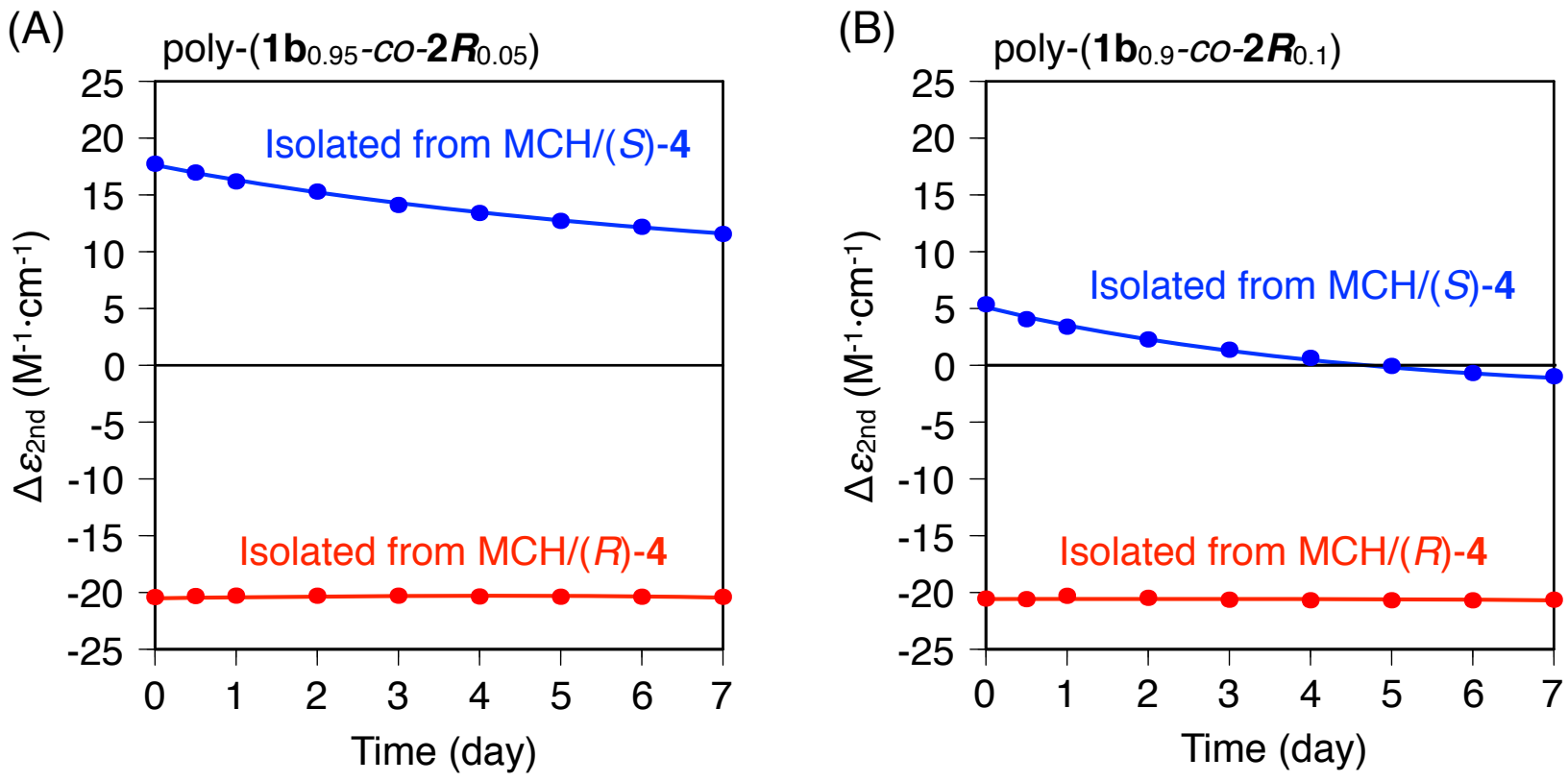

Figure S21. Time-dependent ICD intensity $\left(\Delta \varepsilon_{2 n d}\right.$ at $\left.380 \mathrm{~nm}\right)$ changes of the isolated poly- $\left(\mathbf{1 b}_{0.95}-c o-\right.$ $\left.\mathbf{2} \boldsymbol{R}_{0.05}\right)$ (A) and poly-(1) $\left.\mathbf{b}_{0.9}-c o-2 \boldsymbol{R}_{0.1}\right)$ (B) with helicity memory from $\mathrm{MCH} /(S)-\mathbf{4}(80 / 20, \mathrm{v} / \mathrm{v})$ and $\mathrm{MCH} /(R)-4(80 / 20, \mathrm{v} / \mathrm{v})$ in $\mathrm{MCH}$ at $-10{ }^{\circ} \mathrm{C}$. [Polymer $]=1.0 \mathrm{mM}$. 


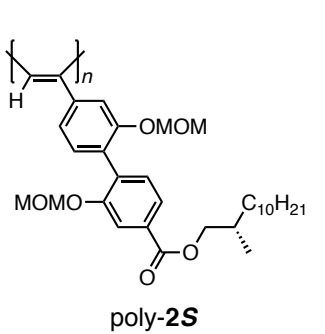

oly-2s
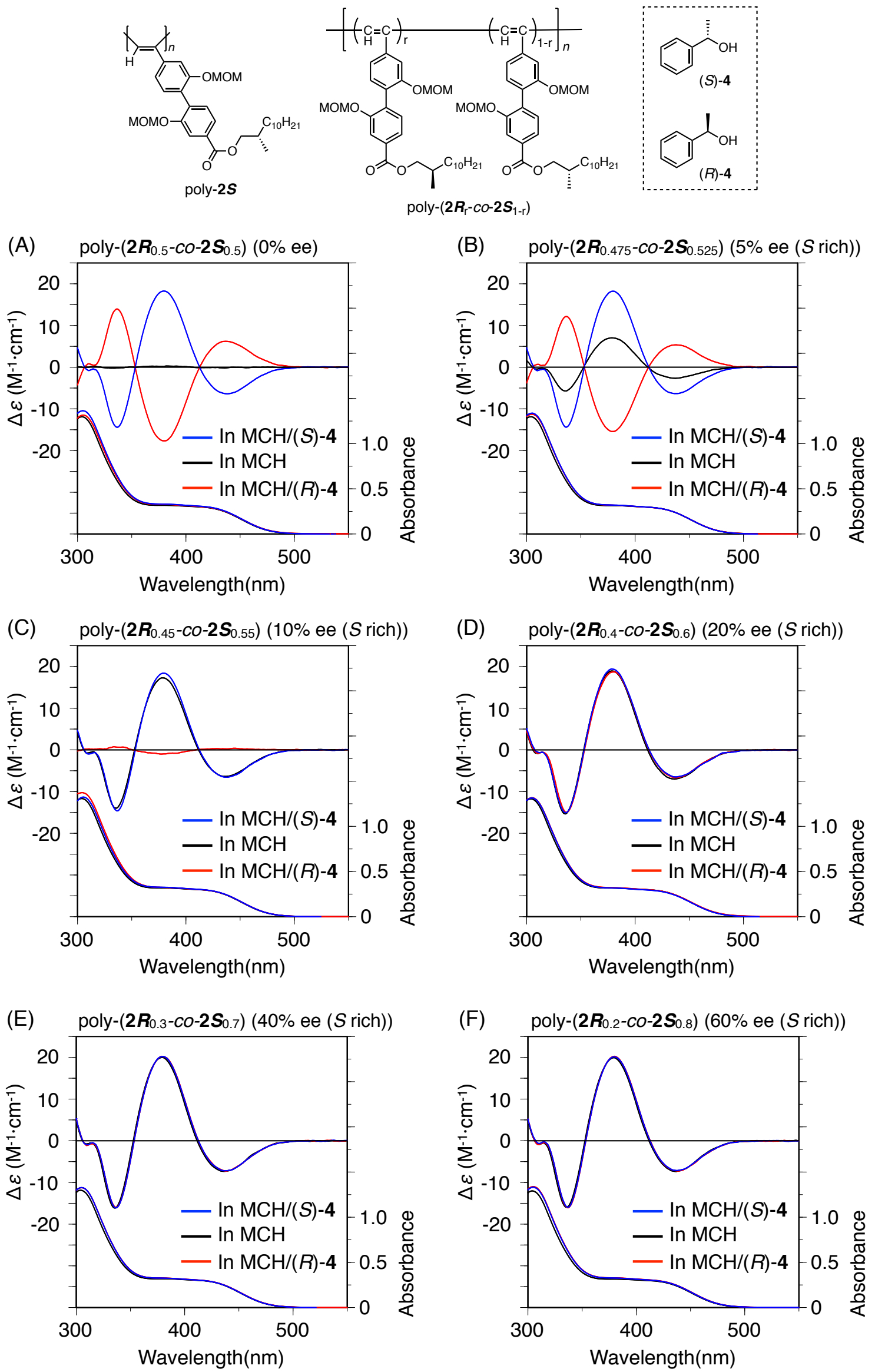

(Figure S22 to be continued) 

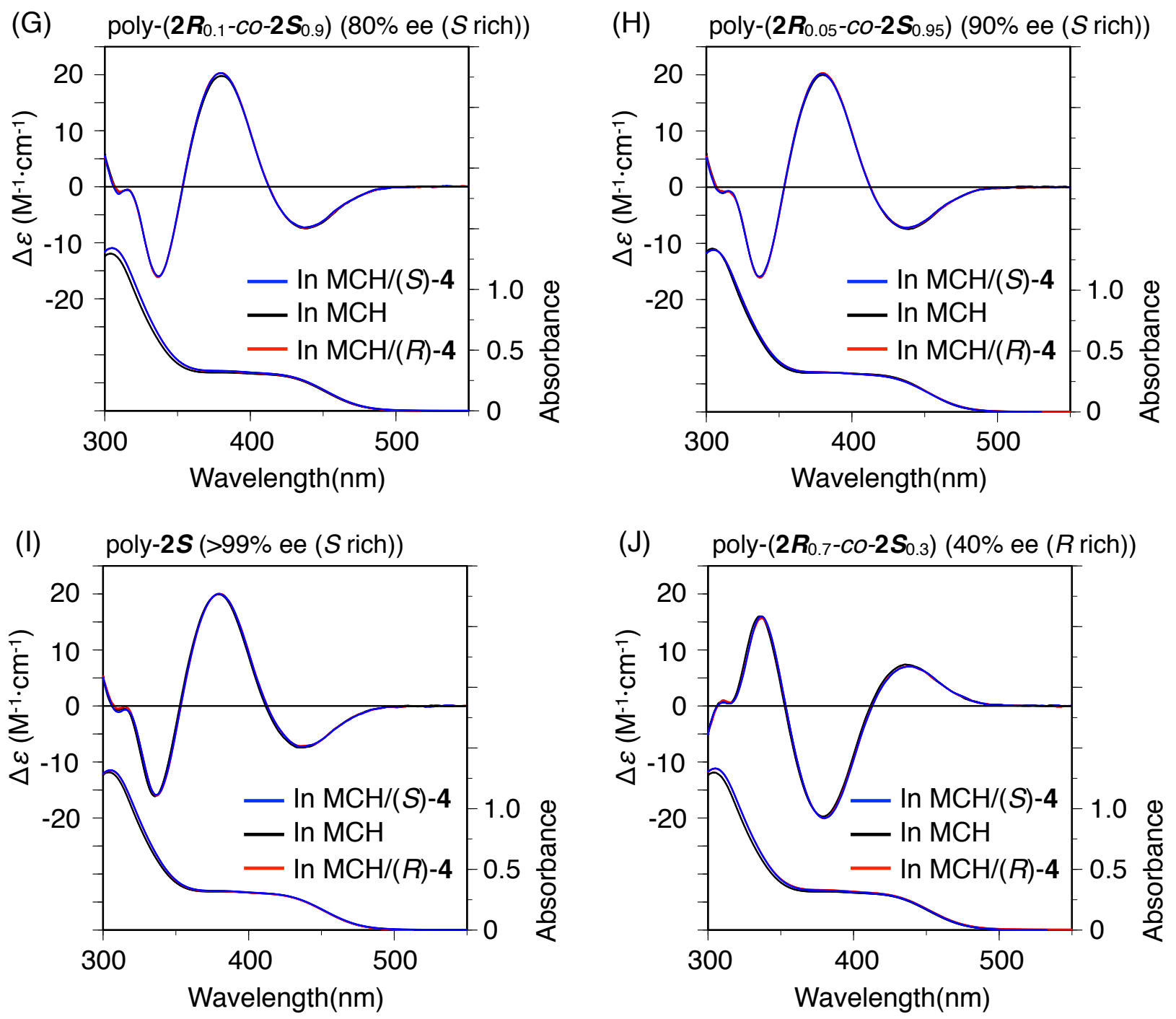

Figure S22. CD and absorption spectra of poly-(2 $\left.\boldsymbol{R}_{\mathrm{r}}-c o-2 \boldsymbol{S}_{1-\mathrm{r}}\right)(\mathrm{r}=0.5(\mathrm{~A}), 0.475(\mathrm{~B}), 0.45$ (C), 0.4 (D), $0.3(\mathrm{E}), 0.2(\mathrm{~F}), 0.1(\mathrm{G}), 0.05(\mathrm{H})$, and $0.7(\mathrm{~J}))$, and poly-2S (I) in the absence and presence of $(R)$ - and $(S)-4$ in $\mathrm{MCH}(\mathrm{MCH} / \mathbf{4}=80 / 20, \mathrm{v} / \mathrm{v})$ at $25{ }^{\circ} \mathrm{C}$ after standing at $25{ }^{\circ} \mathrm{C}$ for 5 days. [Polymer] $=1.0 \mathrm{mM} ; 4]=1.65 \mathrm{M}$. 

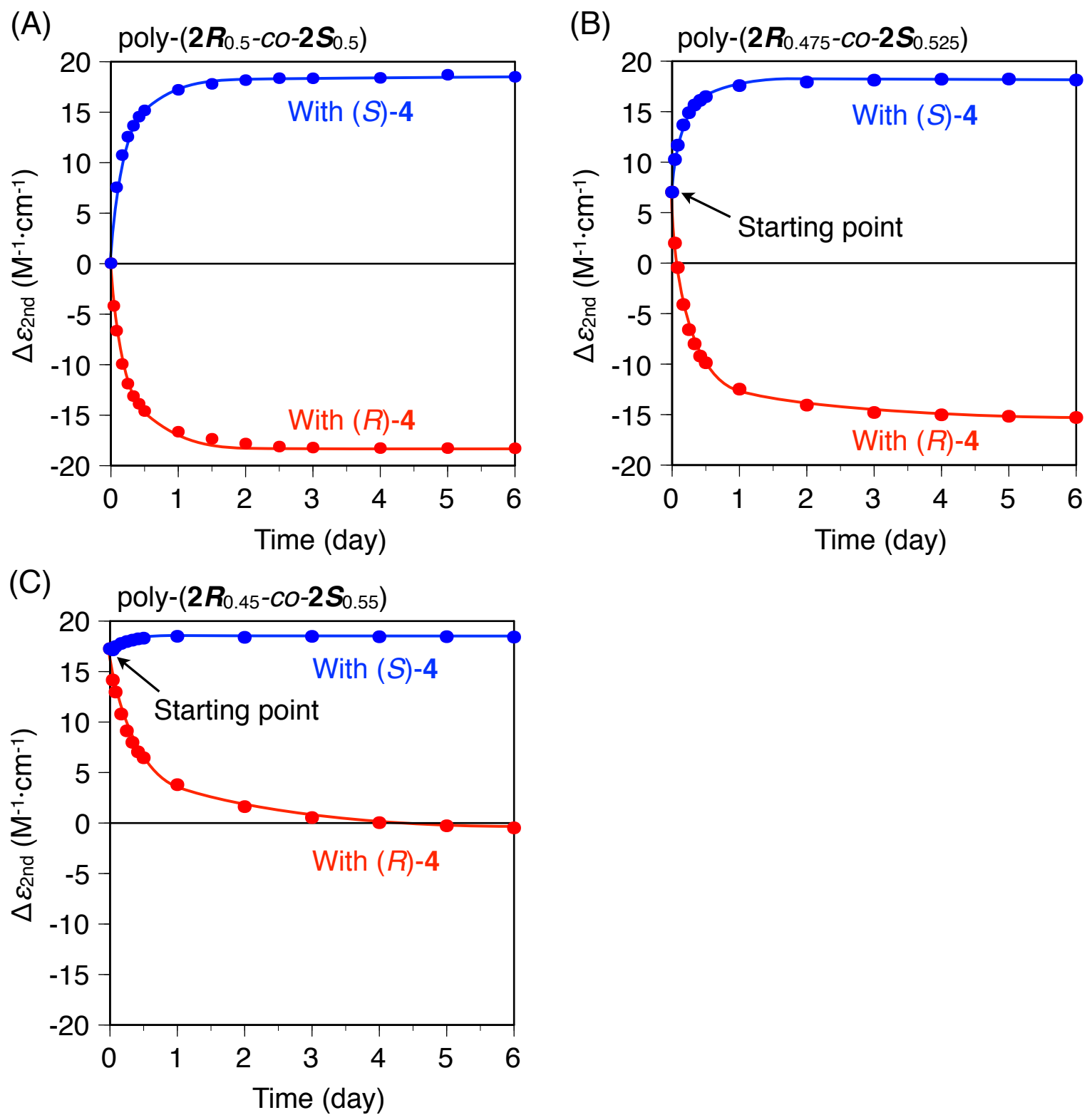

Figure S23. Time-dependent ICD intensity $\left(\Delta \varepsilon_{2}\right.$ nd at $\left.380 \mathrm{~nm}\right)$ changes of poly- $\left(\mathbf{2} \boldsymbol{R}_{0.5}-c o-2 \boldsymbol{S}_{0.5}\right)(\mathrm{A})$,

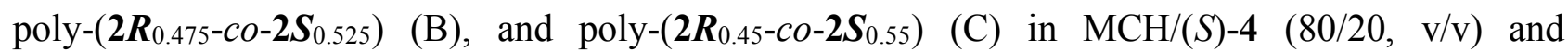
$\mathrm{MCH} /(R)-4(80 / 20, \mathrm{v} / \mathrm{v})$ at $25^{\circ} \mathrm{C}$. [Polymer] $=1.0 \mathrm{mM} ;[4]=1.65 \mathrm{M}$. 


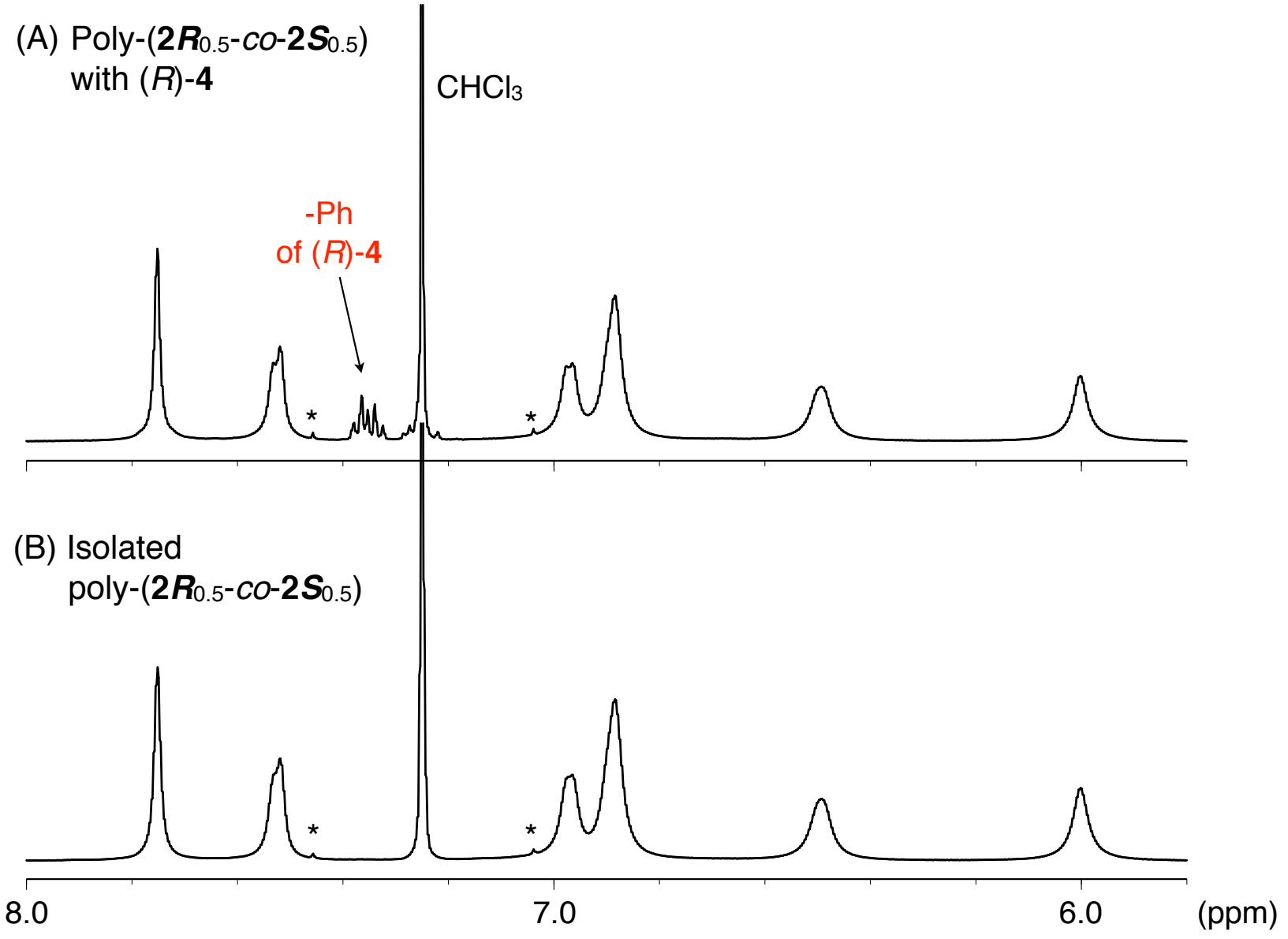

Figure S24. ${ }^{1} \mathrm{H}$ NMR spectra of poly- $\left(2 \boldsymbol{R}_{0.50}-c o-2 \boldsymbol{S}_{0.50}\right)$ with $(R)-\mathbf{4}\left([(R)-\mathbf{4}] /\left[\right.\right.$ poly- $\left.\left(\mathbf{2} \boldsymbol{R}_{0.50}-c o-\mathbf{2} \boldsymbol{S}_{0.50}\right)\right]$ $=0.1)(\mathrm{A})$ and the isolated poly- $\left(2 \boldsymbol{R}_{0.50}-c o-2 S_{0.50}\right)$ with helicity memory $(\mathrm{B})$ in $\mathrm{CDCl}_{3}$ at $50{ }^{\circ} \mathrm{C}$. 
(A)

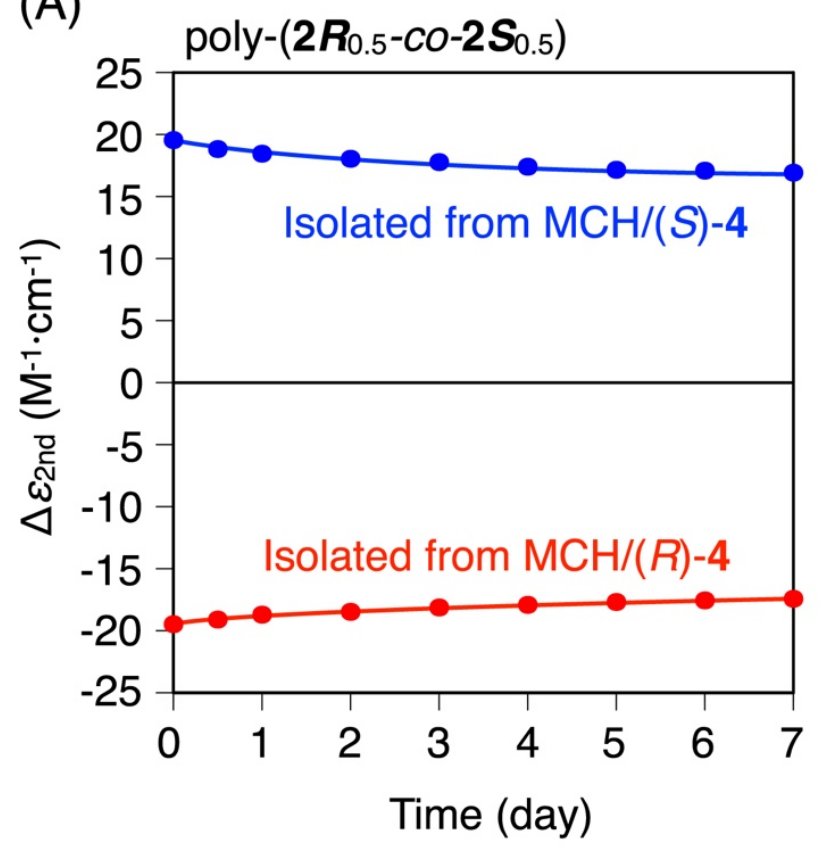

(C)

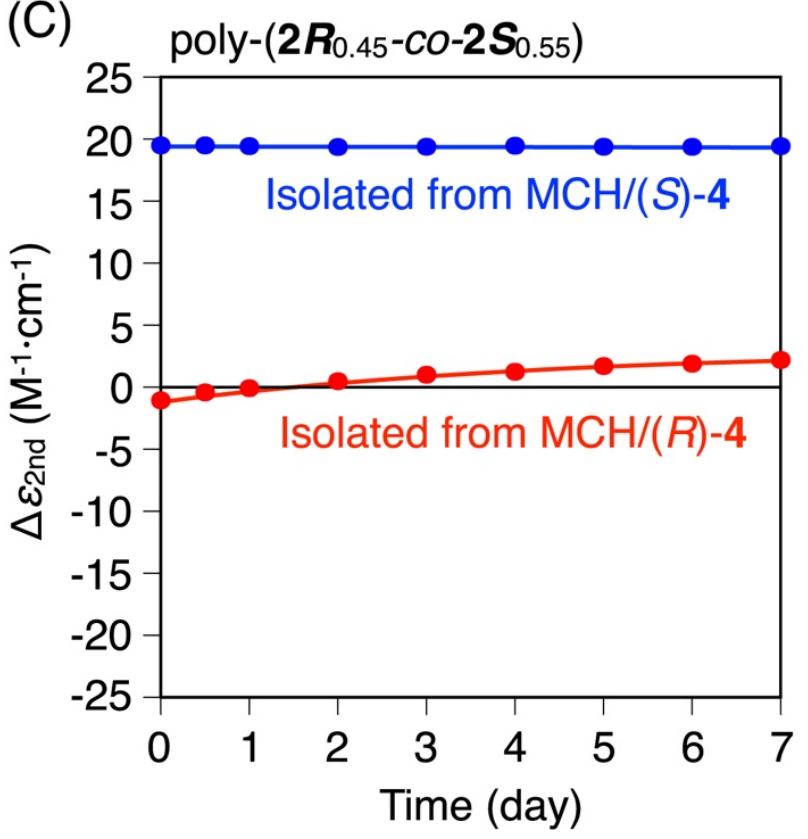

(B)

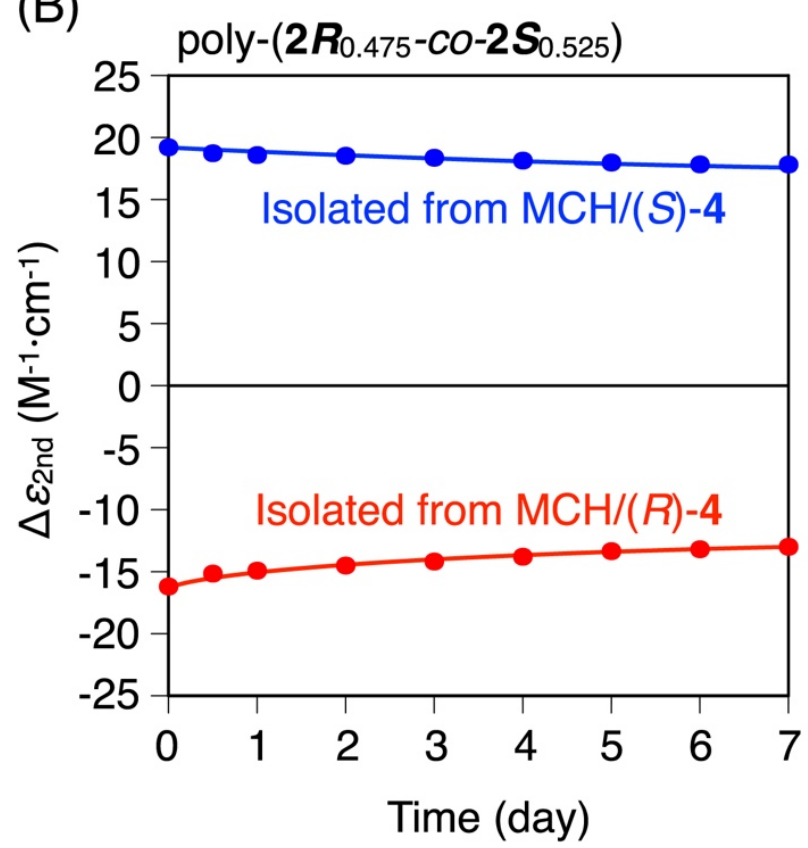

(D)

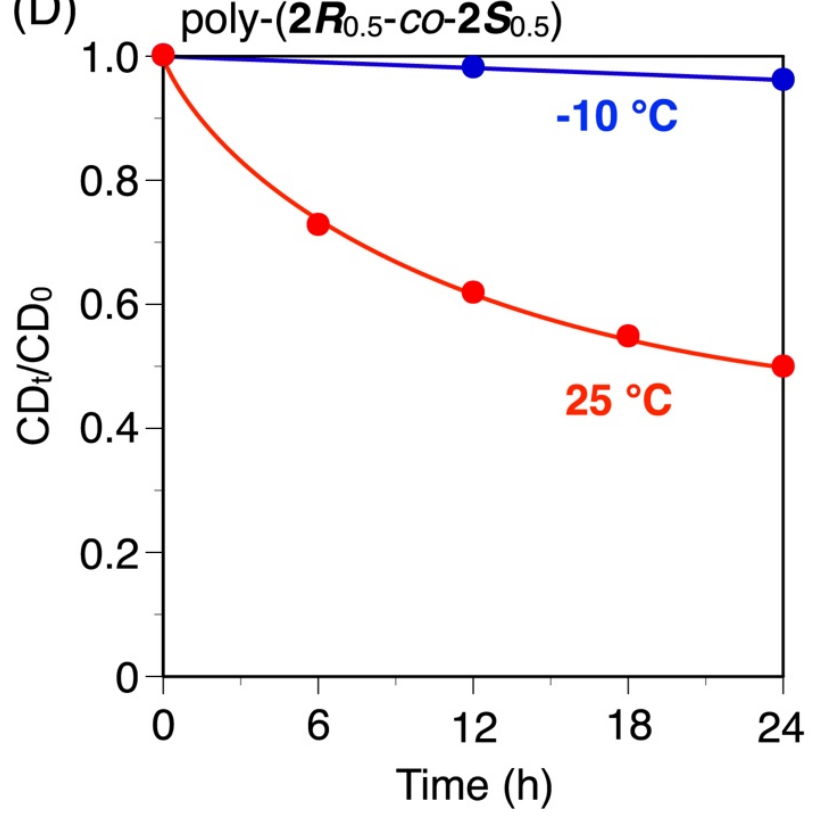

Figure S25. Time-dependent ICD intensity $\left(\Delta \varepsilon_{2 n d}\right.$ at $\left.380 \mathrm{~nm}\right)$ changes of the isolated poly- $\left(\mathbf{2} \boldsymbol{R}_{0.5}-c o-\right.$

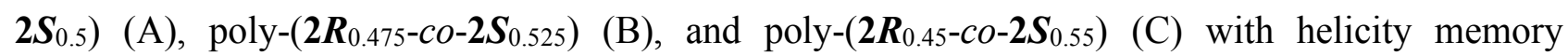
obtained from MCH/(S)-4 (80/20, v/v) and MCH/(R)-4 (80/20, v/v) in $\mathrm{MCH}$ at $-10{ }^{\circ} \mathrm{C}$. Plots of ICD intensity changes $\left(\mathrm{CD}_{t} / \mathrm{CD}_{0}\right)$ of the isolated poly- $\left(2 \boldsymbol{R}_{0.5}-\mathrm{co}-\mathbf{2} \boldsymbol{S}_{0.5}\right)$ in $\mathrm{MCH}$ at $-10{ }^{\circ} \mathrm{C}$ and $25{ }^{\circ} \mathrm{C}$ (D). The ICD intensity changes at $380 \mathrm{~nm}$ were directly followed at each temperature. $\mathrm{CD}_{0}$ represents the initial ICD intensity of the isolated poly- $\left(2 \boldsymbol{R}_{0.5}-\mathrm{Co}-\mathbf{2} \boldsymbol{S}_{0.5}\right)$ at $380 \mathrm{~nm}$ in $\mathrm{MCH}$ at each temperature. $[$ Polymer $]=1.0 \mathrm{mM}$. 


\section{A Enhancement, inversion, and memory of the macromolecular helicity}

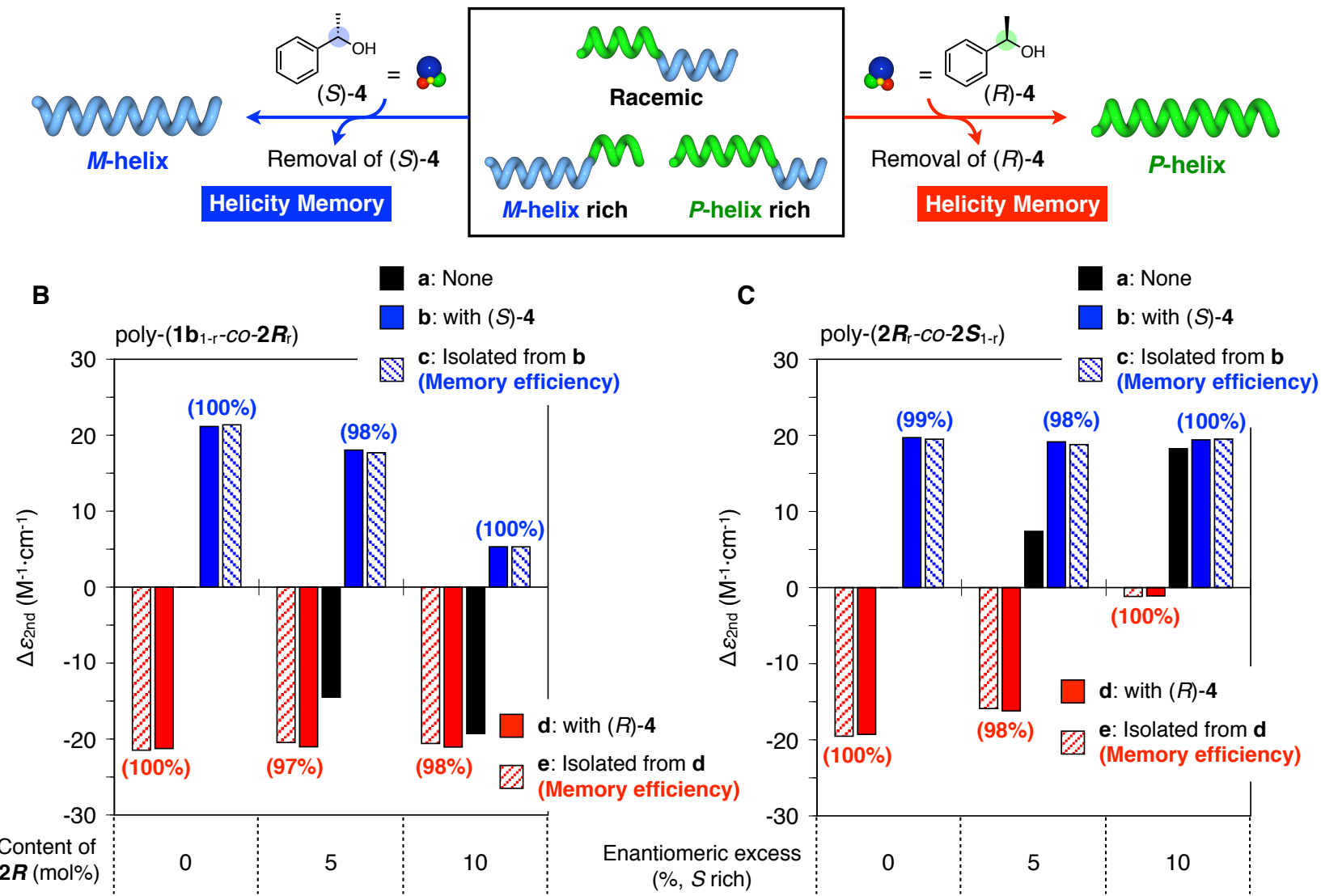

Figure S26. (A) Schematic illustration of helix-sense excess enhancement and inversion of the helicity of poly- $\left(\mathbf{1} \mathbf{b}_{1-\mathrm{r}}-c o-2 \boldsymbol{R}_{\mathrm{r}}\right)$ and poly-(2 $\left.\boldsymbol{R}_{\mathrm{r}}-c o-2 S_{1-\mathrm{r}}\right)$ through noncovalent interactions with a chiral alcohol $((S)$ - or $(R)-4)$ and subsequent memory of the helicity. (B and C) ICD intensity $\left(\Delta \varepsilon_{2 \text { nd }}\right.$ at 380 $\mathrm{nm})$ changes of poly- $\left(\mathbf{1} \mathrm{b}_{1-\mathrm{r}}-c o-\mathbf{2} \boldsymbol{R}_{\mathrm{r}}\right)(\mathrm{r} \leq 20)$ and poly- $\left(\mathbf{2} \boldsymbol{R}_{\mathrm{r}}-c o-\mathbf{2} \boldsymbol{S}_{1-\mathrm{r}}\right)(\% \mathrm{ee}<20)$ versus the content of $\mathbf{2 R}(\mathrm{B})$ and \%ee of $\mathbf{2}(S$ rich) $(\mathrm{C})$, respectively, before (a) and after interactions with $(S)$ - (b) and $(R)$ 4 (d) in $\mathrm{MCH}(\mathrm{MCH} / 4=80 / 20, \mathrm{v} / \mathrm{v})$ at $25^{\circ} \mathrm{C}$ for 5 days, followed by memory of the helicity (c and e) after removal of 4. The $\mathrm{CD}$ intensities were measured in $\mathrm{MCH}$ at $-10^{\circ} \mathrm{C}$. [Polymer] $=1.0 \mathrm{mM}$; [4] $=1.65 \mathrm{M}$. Memory efficiencies (\%) were estimated based on the ICD values $\left(\Delta \varepsilon_{2 \mathrm{nd}}\right.$ at $\left.380 \mathrm{~nm}\right)$ of the isolated polymers measured in $\mathrm{MCH}$ at $-10{ }^{\circ} \mathrm{C}$ (c and e). The ICD values of the polymers in the presence of $(R)$ - and $(S)-4$ in $\mathrm{MCH}(\mathrm{MCH} / 4=80 / 20, \mathrm{v} / \mathrm{v})$ at $-10{ }^{\circ} \mathrm{C}$ after standing at $25^{\circ} \mathrm{C}$ for 5 days ( $b$ and $d$ ) were used as the base values. 


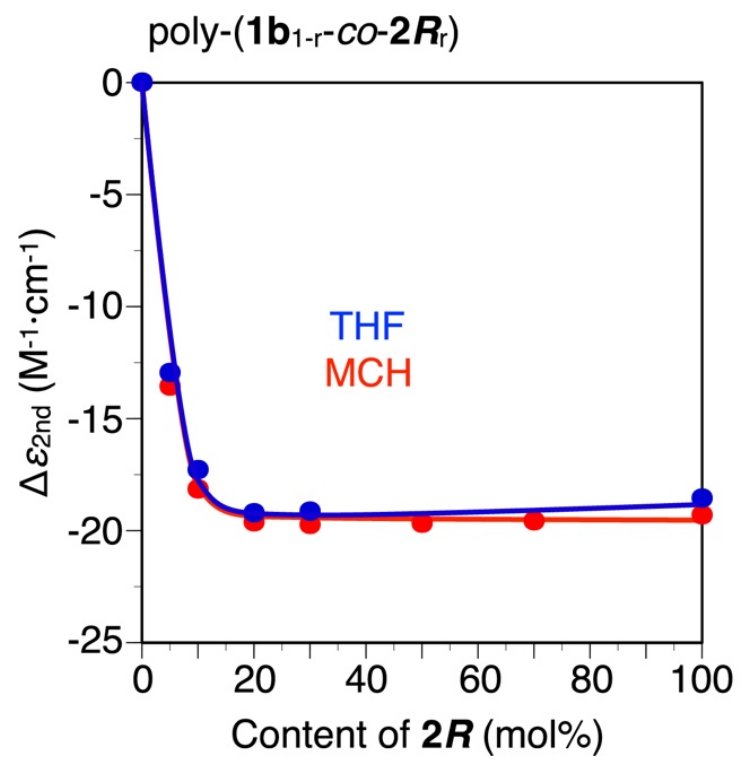

Figure S27. Plots of ICD intensity $\left(\Delta \varepsilon_{2 n d}\right.$ at $\left.380 \mathrm{~nm}\right)$ of poly- $\left(\mathbf{1 b}_{1-\mathrm{r}}-c o-\mathbf{2} \boldsymbol{R}_{\mathrm{r}}\right)$ in THF and MCH versus the content of $\mathbf{2} \boldsymbol{R}$. [Polymer] $=1.0 \mathrm{mM}$.

\section{Supporting References}

(1) Ishidate, R.; Shimomura, K.; Ikai, T.; Kanoh, S.; Maeda, K. Macromolecular Helicity Induction and Memory in a Poly(biphenylylacetylene) Bearing an Ester Group and Its Application to a Chiral Stationary Phase for High-Performance Liquid Chromatography. Chem. Lett. 2015, 44, 946-948.

(2) Ishidate, R.; Ikai, T.; Kanoh, S.; Yashima, E.; Maeda, K. Chromatographic Enantioseparation by Poly(biphenylylacetylene) Derivatives with Memory of Both Axial Chirality and Macromolecular Helicity. Chirality 2017, 29, 120-129.

(3) Tahara, K.; Yamaga, H.; Ghijsens, E.; Inukai, K.; Adisoejoso, J.; Blunt, M. O.; De Feyter, S.; Tobe, Y. Control and Induction of Surface-Confined Homochiral Porous Molecular Networks. Nat. Chem. 2011, 3, 714-719.

(4) Shimomura, K.; Ikai, T.; Kanoh, S.; Yashima, E.; Maeda, K. Switchable Enantioseparation Based on Macromolecular Memory of a Helical Polyacetylene in the Solid State. Nat. Chem. 2014, 6, 429-434.

(5) (a) Simionescu, C. I.; Percec, V.; Dumitrescu, S. Polymerization of Acetylenic Derivatives. XXX. Isomers of Polyphenylacetylene. J. Polym. Sci., Part A: Polym. Chem. 1977, 15, 2497-2509. (b) Furlani, A.; Napoletano, C.; Russo, M. V.; Feast, W. J. Stereoregular Polyphenylacetylene. Polym. Bull. 1986, 16, 311-317. (c) Kishimoto, Y.; Eckerle, P.; Miyatake, T.; Kainosho, M.; Ono, A.; Ikariya, T.; Noyori, R. Well-Controlled Polymerization of Phenylacetylenes with Organorhodium(I) Complexes: Mechanism and Structure of the Polyenes. J. Am. Chem. Soc. 
1999, 121, 12035-12044. (d) Percec, V.; Rudick, J. G.; Peterca, M.; Wagner, M.; Obata, M.; Mitchell, C. M.; Cho, W. D.; Balagurusamy, V. S. K.; Heiney, P. A. Thermoreversible CisCisoidal to Cis-Transoidal Isomerization of Helical Dendronized Polyphenylacetylenes. J. Am. Chem. Soc. 2005, 127, 15257-15264. (e) Nagai, K.; Sakajiri, K.; Maeda, K.; Okoshi, K.; Sato, T.; Yashima, E. Hierarchical Amplification of Macromolecular Helicity in a Lyotropic Liquid Crystalline Charged Poly(phenylacetylene) by Nonracemic Dopants in Water and Its Helical Structure. Macromolecules 2006, 39, 5371-5380.

(6) (a) Shirakawa, H.; Ito, T.; Ikeda, S. Raman-Scattering and Electronic-Spectra of Poly(acetylene). Polym. J. 1973, 4, 460-462. (b) Tabata, M.; Tanaka, Y.; Sadahiro, Y.; Sone, T.; Yokota, K.; Miura, I. Pressure-Induced Cis to Trans Isomerization of Aromatic Polyacetylenes. 2. Poly $((o-$ ethoxyphenyl)acetylene) Stereoregularly Polymerized Using a Rh Complex Catalyst. Macromolecules 1997, 30, 5200-5204. (c) Ohsawa, S.; Sakurai, S.; Nagai, K.; Banno, M.; Maeda, K.; Kumaki, J.; Yashima, E. Hierarchical Amplification of Macromolecular Helicity of Dynamic Helical Poly(phenylacetylene)s Composed of Chiral and Achiral Phenylacetylenes in Dilute Solution, Liquid Crystal, and Two-Dimensional Crystal. J. Am. Chem. Soc. 2011, 133, 108-114.

(d) Tang, Z. L.; Iida, H.; Hu, H. Y.; Yashima, E. Remarkable Enhancement of the Enantioselectivity of an Organocatalyzed Asymmetric Henry Reaction Assisted by Helical Poly(phenylacetylene)s Bearing Cinchona Alkaloid Pendants via an Amide Linkage. ACS Macro Lett. 2012, 1, 261-265.

(7) Gu, H.; Sato, T.; Teramoto, A.; Varichon, L.; Green, M. M. Molecular Mechanisms for the Optical Activities of Polyisocyanates Induced by Intramolecular Chiral Perturbations. Polym. J. 1997, 29, $77-84$.

(8) Lifson, S.; Andreola, C.; Peterson, N. C.; Green, M. M. Macromolecular Stereochemistry: Helical Sense Preference in Optically Active Polyisocyanates. Amplification of a Conformational Equilibrium Deuterium Isotope Effect. J. Am. Chem. Soc. 1989, 111, 8850-8858.

(9) Newman, M. E. J.; Barkema, G. T. Monte Carlo Methods in Statistical Physics; Oxford University Press: Oxford, 1999. 


\section{9. ${ }^{1} \mathrm{H}$ and ${ }^{13} \mathrm{C}$ NMR Spectra of Monomers and Polymers}

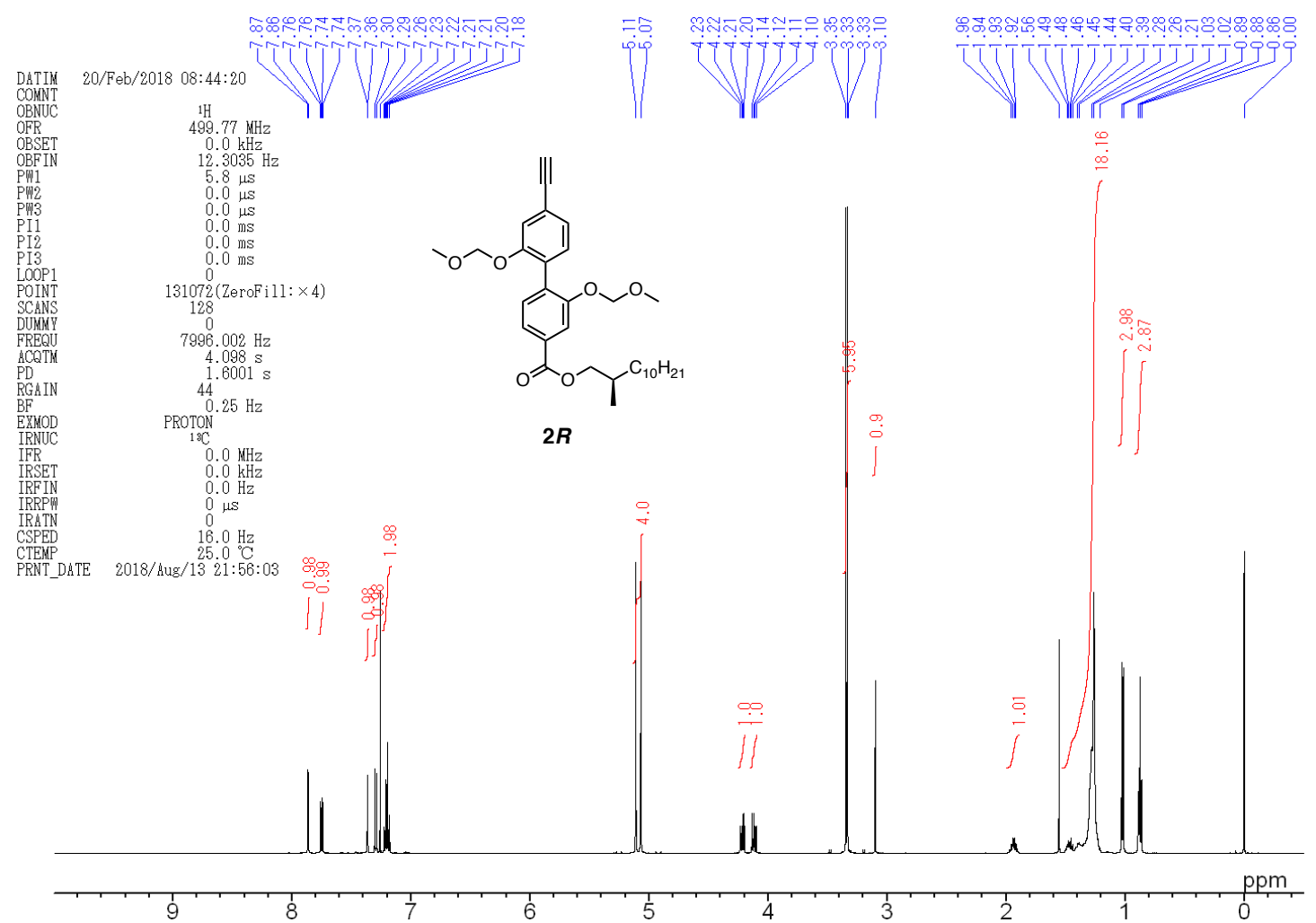

Figure S28. ${ }^{1} \mathrm{H}$ NMR spectrum of $\mathbf{2} \boldsymbol{R}$ in $\mathrm{CDCl}_{3}$ at $25{ }^{\circ} \mathrm{C}$.

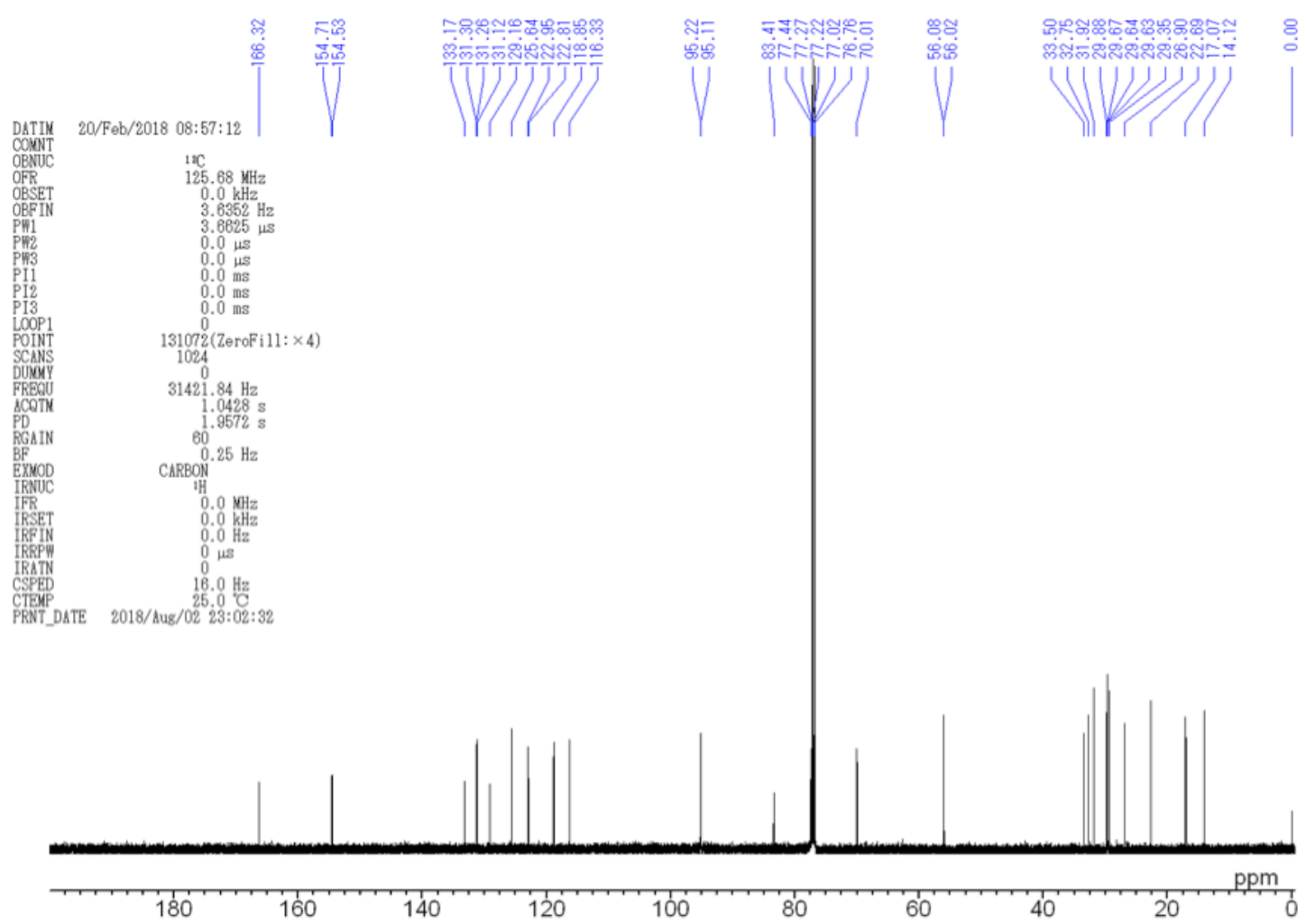

Figure S29. ${ }^{13} \mathrm{C}$ NMR spectrum of $\mathbf{2} \boldsymbol{R}$ in $\mathrm{CDCl}_{3}$ at $25{ }^{\circ} \mathrm{C}$. 


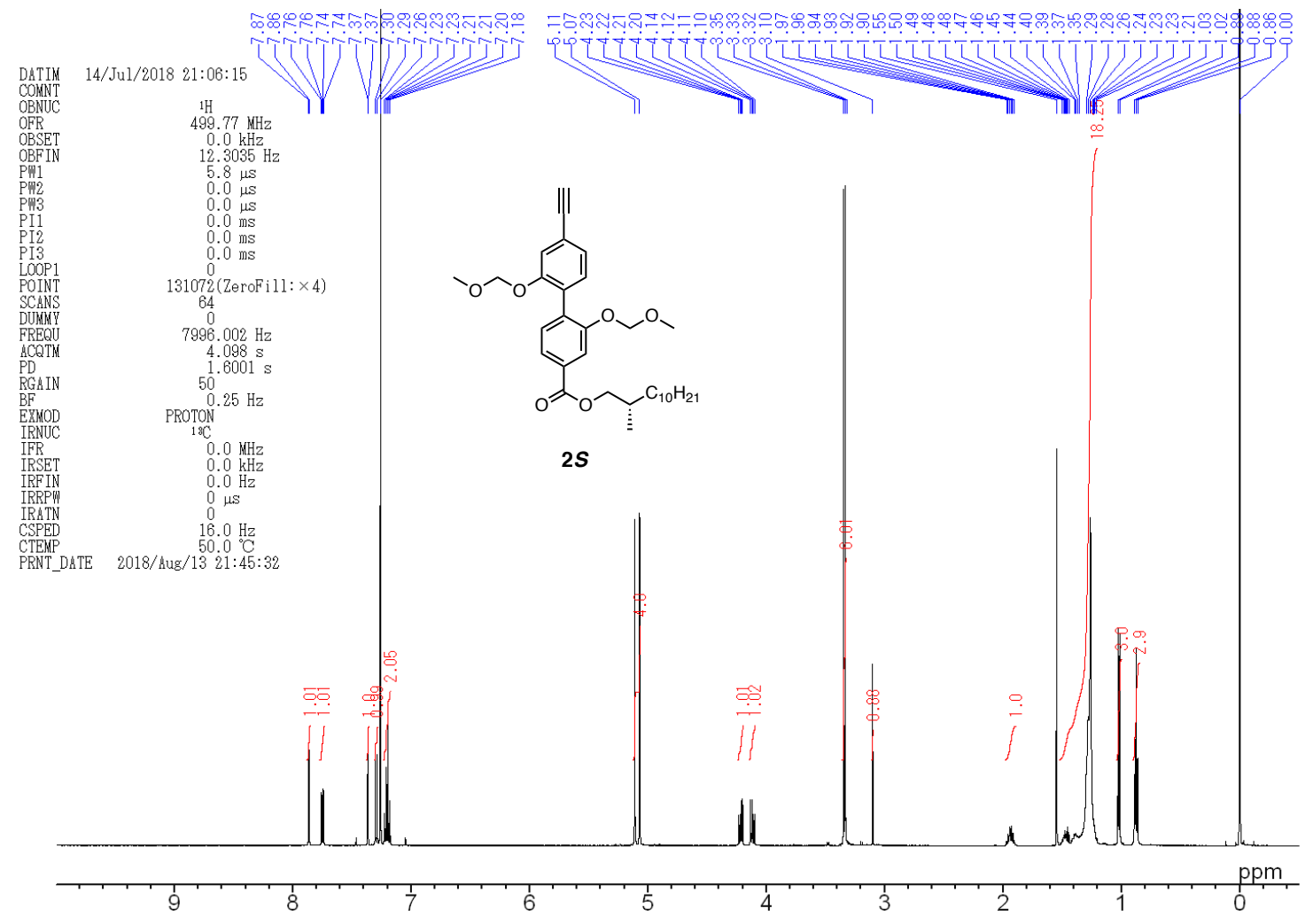

Figure S30. ${ }^{1} \mathrm{H}$ NMR spectrum of $2 S$ in $\mathrm{CDCl}_{3}$ at $25{ }^{\circ} \mathrm{C}$.

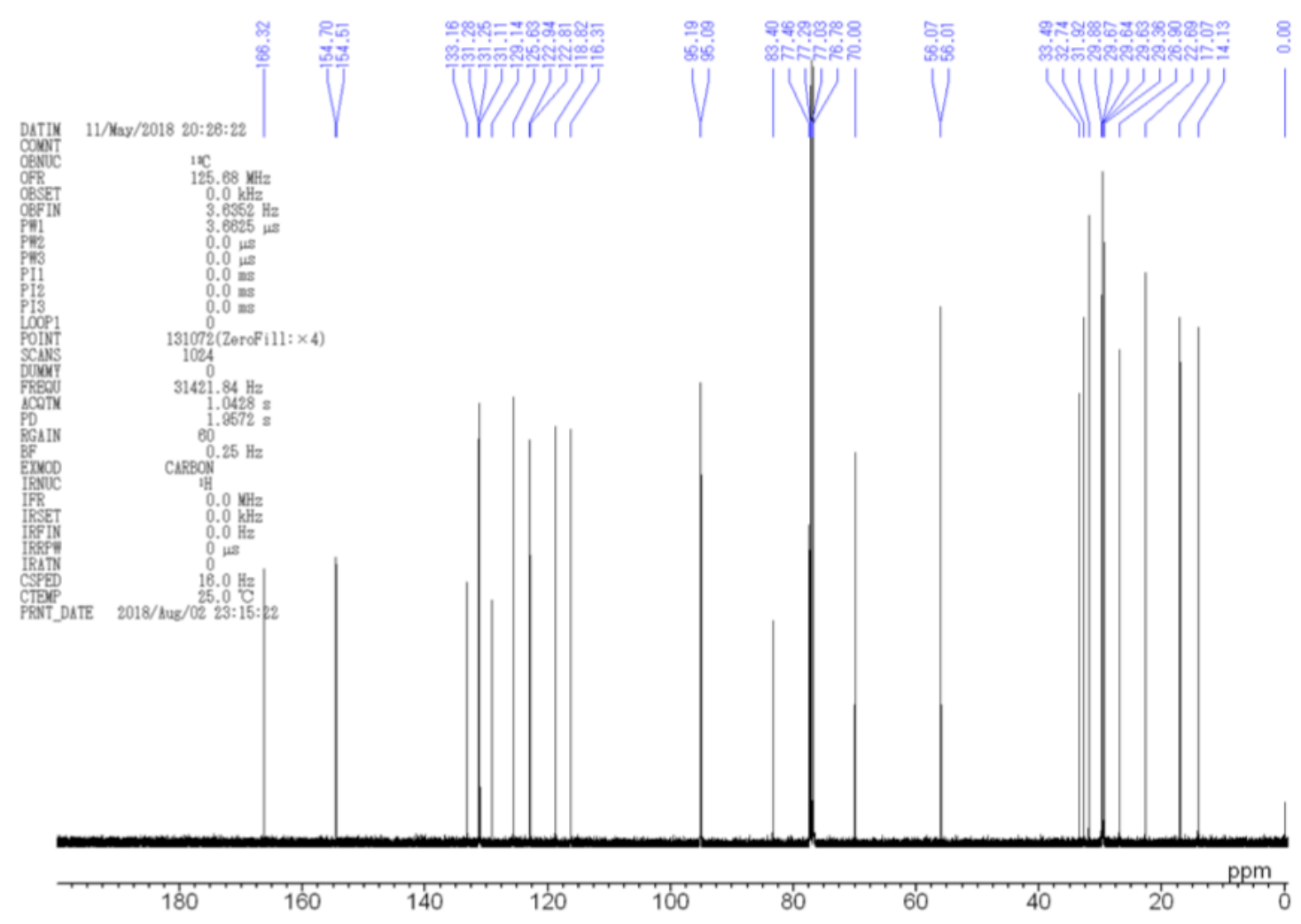

Figure S31. ${ }^{13} \mathrm{C}$ NMR spectrum of $2 \mathrm{~S}$ in $\mathrm{CDCl}_{3}$ at $25{ }^{\circ} \mathrm{C}$. 


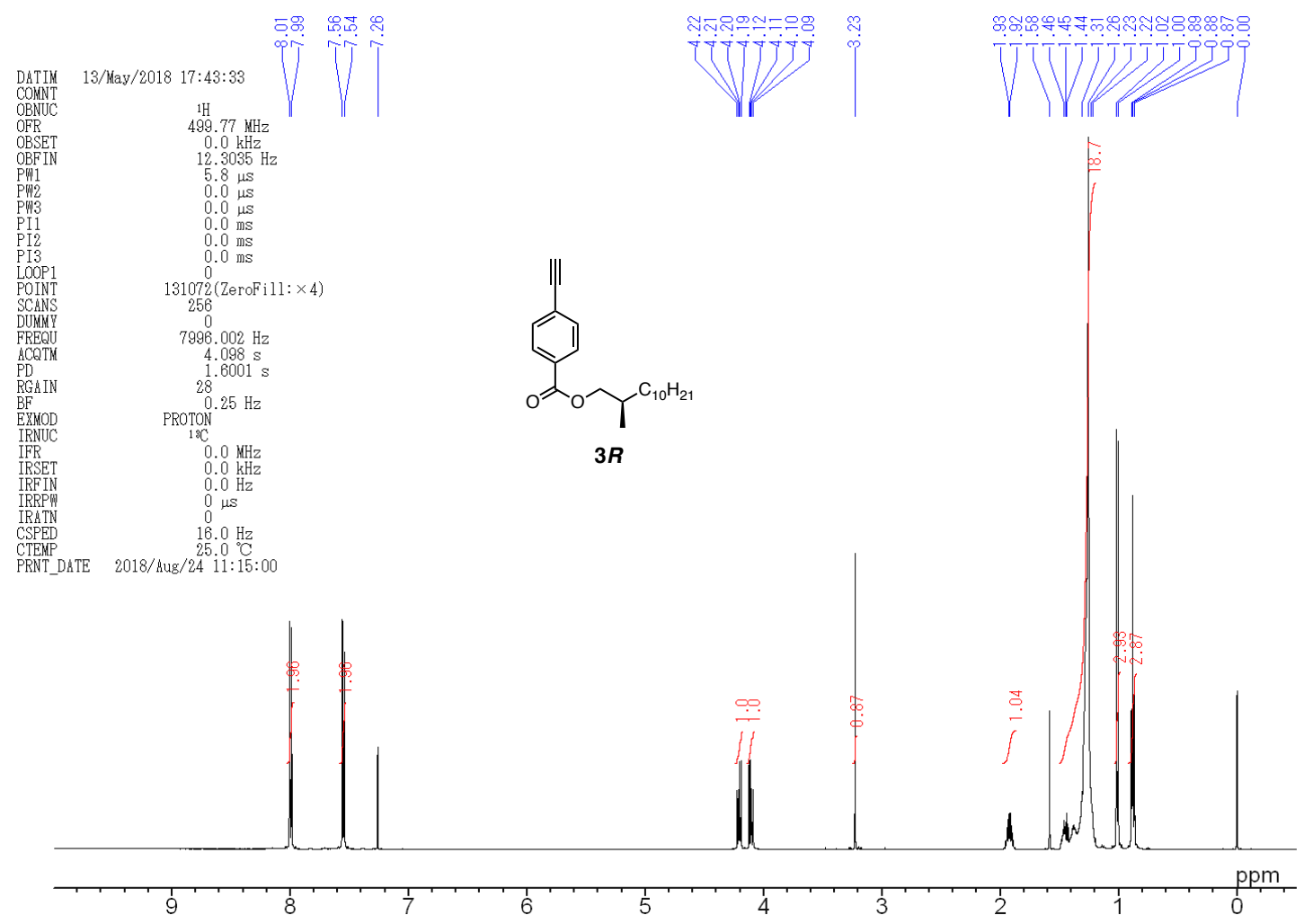

Figure S32. ${ }^{1} \mathrm{H}$ NMR spectrum of $\mathbf{3 R}$ in $\mathrm{CDCl}_{3}$ at $25{ }^{\circ} \mathrm{C}$.

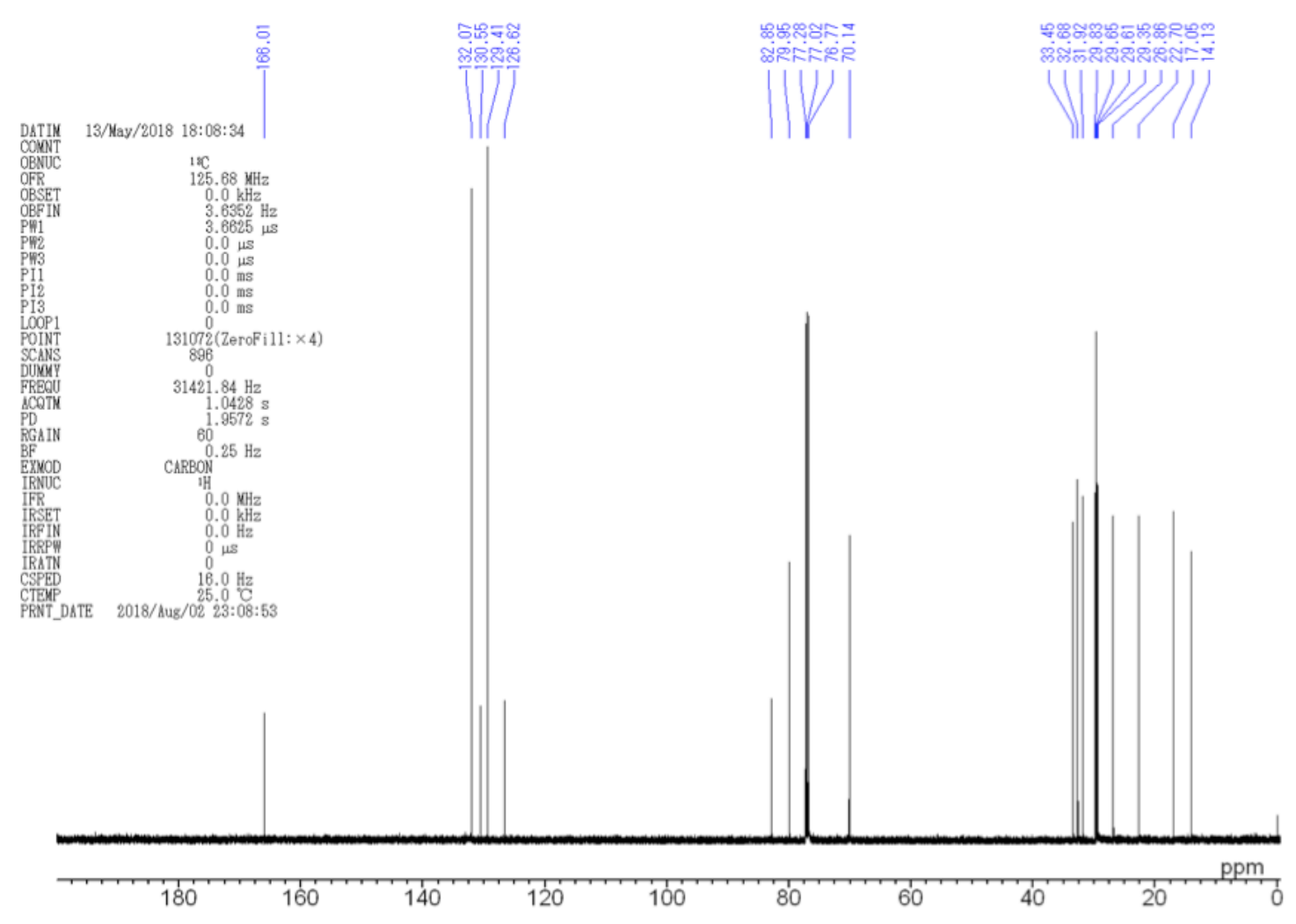

Figure S33. ${ }^{13} \mathrm{C}$ NMR spectrum of $\mathbf{3} \boldsymbol{R}$ in $\mathrm{CDCl}_{3}$ at $25{ }^{\circ} \mathrm{C}$. 


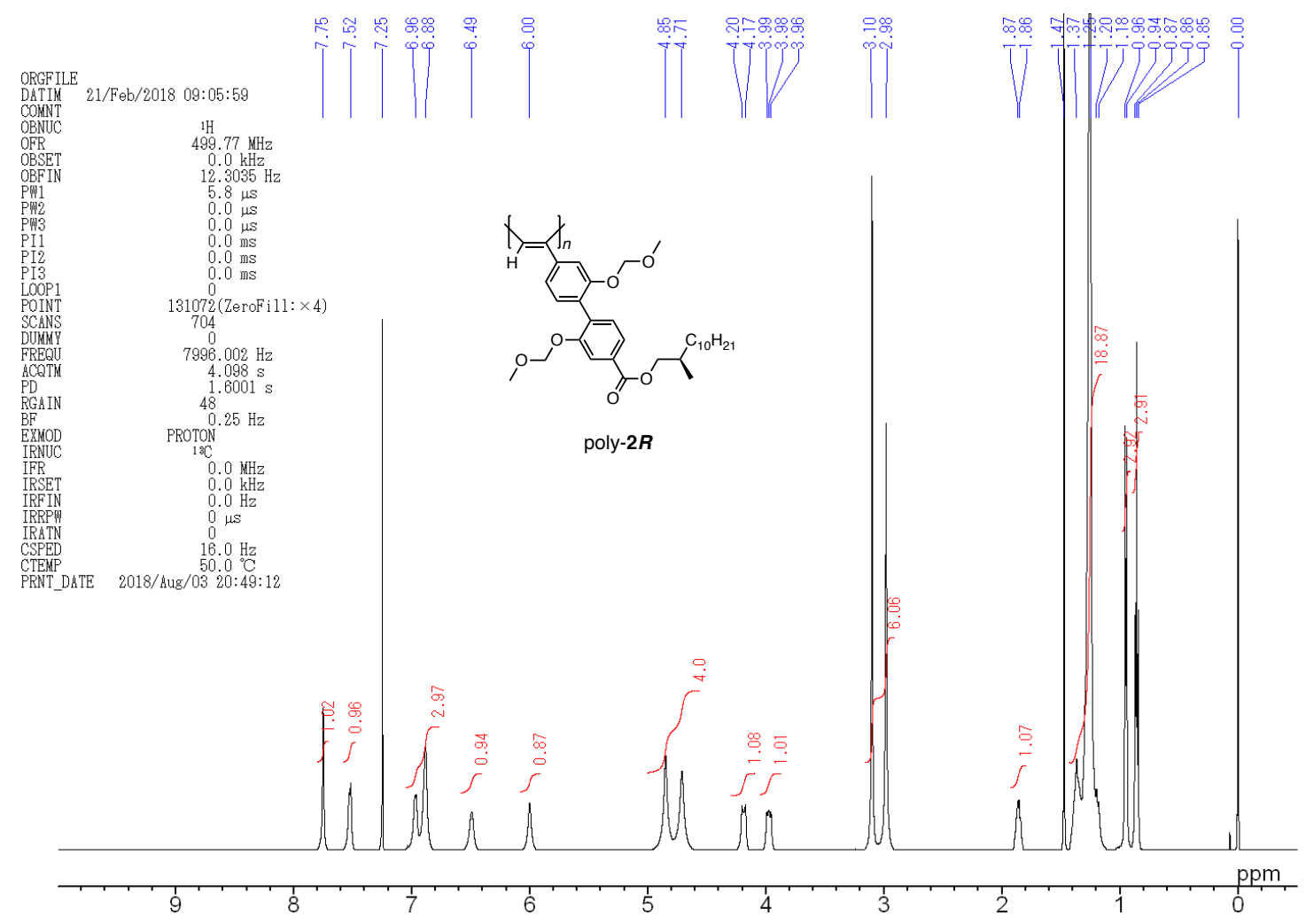

Figure S34. ${ }^{1} \mathrm{H}$ NMR spectrum of poly-2R in $\mathrm{CDCl}_{3}$ at $50{ }^{\circ} \mathrm{C}$.

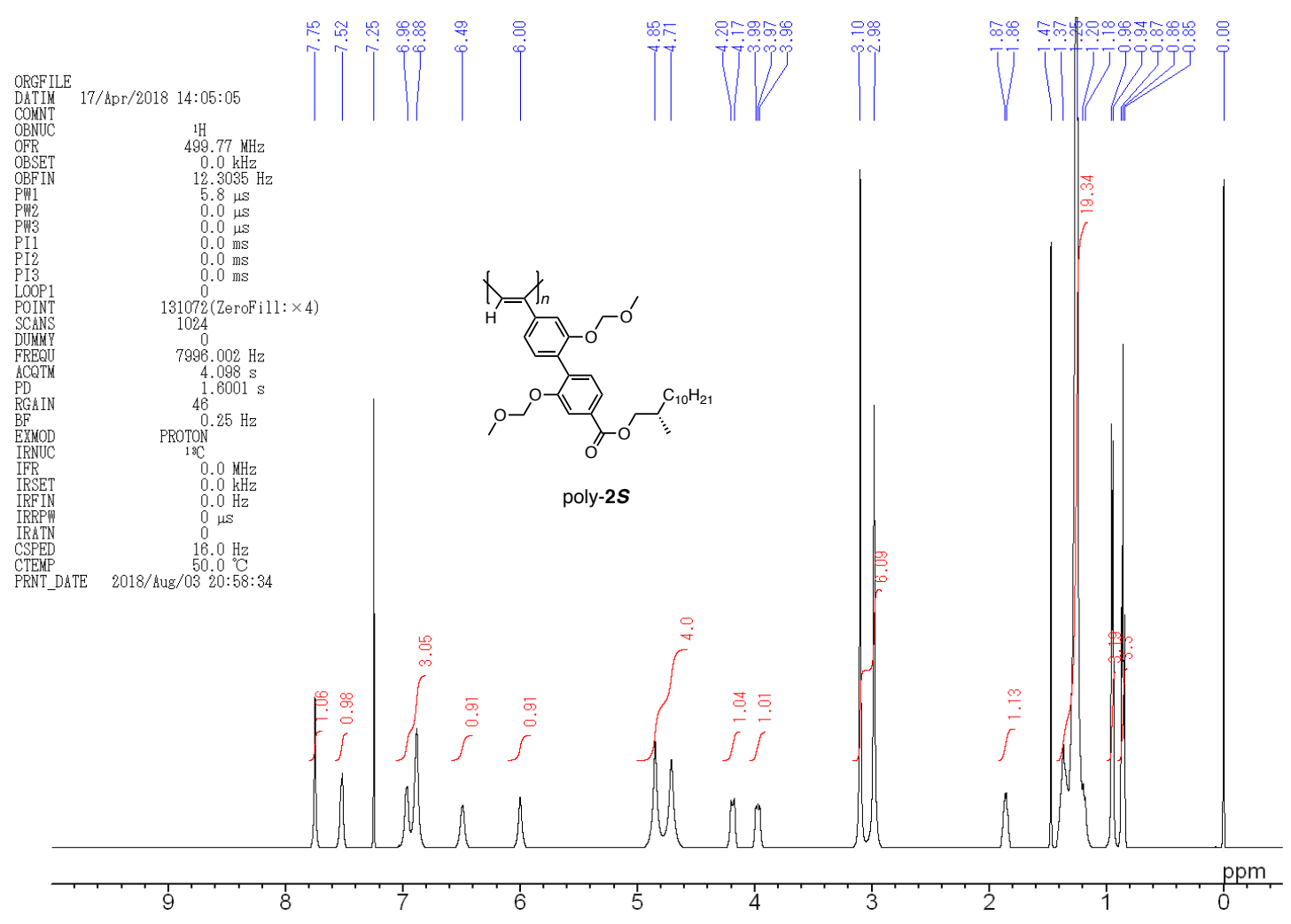

Figure S35. ${ }^{1} \mathrm{H}$ NMR spectrum of poly-2S in $\mathrm{CDCl}_{3}$ at $50{ }^{\circ} \mathrm{C}$. 


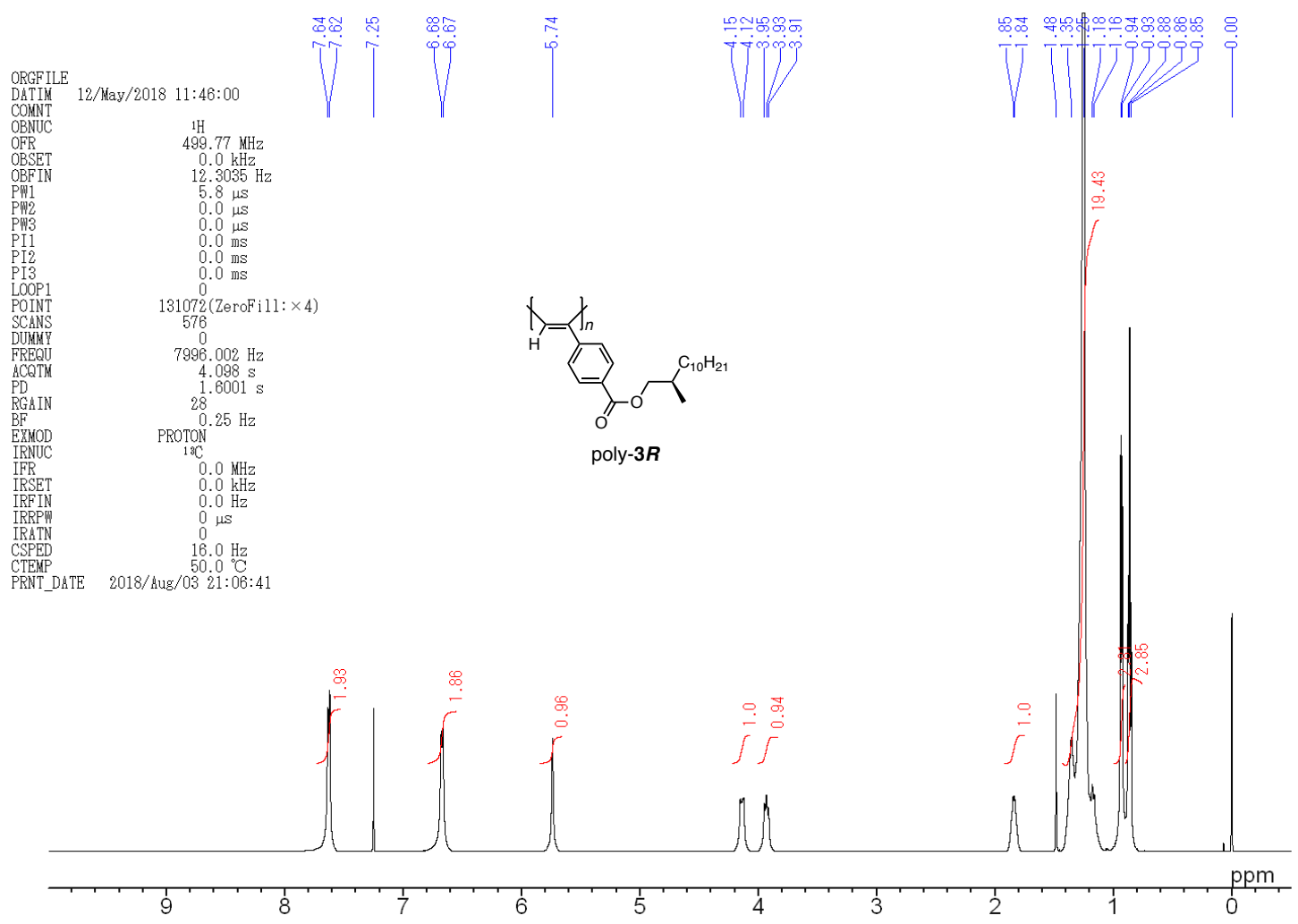

Figure S36. ${ }^{1} \mathrm{H}$ NMR spectrum of poly-3R in $\mathrm{CDCl}_{3}$ at $50{ }^{\circ} \mathrm{C}$.

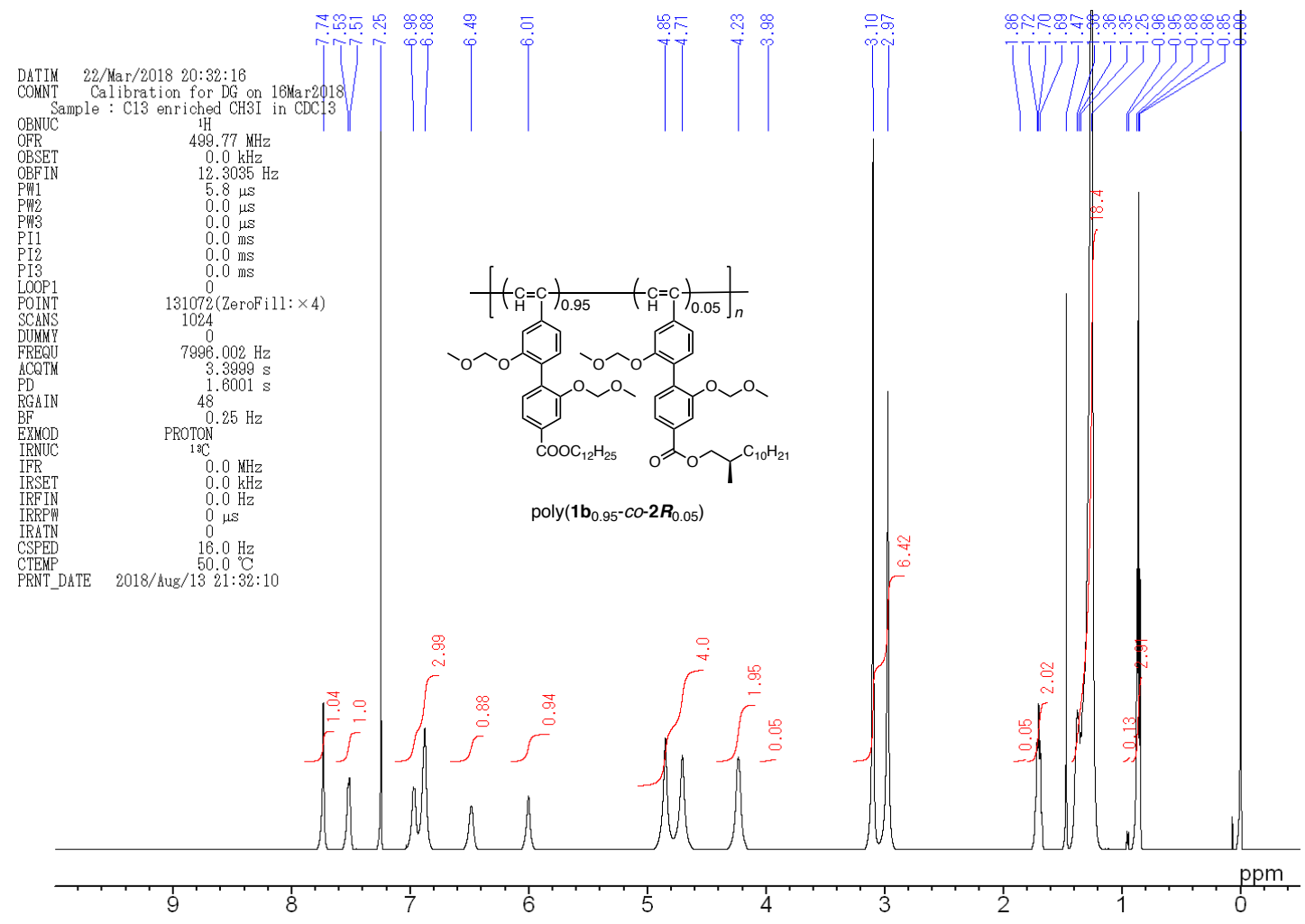

Figure S37. ${ }^{1} \mathrm{H}$ NMR spectrum of poly- $\left(\mathbf{1 b}_{0.95}-c o-2 \boldsymbol{R}_{0.05}\right)$ in $\mathrm{CDCl}_{3}$ at $50{ }^{\circ} \mathrm{C}$. 


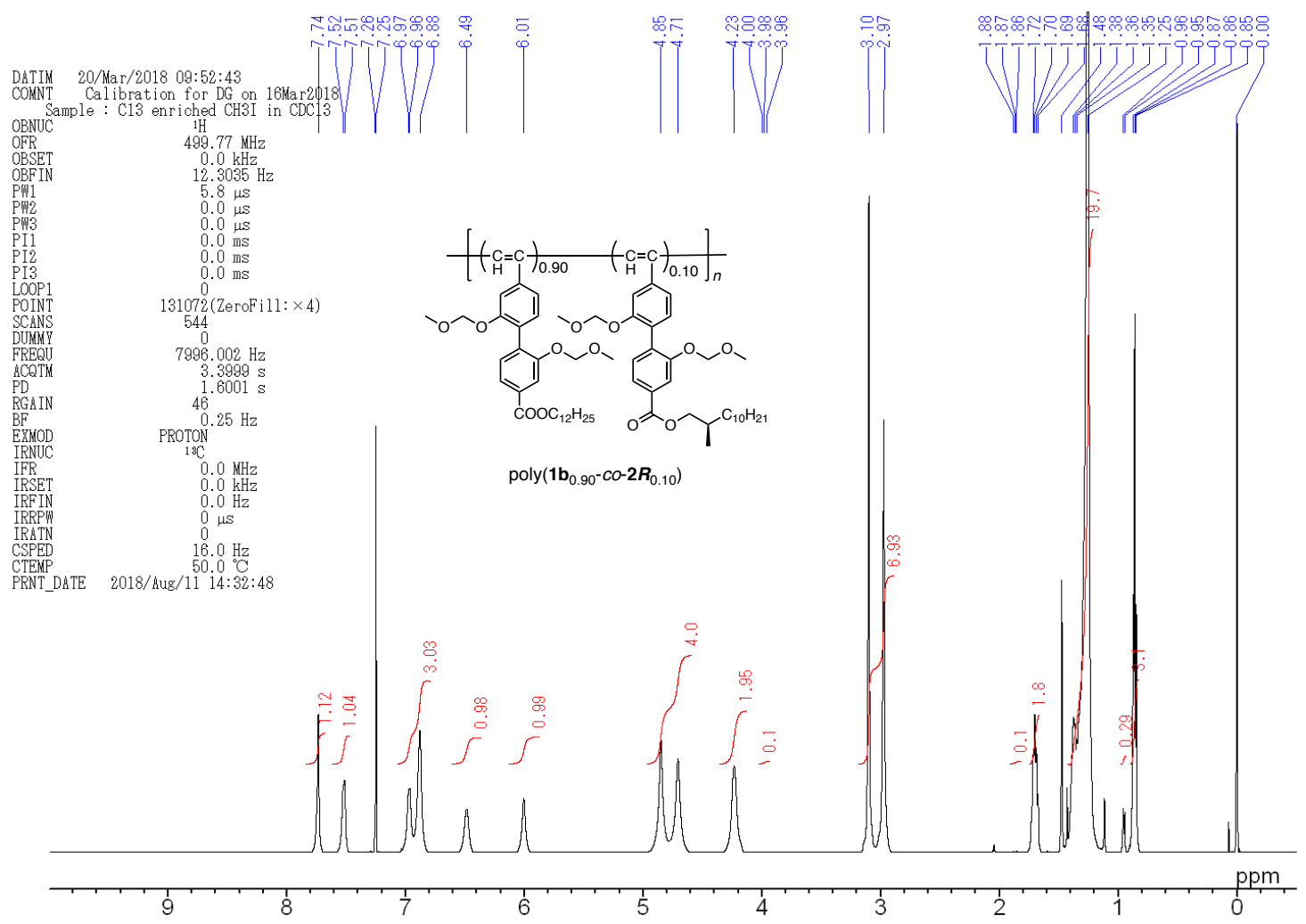

Figure S38. ${ }^{1} \mathrm{H}$ NMR spectrum of poly- $\left(\mathbf{1 b}_{0.90}-c o-\mathbf{2} \boldsymbol{R}_{0.10}\right)$ in $\mathrm{CDCl}_{3}$ at $50{ }^{\circ} \mathrm{C}$.

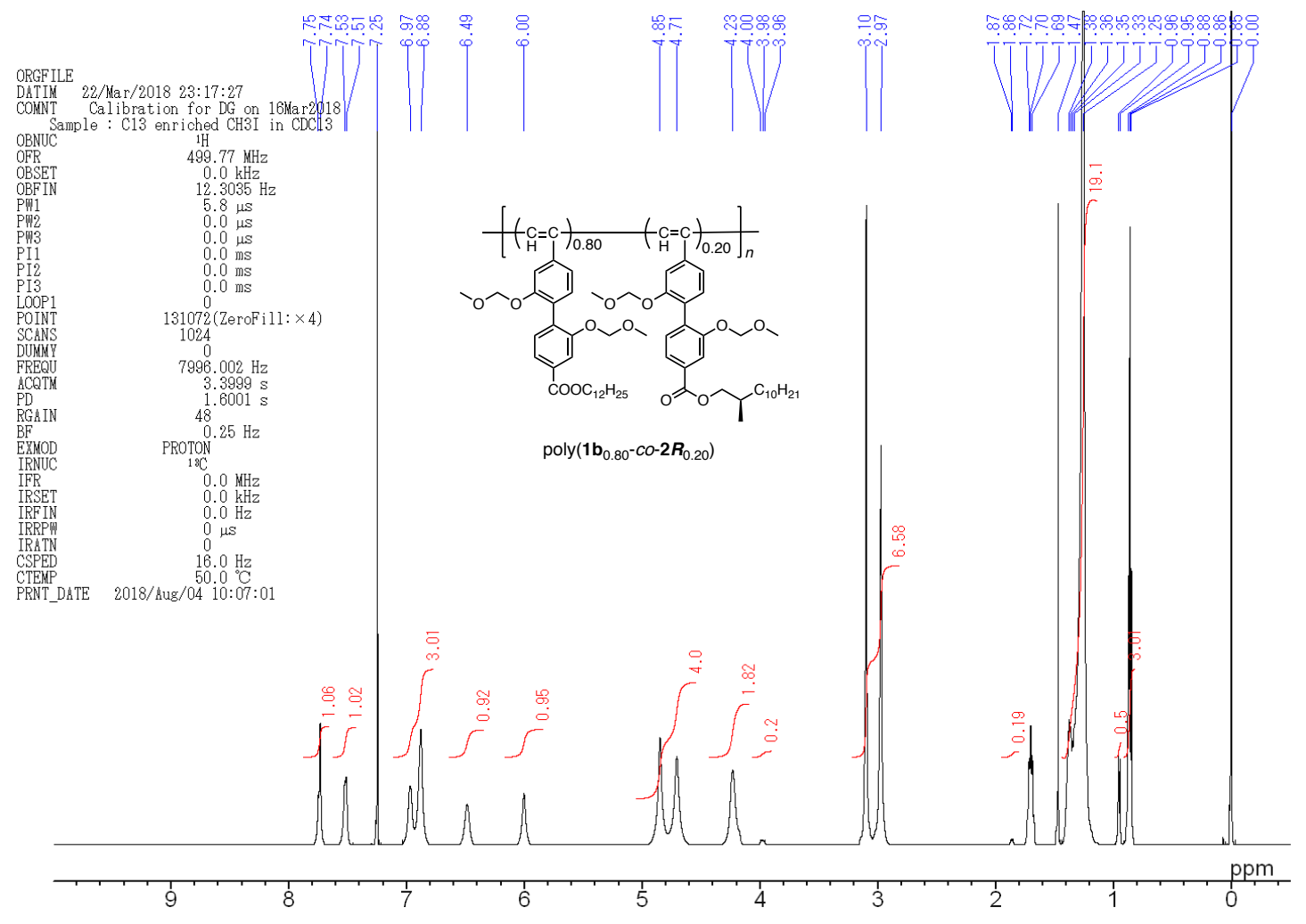

Figure S39. ${ }^{1} \mathrm{H}$ NMR spectrum of poly- $\left(\mathbf{1 b}_{0.80}-c o-2 \boldsymbol{R}_{0.20}\right)$ in $\mathrm{CDCl}_{3}$ at $50{ }^{\circ} \mathrm{C}$. 


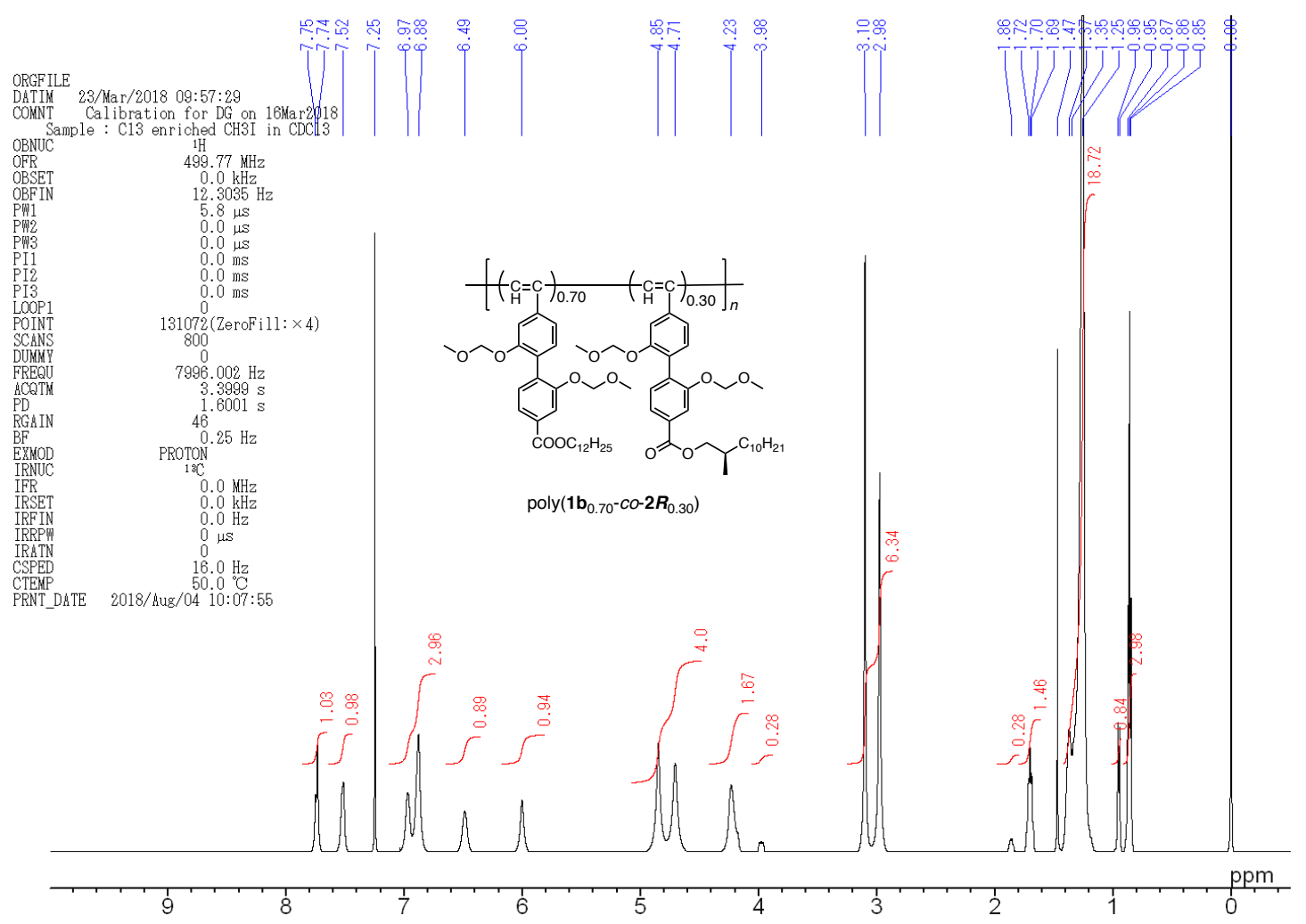

Figure S40. ${ }^{1} \mathrm{H}$ NMR spectrum of poly- $\left(\mathbf{1 b}_{0.70}-c o-\mathbf{2} \boldsymbol{R}_{0.30}\right)$ in $\mathrm{CDCl}_{3}$ at $50{ }^{\circ} \mathrm{C}$.

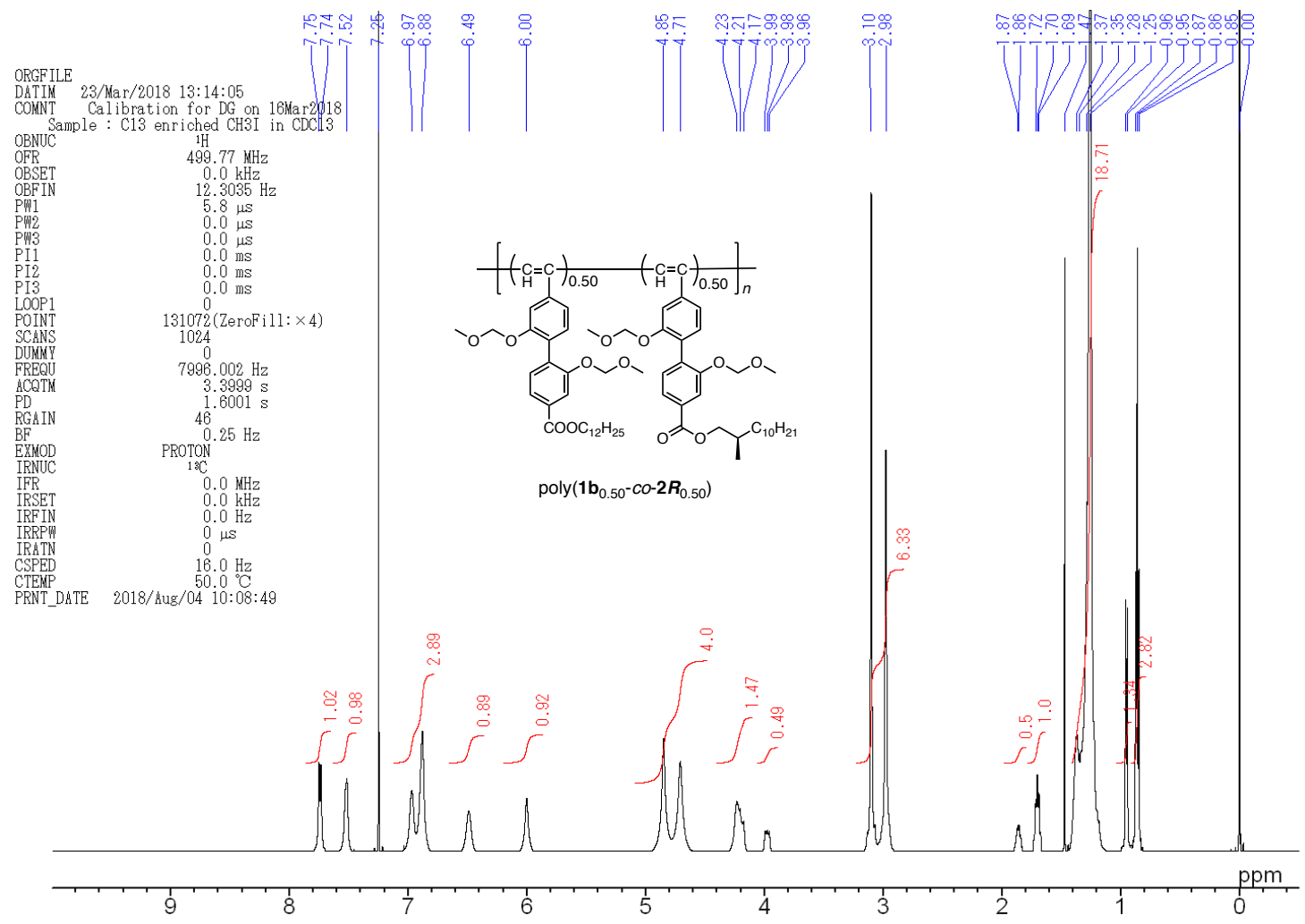

Figure S41. ${ }^{1} \mathrm{H}$ NMR spectrum of poly- $\left(\mathbf{1 b}_{0.50-c o-2} \boldsymbol{R}_{0.50}\right)$ in $\mathrm{CDCl}_{3}$ at $50{ }^{\circ} \mathrm{C}$. 


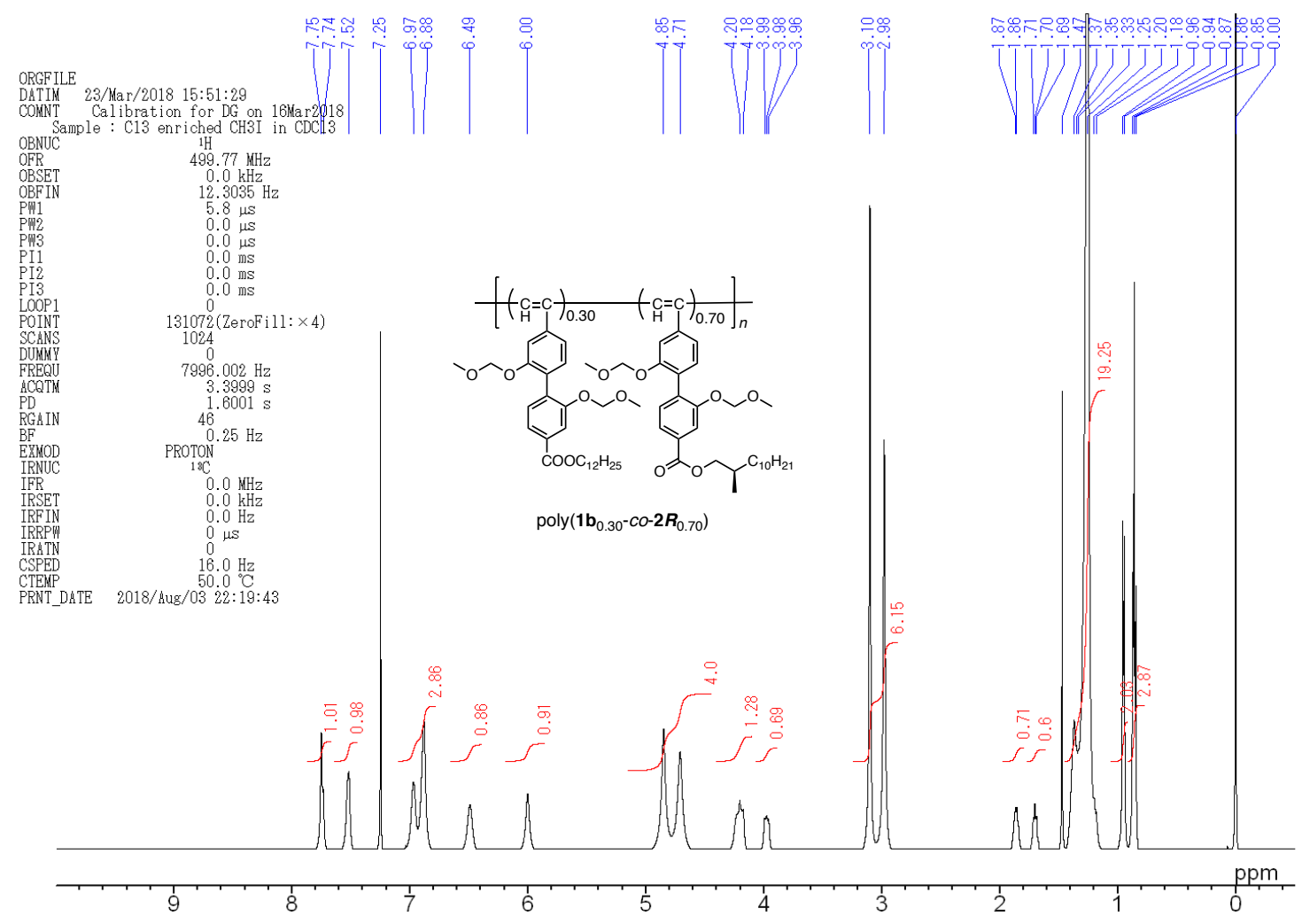

Figure S42. ${ }^{1} \mathrm{H}$ NMR spectrum of poly- $\left(\mathbf{1 b}_{0.30}-\mathrm{co}-\mathbf{2} \boldsymbol{R}_{0.70}\right)$ in $\mathrm{CDCl}_{3}$ at $50{ }^{\circ} \mathrm{C}$.

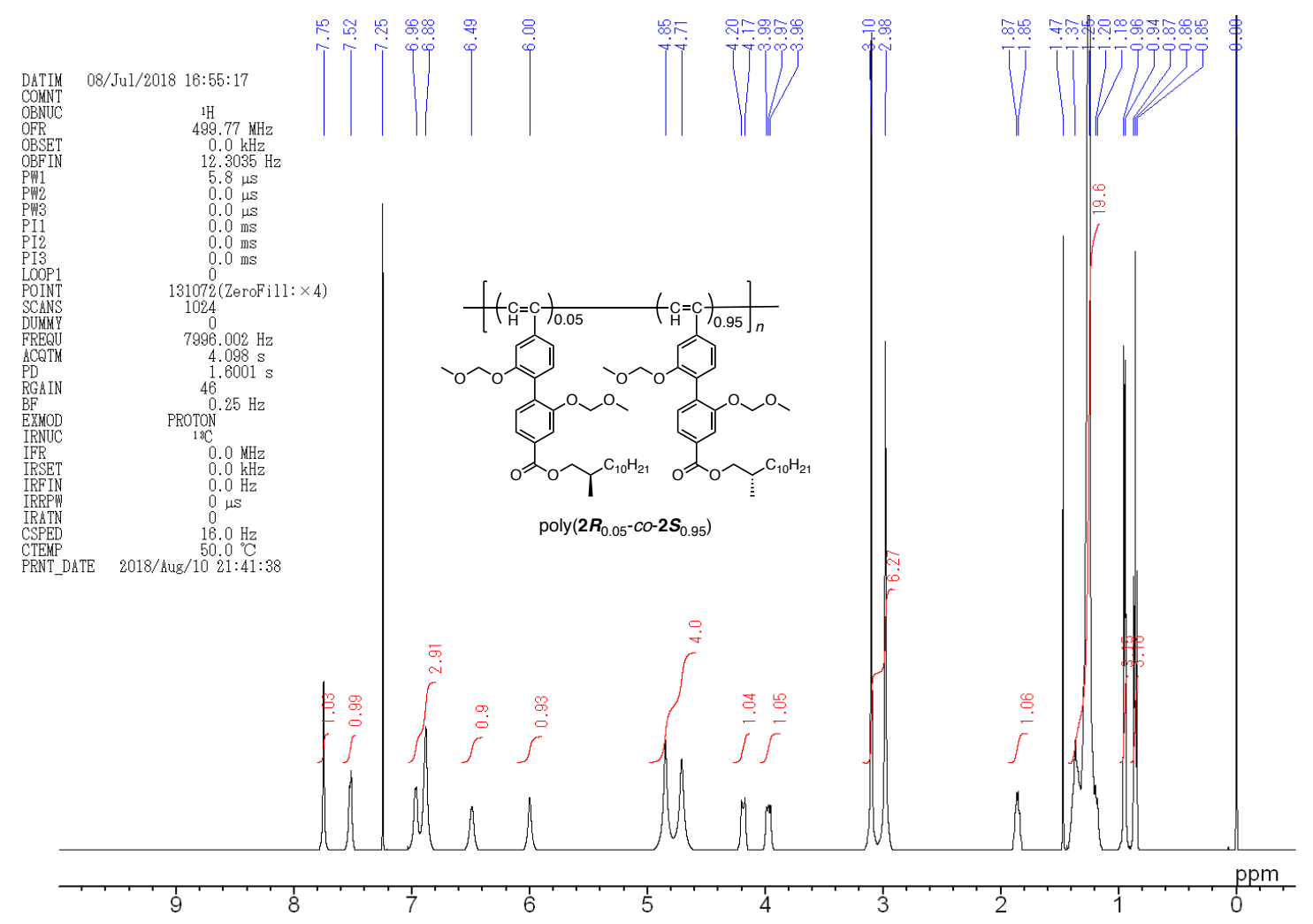

Figure S43. ${ }^{1} \mathrm{H}$ NMR spectrum of poly- $\left(2 \boldsymbol{R}_{0.05}-c o-\mathbf{2 S}_{0.95}\right)$ in $\mathrm{CDCl}_{3}$ at $50{ }^{\circ} \mathrm{C}$. 


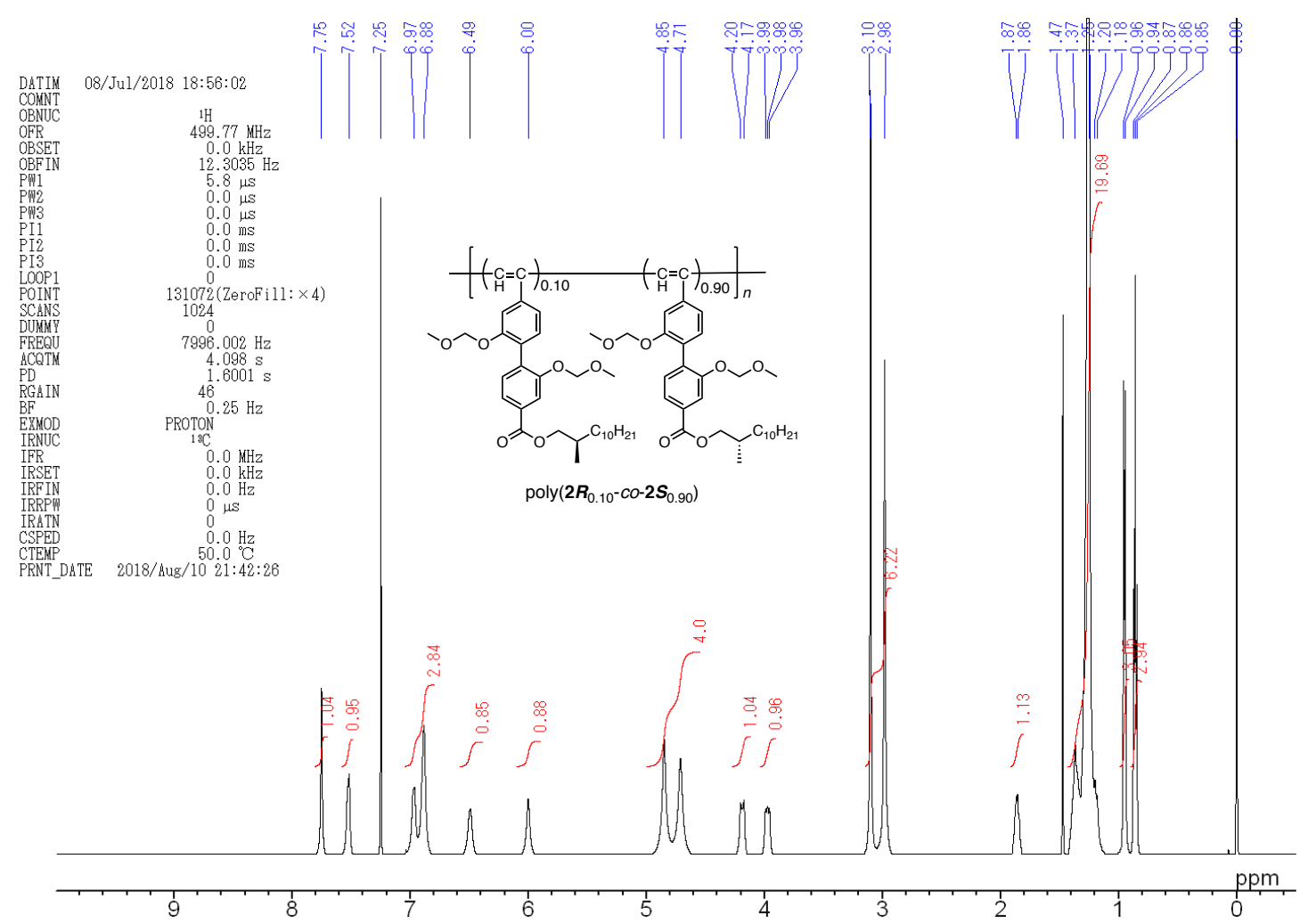

Figure S44. ${ }^{1} \mathrm{H}$ NMR spectrum of poly- $\left(2 \boldsymbol{R}_{0.10}-c o-2 \boldsymbol{S}_{0.90}\right)$ in $\mathrm{CDCl}_{3}$ at $50{ }^{\circ} \mathrm{C}$.

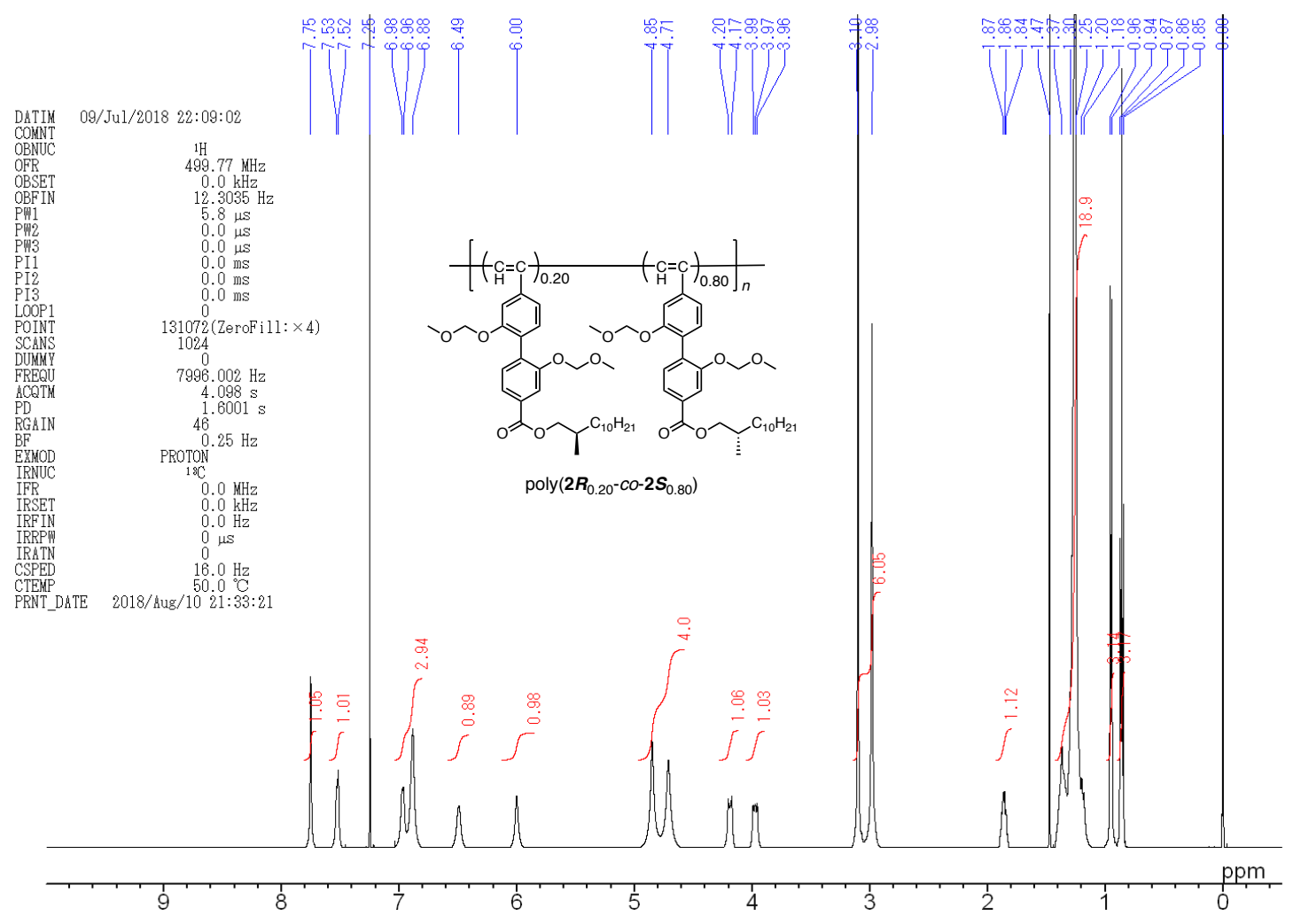

Figure S45. ${ }^{1} \mathrm{H}$ NMR spectrum of poly- $\left(2 \boldsymbol{R}_{0.20}-c o-2 \boldsymbol{S}_{0.80}\right)$ in $\mathrm{CDCl}_{3}$ at $50{ }^{\circ} \mathrm{C}$. 


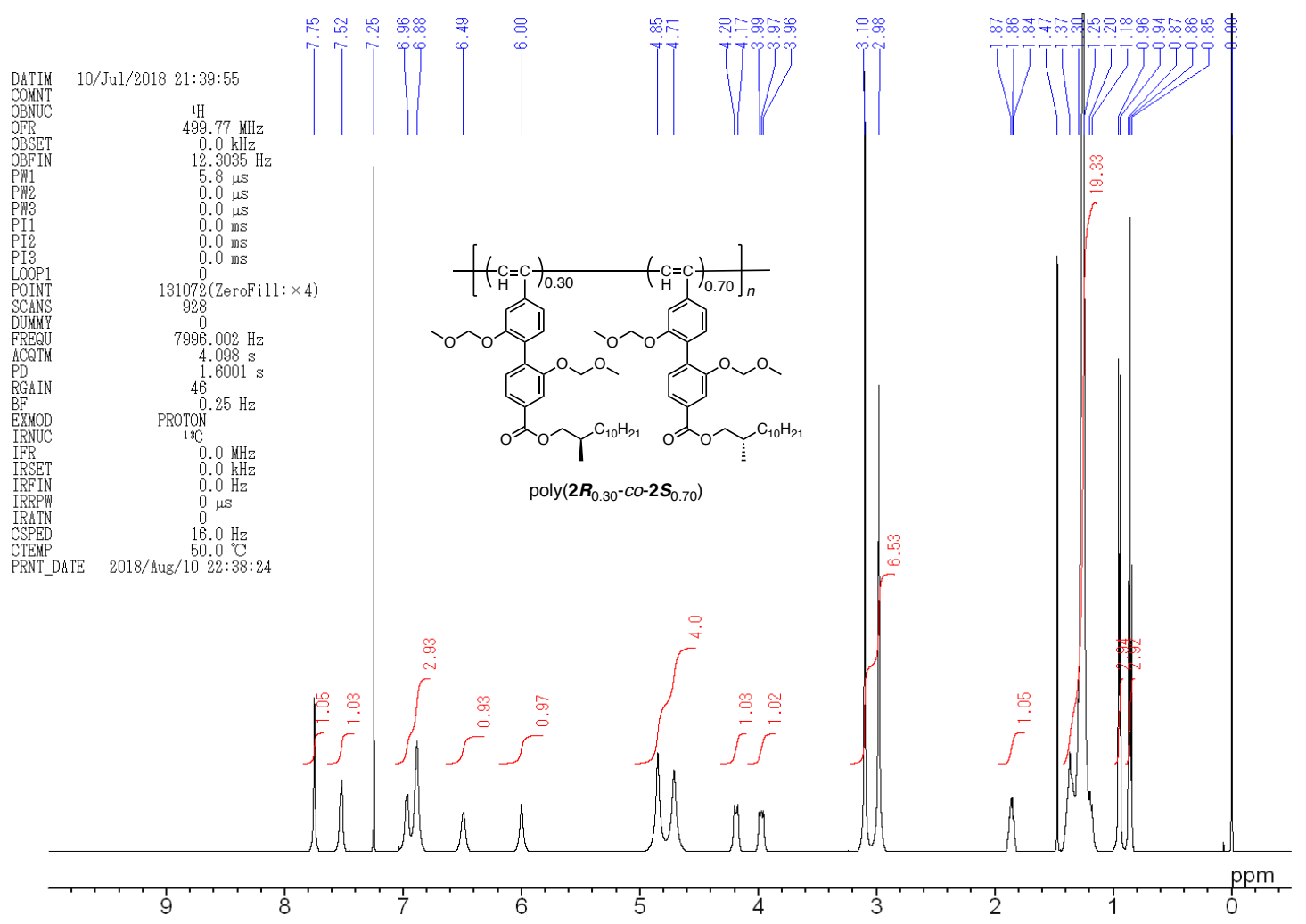

Figure S46. ${ }^{1} \mathrm{H}$ NMR spectrum of poly- $\left(2 \boldsymbol{R}_{0.30}-\mathrm{co}-\mathbf{2} \boldsymbol{S}_{0.70}\right)$ in $\mathrm{CDCl}_{3}$ at $50{ }^{\circ} \mathrm{C}$.

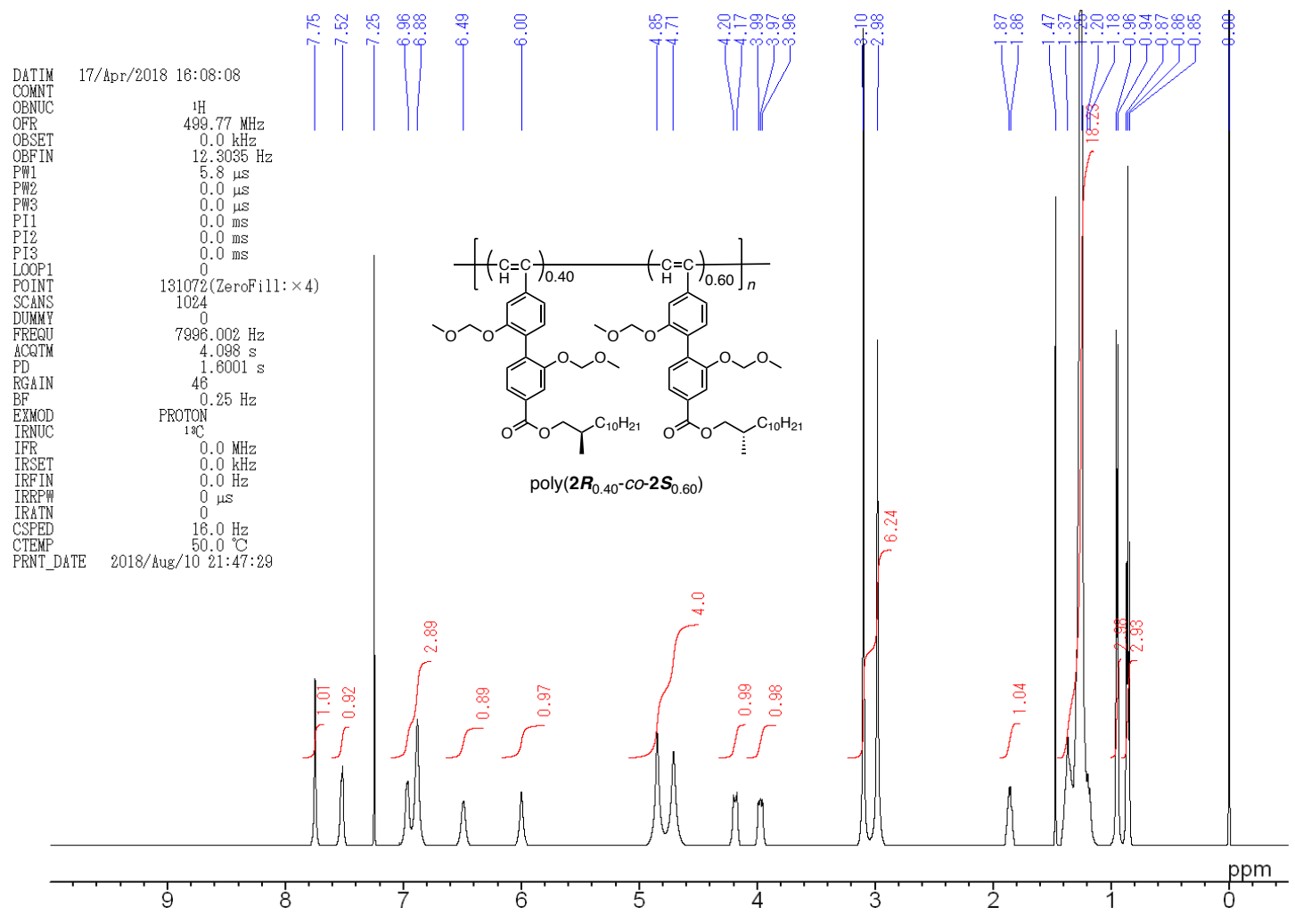

Figure S47. ${ }^{1} \mathrm{H}$ NMR spectrum of poly- $\left(2 \boldsymbol{R}_{0.40}-c o-2 \boldsymbol{S}_{0.60}\right)$ in $\mathrm{CDCl}_{3}$ at $50{ }^{\circ} \mathrm{C}$. 


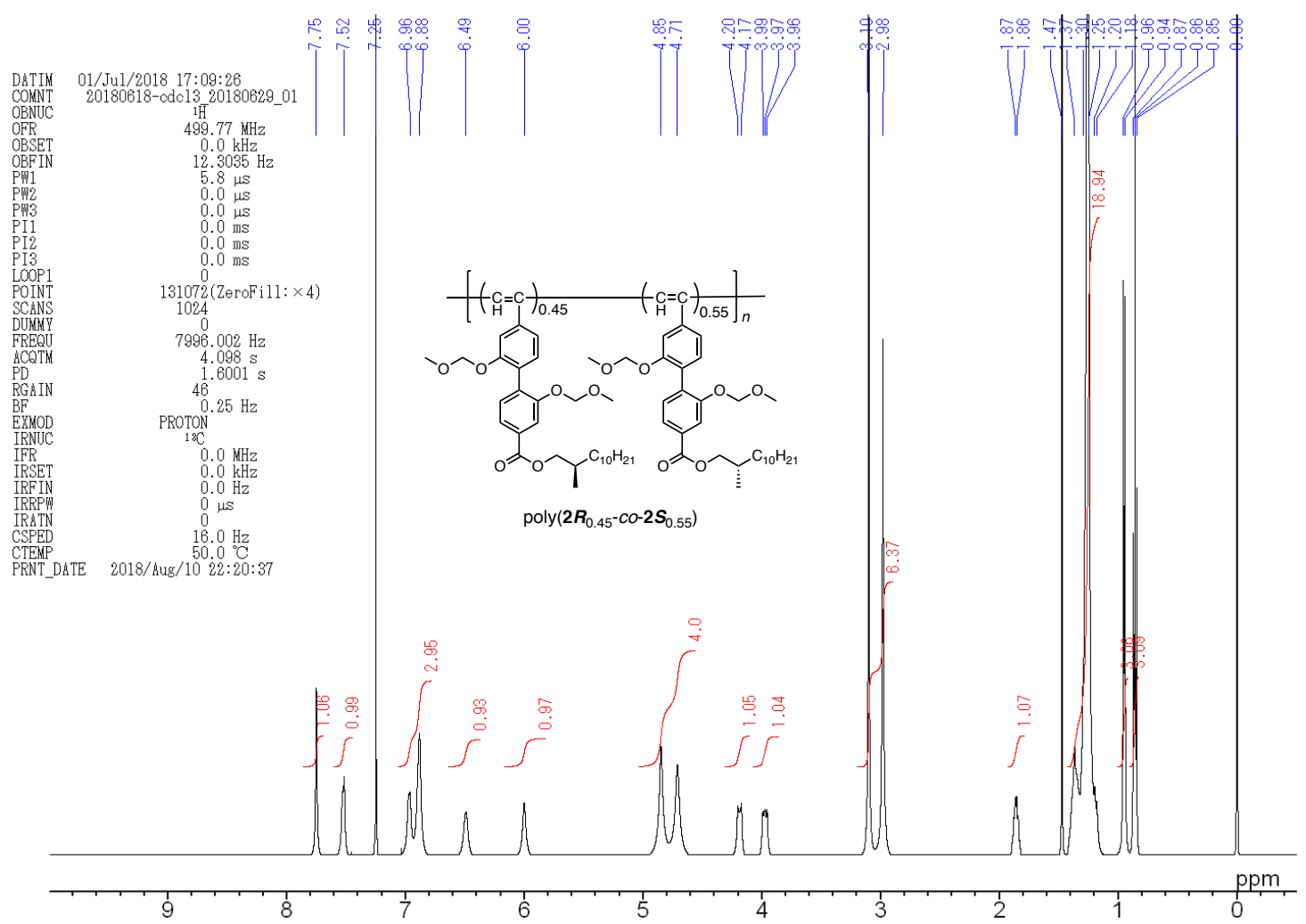

Figure S48. ${ }^{1} \mathrm{H}$ NMR spectrum of poly- $\left(2 \boldsymbol{R}_{0.45}-\mathrm{co}-\mathbf{2} \boldsymbol{S}_{0.55}\right)$ in $\mathrm{CDCl}_{3}$ at $50{ }^{\circ} \mathrm{C}$.

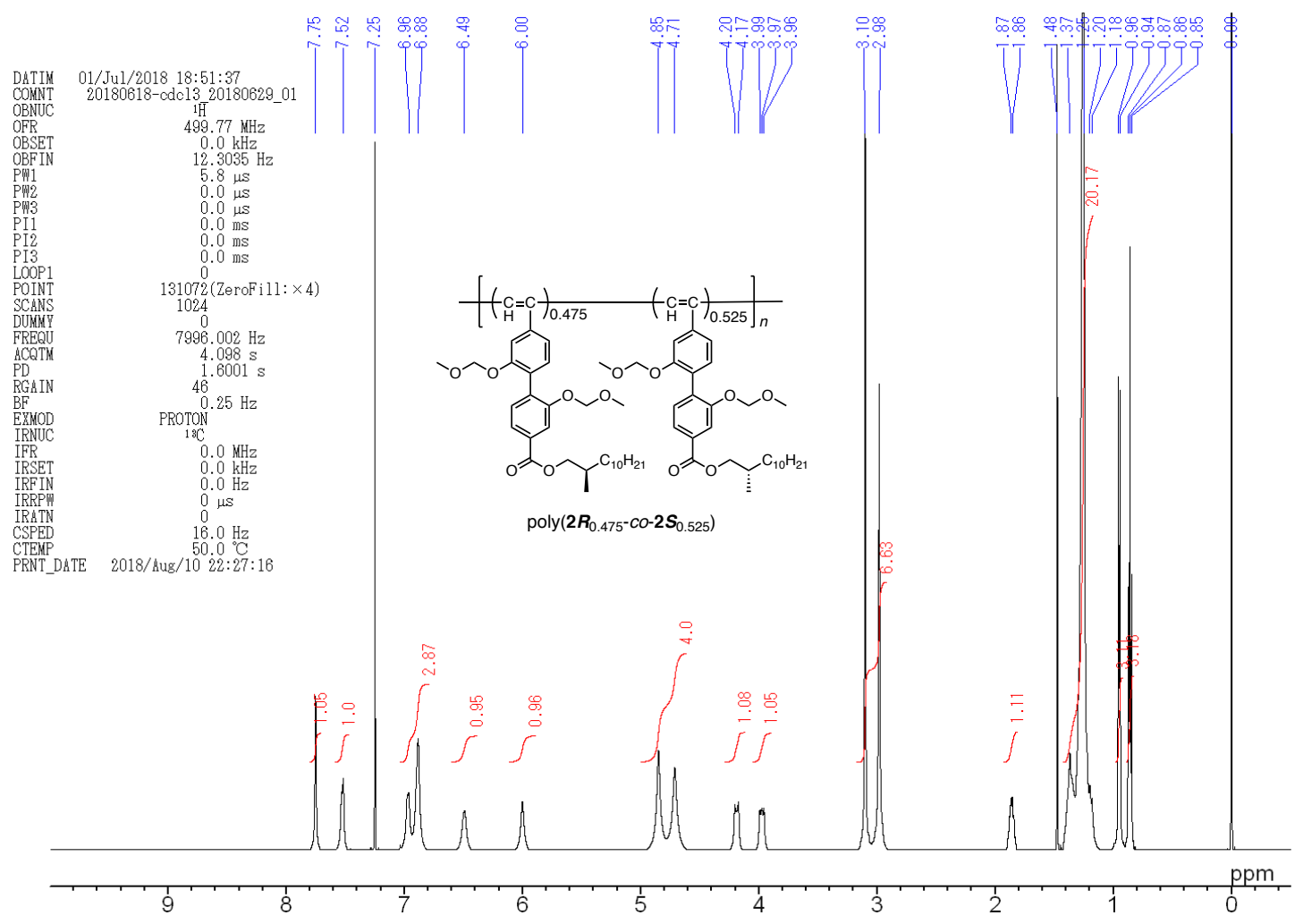

Figure S49. ${ }^{1} \mathrm{H}$ NMR spectrum of poly- $\left(2 \boldsymbol{R}_{0.475}-\mathrm{co}-\mathbf{2} \boldsymbol{S}_{0.525}\right)$ in $\mathrm{CDCl}_{3}$ at $50{ }^{\circ} \mathrm{C}$. 


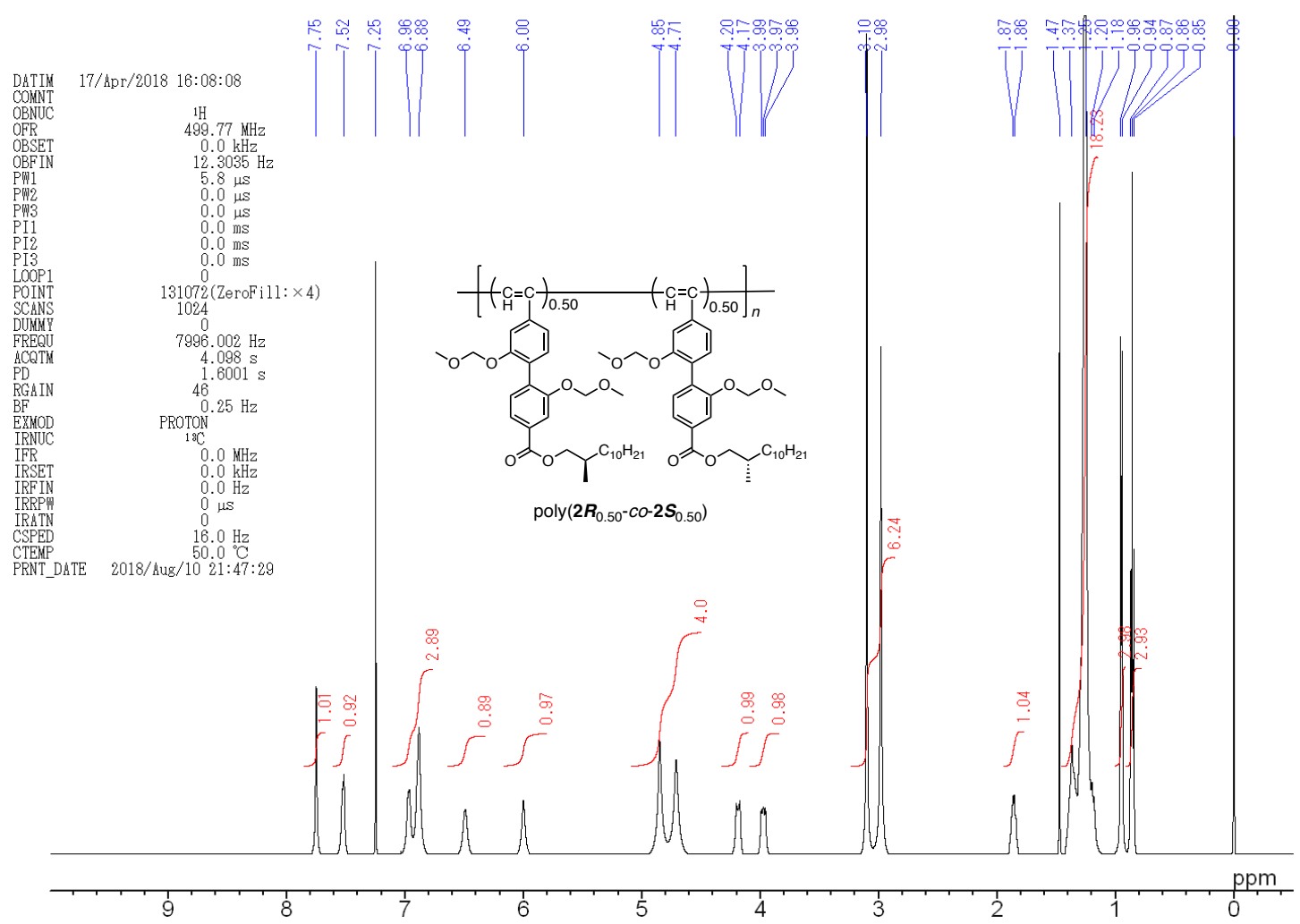

Figure S50. ${ }^{1} \mathrm{H}$ NMR spectrum of poly- $\left(2 \boldsymbol{R}_{0.50}-c o-2 S_{0.50}\right)$ in $\mathrm{CDCl}_{3}$ at $50{ }^{\circ} \mathrm{C}$.

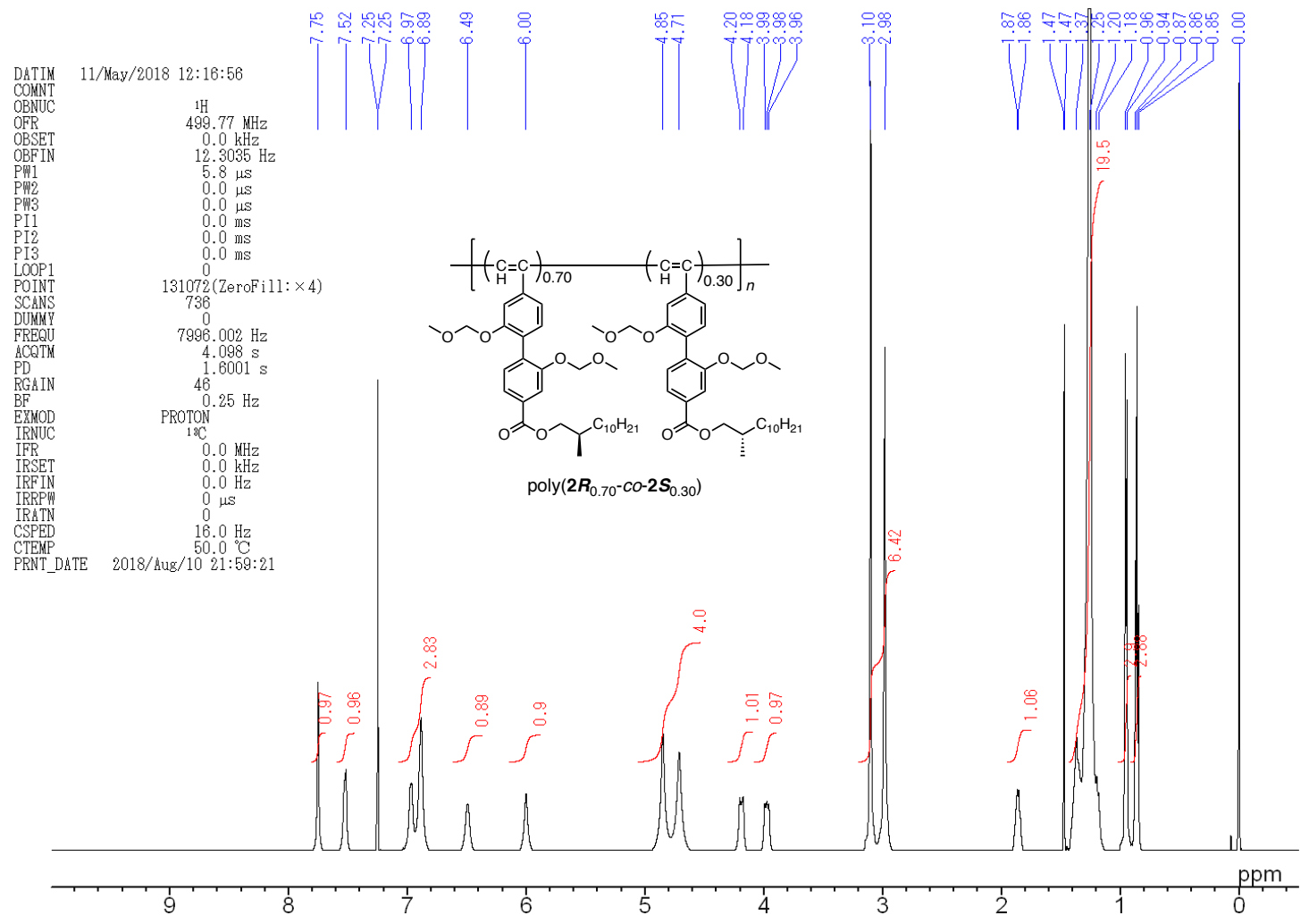

Figure S51. ${ }^{1} \mathrm{H}$ NMR spectrum of poly- $\left(2 \boldsymbol{R}_{0.70}-c o-2 \boldsymbol{S}_{0.30}\right)$ in $\mathrm{CDCl}_{3}$ at $50{ }^{\circ} \mathrm{C}$. 